\title{
Development of an Online Toolkit for Measuring Commercial Building Energy Efficiency Performance
}

\section{Scoping Study}

\section{Final Report}

\author{
N Wang
}

March 2013

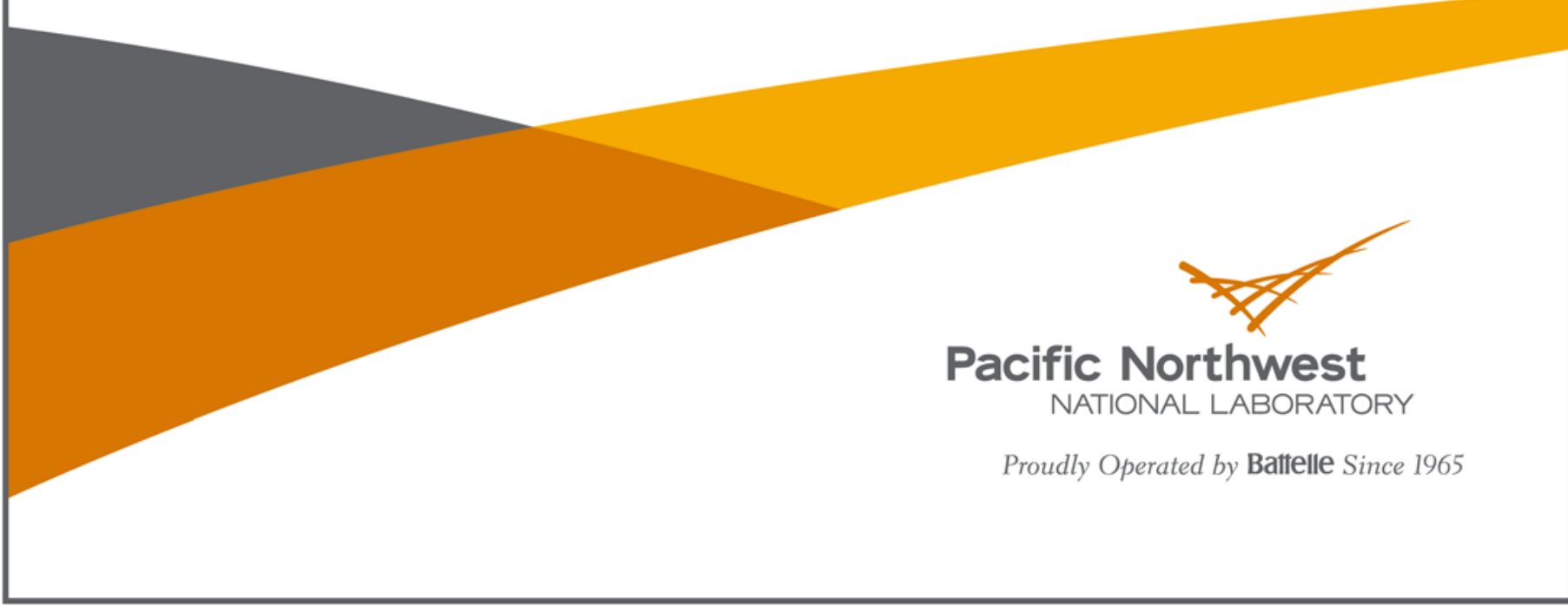




\title{
DISCLAIMER
}

This report was prepared as an account of work sponsored by an agency of the United States Government. Neither the United States Government nor any agency thereof, nor Battelle Memorial Institute, nor any of their employees, makes any warranty, express or implied, or assumes any legal liability or responsibility for the accuracy, completeness, or usefulness of any information, apparatus, product, or process disclosed, or represents that its use would not infringe privately owned rights. Reference herein to any specific commercial product, process, or service by trade name, trademark, manufacturer, or otherwise does not necessarily constitute or imply its endorsement, recommendation, or favoring by the United States Government or any agency thereof, or Battelle Memorial Institute. The views and opinions of authors expressed herein do not necessarily state or reflect those of the United States Government or any agency thereof.

\author{
PACIFIC NORTHWEST NATIONAL LABORATORY \\ operated by \\ BATTELLE \\ for the \\ UNITED STATES DEPARTMENT OF ENERGY \\ under Contract DE-AC05-76RL01830
}

Printed in the United States of America

$$
\begin{aligned}
& \text { Available to DOE and DOE contractors from the } \\
& \text { Office of Scientific and Technical Information, } \\
& \text { P.O. Box } 62 \text {, Oak Ridge, TN } 37831-0062 \text {; } \\
& \text { ph: }(865) 576-8401 \\
& \text { fax: (865) 576-5728 } \\
& \text { email: reports@adonis.osti.gov }
\end{aligned}
$$

Available to the public from the National Technical Information Service

5301 Shawnee Rd., Alexandria, VA 22312 ph: (800) 553-NTIS (6847)

email: orders@ntis.gov $<$ http://www.ntis.gov/about/form.aspx $>$ Online ordering: http://www.ntis.gov 


\section{Development of an Online Toolkit for Measuring Commercial Building Energy Efficiency Performance}

\section{Scoping Study}

\section{Final Report}

N Wang

March 2013

Prepared for

the U.S. Department of Energy

under Contract DE-AC05-76RL01830

Pacific Northwest National Laboratory

Richland, Washington 99352 



\section{Summary}

This study analyzes the market needs for building performance evaluation tools. The purpose is to identify existing gaps and provide information for the U.S. Department of Energy (DOE) to use in developing a linked set of tools for optimizing energy performance of commercial buildings over their life cycles.

The proposed toolkit is intended to help building owners, operators, and managers understand, track, and improve both short- and long-term building performance. These stakeholders are the primary audience because they are the decision makers for implementing energy efficiency strategies and hold the key to unlocking energy savings. The toolkit is also intended to help them make informed retrofit decisions. Secondary audiences are building appraisers and financiers, who need consistent and reliable information to thoroughly evaluate the effects of energy performance on property value as the commercial building market becomes increasingly aware of energy efficiency.

A literature review and market research revealed that a successful toolkit would meet the needs of different types of property owners and managers, including large-portfolio, mid-size, and small property owners and managers. To do this, the toolkit would need to

- be incorporated with the existing tools, particularly with ENERGY STAR Portfolio Manager (ESPM)

- maintain a low implementation cost

- alleviate market confusion of different rating systems and tools

- provide ongoing performance measurement and a feedback loop.

A comprehensive review of 14 existing tools, standards, and rating systems revealed the following major gaps:

- There is no link between calculated (modeled) and measured building energy use. Energy modeling is used mainly during building design or to recommend retrofits. Once a building is in operation, measured energy data from utility bills are used to compare similar buildings and track performance. Monthly utility data are inadequate for diagnosing problems, identifying improvement opportunities, or providing an effective feedback loop because these data are affected by many interrelated infrastructural, operational, and behavioral factors. Interval meter data or submetering data can be used to monitor system performance and provide diagnostic information. However, the cost of querying and processing this level of data and installing submeters can be prohibitive. Energy modeling can simulate a building's energy use pattern and optimize its performance, but building owners do not fully recognize this advantage because of concerns about the cost of modeling, the reliability of the results, and the lack of standardized practice. For many new construction projects for which energy models have already been developed, this disconnect between modeled and measured energy use limits full delivery of designed energy performance from a building's design/build phase to its in-use phase. 
- Existing tools do not have consistent input values, consistent definitions of metrics, or comparable outputs. For example, ANSI/ASHRAE/IESNA ${ }^{1}$ standards 105 and 90.1, ESPM, the Commercial Building Energy Consumption Survey, and Section 433 of the Energy Independence and Security Act of 2007 use gross floor area as the denominator to calculate energy use intensity (EUI). Conditioned floor area is specified in the California Energy Code, Title 24, to obtain the energy budget, and in ANSI/ASHRAE/IESNA Standard 100-2006 to calculate EUI from utility bills. The Building Owners and Managers Association and the International Facility Management Association use rentable floor area to measure building income and expense. These differences confuse tool users and provide inconsistent information to the commercial buildings market.

- There is no standard method for estimating energy cost and maintenance cost. Complicated utility tariff structures make it difficult to predict energy costs. Different reference values (such as local average, historical average, time-dependent valuation) are used in the existing tools. Maintenance cost savings are considered in the life-cycle analysis of energy efficiency measures; however, there is no standard way to estimate maintenance cost savings. Building owners have been methodical about reducing costs and raising net income based on their experience and internal documentation. Appraisers, however, need a reliable and consistent source that provides a building's energy and maintenance cost information.

- Building owners cannot directly receive actionable strategies to make appropriate energy efficiency improvements. Building owners can use the existing tools to compare their buildings to peer buildings or a target building, track utility consumption, and receive general best practice guidelines. However, to devise efficiency strategies, they must seek external expertise from professional consulting firms for customized cost savings analysis and recommendations before making investment decisions. The cost of hiring a professional and the uncertainty of potential savings prevent some building owners from seeking external technical assistance.

To meet the market needs and fill the gaps left by the existing tools, this research suggests that a toolkit include three inter-linked components: building energy asset, building operation, and energyrelated cost (Table S.1). Through these components, toolkit would meet stakeholder requirements for peer comparison, self-diagnosis and improvement, and building valuation. To support ongoing performance measurement and provide useful feedback to the implemented energy efficiency measures, both current and potential energy use and cost would need to be included.

- The building energy asset component would focus on building infrastructure. Evaluation of a building's as-built efficiency can rely on energy simulation to separate building systems from building operation variables. A current energy asset score (based on existing building performance without energy efficiency upgrades) would allow apples-to-apples comparisons between building infrastructures and provide a standard way to evaluate and diagnose building systems (envelopes and electrical and mechanical systems). A potential energy asset score (based on building performance with energy efficiency upgrades) would identify for building owners, valuators, and buyers the investment opportunities that could be gained through building upgrades. The energy asset scoring tool being developed by DOE provides these functionalities.

- The building operation component would focus on the effectiveness of building operations and maintenance (O\&M). Evaluation of a building's operational outcome primarily relies on measured

\footnotetext{
${ }^{1}$ ANSI is the American National Standards Institute; ASHRAE is the American Society of Heating, Refrigerating and Air-Conditioning Engineers; IESNA is the Illuminating Engineering Society of North America.
} 
energy use data. However, operational outcome is inadequate for diagnosing building O\&M issues because it is affected by both building system efficiencies and operation effectiveness. Energy simulation can be used to control operational factors (e.g., operating schedules, system maintenance, and occupant behavior) and separate their impacts on building performance from the overall operational outcome. Different operating scenarios can also be simulated to predict how changing O\&M practices could save energy. ESPM benchmarks actual building performance (operational outcome). Another tool is needed to link building asset and operation, so that building infrastructure and building operation, and their attribution to the building performance, can be examined separately.

- Energy-related cost information, including maintenance and utility costs, is another important proposed component of the toolkit because many commercial building owners make building upgrade decisions based on return on investment. Current and future cost information could motivate building owners to include building energy efficiency in their business decisions. ESPM tracks only the current energy costs. Future energy cost is not predicted and maintenance cost has not been systematically addressed in the existing energy tools.

Table S.1. Proposed components of the linked toolkit.

\begin{tabular}{|c|c|c|c|c|c|c|c|c|}
\hline $\begin{array}{c}\text { Toolkit } \\
\text { Components }\end{array}$ & \multicolumn{2}{|c|}{ Building Asset } & \multicolumn{2}{|c|}{ Building Operation } & \multicolumn{4}{|c|}{ Energy-Related Cost } \\
\hline Main Metrics & \multicolumn{2}{|c|}{$\begin{array}{l}\text { Modeled Energy } \\
\text { Use }\end{array}$} & $\begin{array}{c}\text { Link of Asset } \\
\text { and } \\
\text { Operation }\end{array}$ & $\begin{array}{l}\text { Measured } \\
\text { Energy Use }\end{array}$ & \multicolumn{2}{|c|}{ Maintenance Cost } & \multicolumn{2}{|c|}{ Energy Cost } \\
\hline $\begin{array}{l}\text { Self-Diagnosis } \\
\text { and } \\
\text { Improvement }\end{array}$ & \multicolumn{2}{|c|}{$\begin{array}{l}\text { Evaluating building } \\
\text { systems } \\
\text { Identifying upgrade } \\
\text { opportunities }\end{array}$} & $\begin{array}{l}\text { Evaluating } \\
\text { O\&M’s } \\
\text { impact on } \\
\text { energy use } \\
\text { Identifying } \\
\text { improvement } \\
\text { opportunities }\end{array}$ & $\begin{array}{l}\text { The } \\
\text { combined } \\
\text { outcomes of } \\
\text { building } \\
\text { infrastructure } \\
\text { and O\&M } \\
\text { are NOT } \\
\text { sufficient }\end{array}$ & \multicolumn{2}{|c|}{$\begin{array}{l}\text { Evaluating the } \\
\text { influence of building } \\
\text { system efficiency and } \\
\text { O\&M activities on } \\
\text { O\&M cost }\end{array}$} & \multicolumn{2}{|c|}{$\begin{array}{l}\text { Energy cost is NOT an } \\
\text { effective indicator of } \\
\text { energy performance }\end{array}$} \\
\hline $\begin{array}{l}\text { Peer } \\
\text { Comparison }\end{array}$ & \multicolumn{2}{|c|}{$\begin{array}{l}\text { Providing a level } \\
\text { ground to compare } \\
\text { building } \\
\text { infrastructures }\end{array}$} & $\begin{array}{l}\text { This linkage } \\
\text { is meant for } \\
\text { self- } \\
\text { comparison, } \\
\text { NOT for } \\
\text { peer- } \\
\text { comparison }\end{array}$ & $\begin{array}{l}\text { Comparing } \\
\text { the overall } \\
\text { outcome }\end{array}$ & \multicolumn{2}{|c|}{$\begin{array}{l}\text { Comparing O\&M } \\
\text { cost }\end{array}$} & \multicolumn{2}{|c|}{$\begin{array}{l}\text { Energy cost metric is } \\
\text { NOT an effective } \\
\text { indicator of energy } \\
\text { performance }\end{array}$} \\
\hline $\begin{array}{l}\text { Building } \\
\text { Valuation }\end{array}$ & \multicolumn{2}{|c|}{$\begin{array}{l}\text { Gaining insight into } \\
\text { building } \\
\text { infrastructure }\end{array}$} & $\begin{array}{l}\text { Separating } \\
\text { building } \\
\text { infrastructure } \\
\text { from building } \\
\text { operation }\end{array}$ & $\begin{array}{l}\text { Obtaining } \\
\text { the overall } \\
\text { outcome of } \\
\text { building } \\
\text { energy } \\
\text { efficiency }\end{array}$ & \multicolumn{2}{|c|}{$\begin{array}{l}\text { Considering long- } \\
\text { term maintenance } \\
\text { cost }\end{array}$} & \multicolumn{2}{|c|}{$\begin{array}{l}\text { Considering long-term } \\
\text { operation cost }\end{array}$} \\
\hline Functionalities & $\begin{array}{l}\text { Current } \\
\text { Score }\end{array}$ & $\begin{array}{l}\text { Potential } \\
\text { Score }\end{array}$ & $\begin{array}{l}\text { Potential } \\
\text { Score }\end{array}$ & $\begin{array}{l}\text { Current } \\
\text { Score }\end{array}$ & $\begin{array}{l}\text { Current } \\
\text { Cost }\end{array}$ & $\begin{array}{l}\text { Potential } \\
\text { Cost }\end{array}$ & $\begin{array}{l}\text { Current } \\
\text { Cost }\end{array}$ & $\begin{array}{l}\text { Potential } \\
\text { Cost }\end{array}$ \\
\hline Existing Tools & \multicolumn{2}{|c|}{$\begin{array}{l}\text { Energy Asset } \\
\text { Scoring Tool (under } \\
\text { development) }\end{array}$} & Missing & $\begin{array}{l}\text { ENERGY } \\
\text { STAR } \\
\text { Portfolio } \\
\text { Manager }\end{array}$ & Missing & Missing & $\begin{array}{l}\text { ENERGY } \\
\text { STAR } \\
\text { Portfolio } \\
\text { Manager }\end{array}$ & Missing \\
\hline
\end{tabular}

Green indicates applicable purposes; grey indicates non-applicable purposes; yellow indicates missing tool functions. 
The energy asset scoring tool being developed by DOE creates an energy model to represent building characteristics and simulate building energy use under standard conditions. This model can be used to investigate O\&M factors by varying the operating conditions. The proposed toolkit would either use the modeling engine of the energy asset scoring tool or simply extract building characteristics from it.

Another key element of the proposed toolkit would be the ESPM outputs (measured energy use data), which would link modeled energy use under standard conditions to actual building performance. To establish such a link, a calibrated model that reflects the actual building energy use would need to be developed. This would require collecting additional operating data such as operating schedules, plug loads, and building controls schedules.

ESPM uses some operating characteristics (such as total number of computers, weekly operating hours, and total number of occupants) to normalize the utility data. The energy asset scoring tool also allows users to enter actual operating conditions (such as total plug loads, facility open and closed hours, and total number of occupants) to customize life-cycle cost analysis; however, these data are not required to obtain an energy asset score. Both ESPM and the energy asset scoring tool provide useful but incomplete data sources to calibrate an energy model. Therefore, the "in-operation" component of the toolkit would need to provide a systematic, standardized way to gather building operating data, calibrate the energy model, and evaluate the effectiveness of building operation.

Figure S.1 illustrates the architecture of the existing and proposed toolkit components. On one hand, the toolkit should work as an integrated system to track building performance over its life cycle and provide a feedback loop to reflect infrastructural upgrades, management practices, or tenant behavioral changes in the building. Feedback tying building infrastructure and building operation to ongoing performance metrics would likely make financing more feasible and drive accountability on the part of designers, contractors, and energy auditors. Users should be able to access the toolkit from a single website and portal. However, each component of the toolkit should function independently to meet the various needs of the different building owners and managers. Users should be able to use individual components of the toolkit, enter limited inputs, and receive information with minimal effort. This would require establishing a system to share building data among multiple building stakeholders during each stage of a building's lifespan, and a system of persistent and unique building identifiers. 


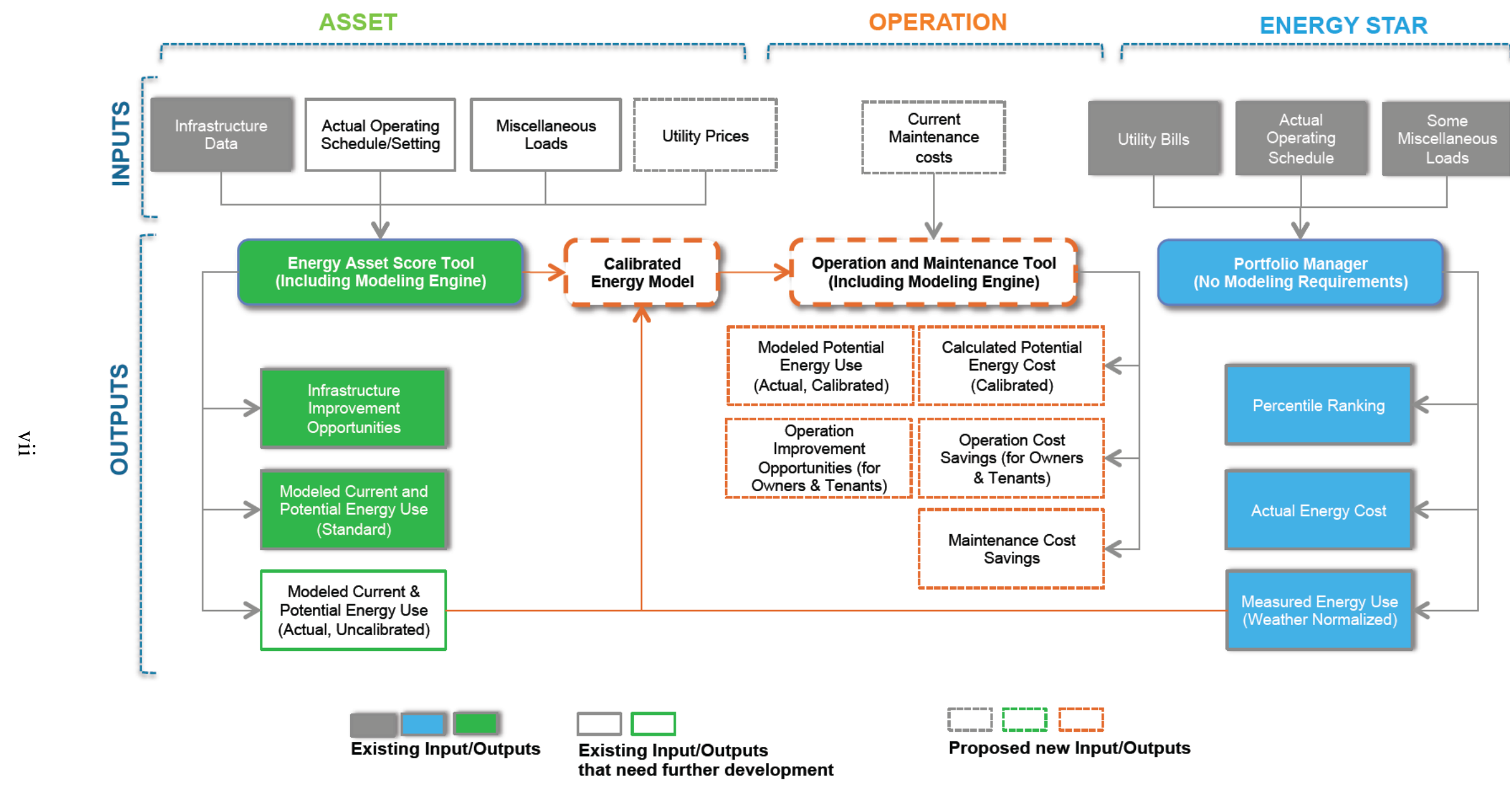

Figure S.1. Proposed structure of the linked toolkit. 


\section{Acknowledgments}

Special thanks to Cody Taylor and Subid Wagley at the U.S. Department of Energy for sharing insights and providing constructive suggestions. Thanks also to Kim Fowler, Andrea Currie, Matt Wilburn, and others at Pacific Northwest National Laboratory for their thorough reviews and useful feedback. 


\section{Acronyms and Abbreviations}

$\$ / k W h$

ANSI

API

ASHRAE

ASTM

B3

bEQ

BOMA

$\mathrm{Btu} / \mathrm{kWh}$

CBE

CBECS

CEUS

COMNET

DOE

EBOM

EEM

EPA

EPSCT

ESPM

EUI

HVAC

IECC

IESNA

IFMA

ISO

IT

$\mathrm{kBtu} / \mathrm{ft}^{2}$

LEED

MBtu

NC

NOAA

NOI

O\&M

PUE

RSF dollars per kilowatt-hour

American National Standards Institute

application programming interface

American Society of Heating, Refrigerating and Air-Conditioning Engineers

ASTM International (formerly known as the American Society for Testing and Materials)

Buildings, Benchmarks and Beyond

Building Energy Quotient

Building Owners and Managers Association

British thermal units per kilowatt-hour

Center for the Built Environment

Commercial Buildings Energy Consumption Survey

California Commercial End-Use Survey

Commercial Energy Services Network

U.S. Department of Energy

Existing Buildings: Operations \& Maintenance

energy efficiency measure

U.S. Environmental Protection Agency

Energy Performance Standard Calculation Toolkit

ENERGY STAR Portfolio Manager

energy use intensity

heating, ventilation, and air conditioning

International Energy Conservation Code

Illuminating Engineering Society of North America

International Facility Management Association

International Organization for Standardization

information technology

thousand British thermal units per square foot

Leadership in Energy and Environmental Design

million British thermal units

new construction

National Oceanic and Atmospheric Administration

net operating income

operations and maintenance

power usage effectiveness

rentable square foot 
SBEM

TDV

TOU

UK

USGBC
Simplified Building Energy Model

time-dependent valuation

time-of-use

United Kingdom

U.S. Green Building Council 


\section{Contents}

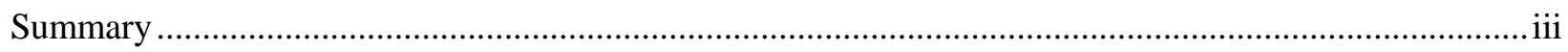

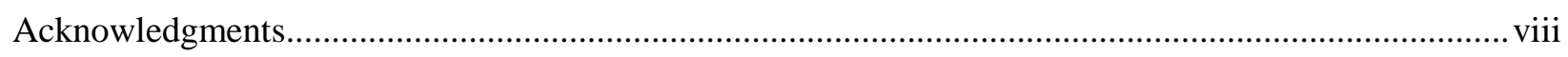

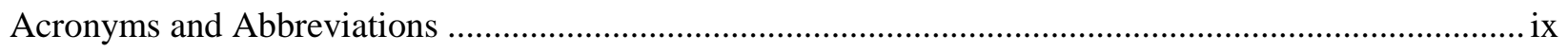

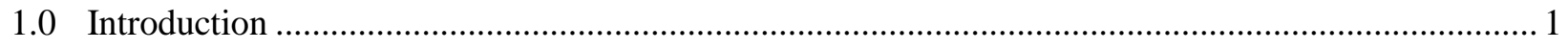

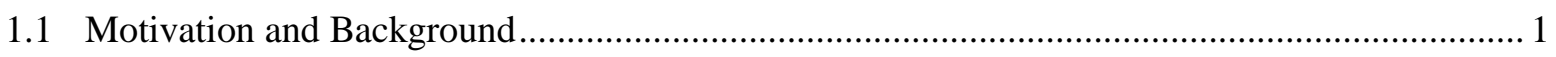

1.2 Scoping Study Purpose and Scope ..................................................................................... 1

2.0 Market Needs and Value Propositions of a Linked Toolkit ............................................................. 3

2.1 Meet Needs of Different Building Owners and Managers ...................................................... 3

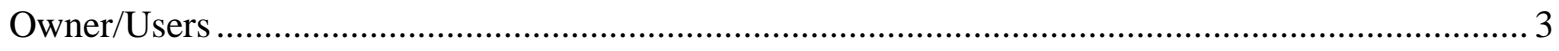

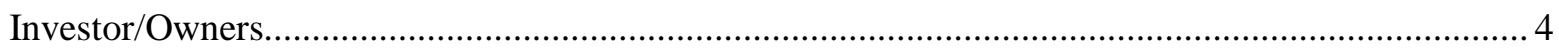

2.2 Support Ongoing Measurement and Provide Feedback Loop................................................. 9

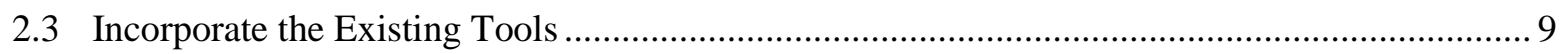

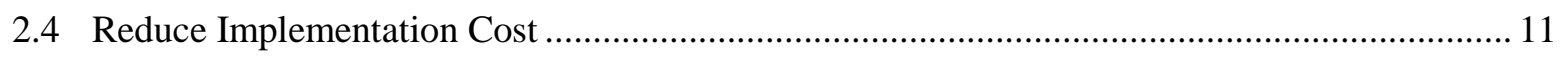

3.0 Energy Metrics in Building Performance Evaluation................................................................ 13

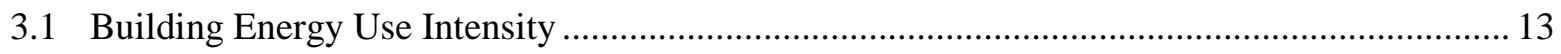

3.1.1 Unadjusted Site EUI Based on Utility Bills ............................................................ 13

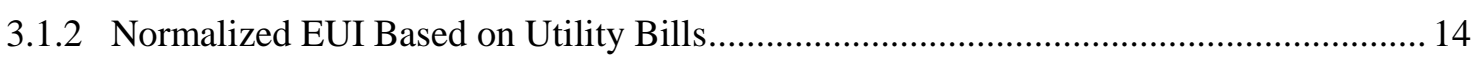

3.1.3 Calculated EUI through Energy Simulation................................................................ 15

3.2 Other Energy Use per Unit of Value .................................................................................. 16

3.3 Energy Cost, Time Value, and Peak Demand .................................................................... 17

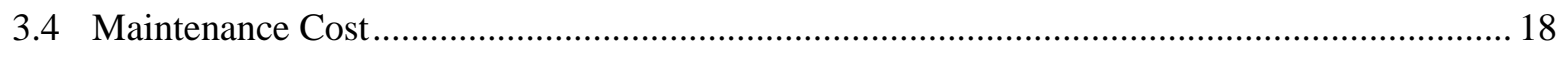

4.0 Existing Tools and Programs to Determine Building Energy Performance .................................... 21

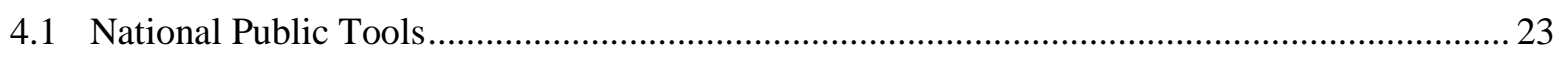

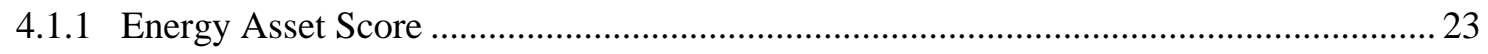

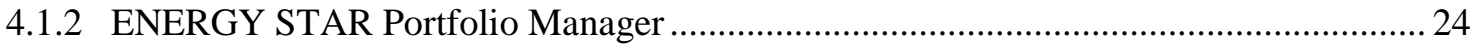

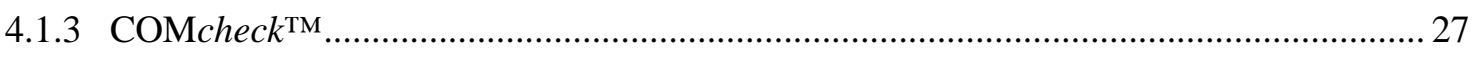

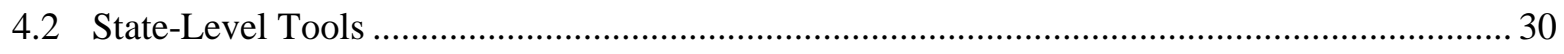

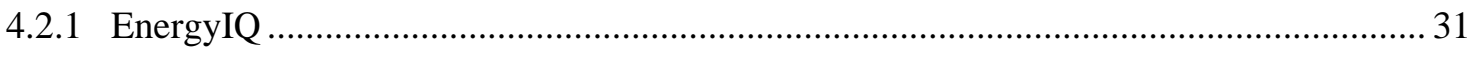

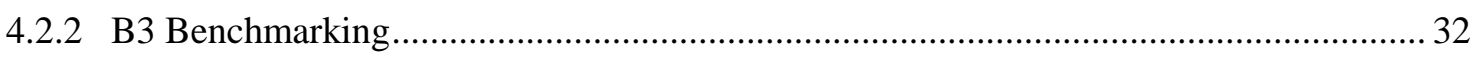

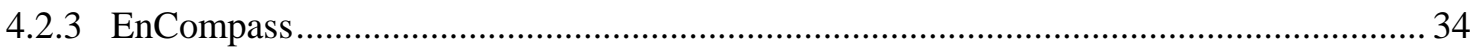

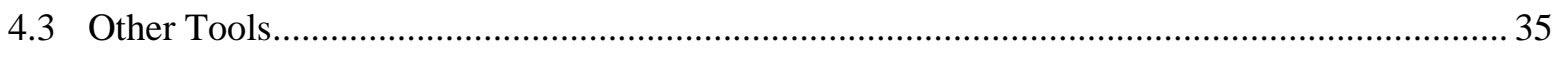

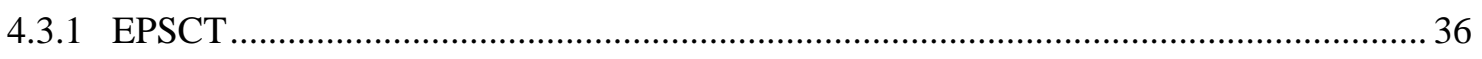

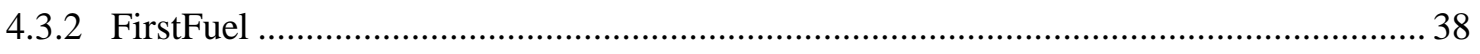

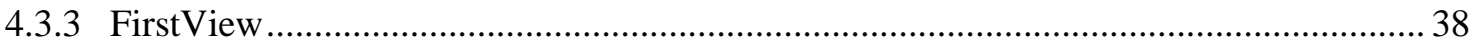

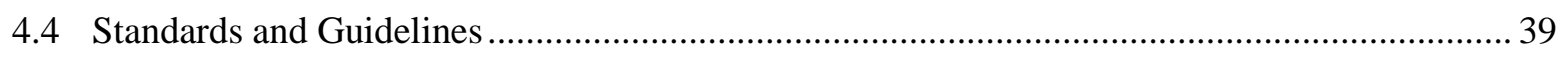

4.4.1 Data Collection and Energy Management Standards ................................................... 39 


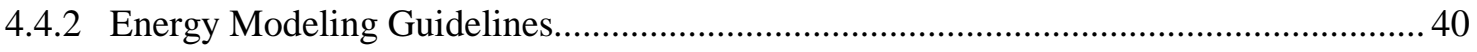

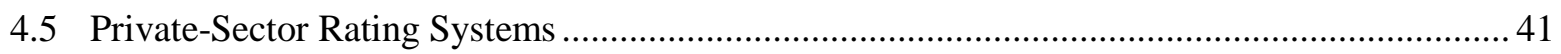

4.5.1 Leadership in Energy and Environmental Design..................................................... 41

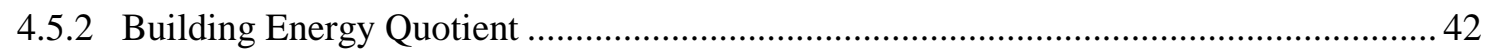

5.0 Missing Components in the Existing Tools and Thoughts on Toolkit Development........................ 45

5.1 Missing Components....................................................................................................... 45

5.1.1 Link Between Modeled and Measured Energy Use .................................................... 45

5.1.2 Standard Measurement of O\&M Costs in Energy Benchmarking .................................. 46

5.1.3 Standard Definitions of Various Metrics for Different Applications .............................. 46

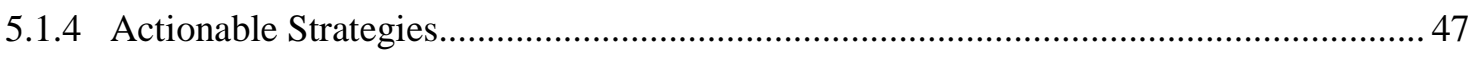

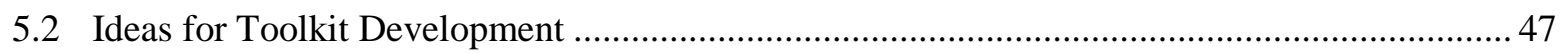

5.2.1 Linkage Between Building Asset and Operation ............................................................ 48

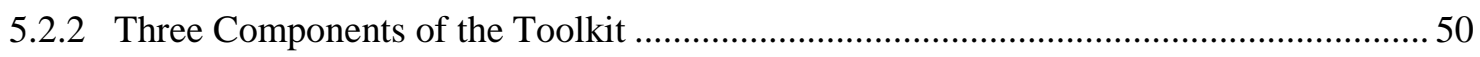

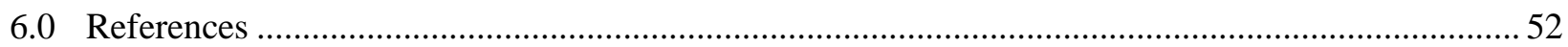




\section{Figures}

Figure S.1. Proposed structure of the linked toolkit. ................................................................................. vii

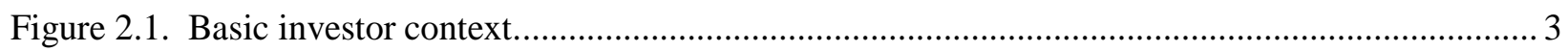

Figure 2.2. Measured versus design EUIs $\left(\mathrm{kBtu} / \mathrm{ft}^{2}\right)$ of LEED new construction buildings

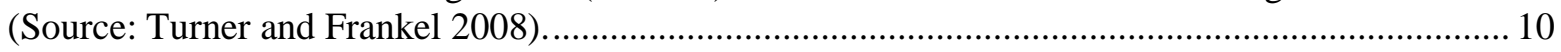

Figure 3.1. Using cooling degree days and heating degree days to understand energy

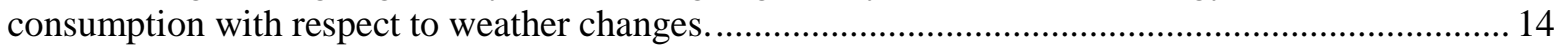

Figure 3.2. Average maintenance cost, dollars per rentable square foot (Source: IFMA 2009)............... 19

Figure 4.1. States that can use COMcheck to show compliance (Source: DOE 2012)............................ 28

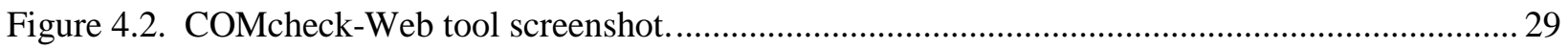

Figure 4.3. EnergyIQ's three functions (Source: energyiq.lbl.gov/)...................................................... 31

Figure 4.4. EnergyIQ benchmark metrics (Source: energyiq.lbl.gov/)................................................ 32

Figure 4.5. B3 Benchmarking program screenshot (Source: Admin Minnesota 2012a)......................... 33

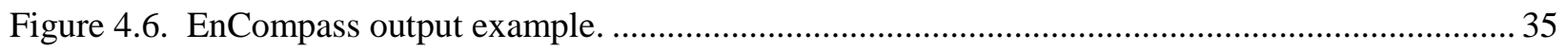

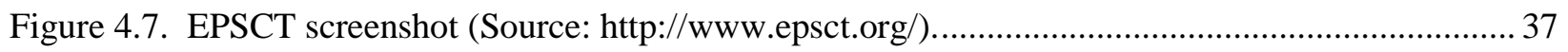

Figure 4.8. FirstFuel screenshot (Source: FirstFuel 2012)................................................................. 38

Figure 4.9. Sample site analysis (Source: Reichmuth and Turner 2011)............................................... 39

Figure 4.10. OpenEI utility data access map (Source: OpenEI 2012) ................................................. 41

Figure 4.11. Building EQ Certificate (Source: http://buildingenergyquotient.org/images/sample-

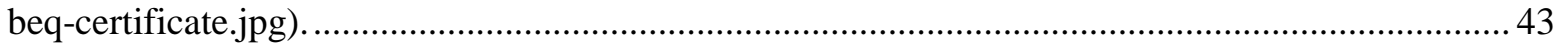

Figure 5.1. Integration of asset score and operational score............................................................... 49

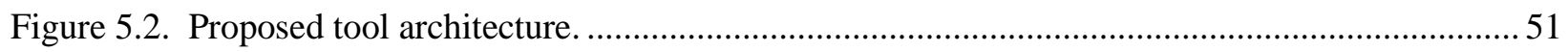

\section{Tables}

Table S.1. Proposed components of the linked toolkit................................................................................

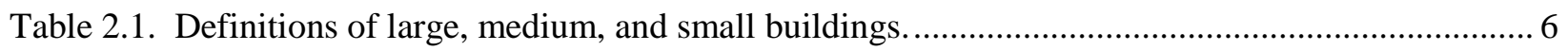

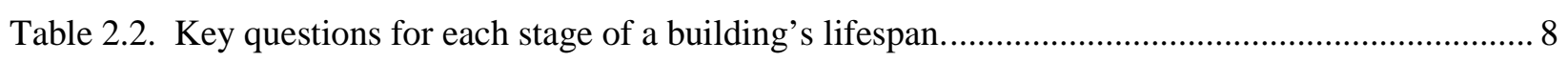

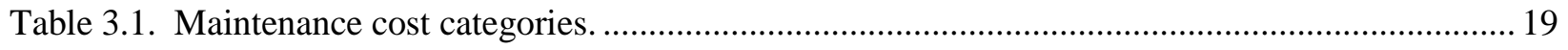

Table 4.1. Summary of programs being reviewed.............................................................................. 21

Table 5.1. Example of four buildings with the same asset score........................................................... 50 



\subsection{Introduction}

\subsection{Motivation and Background}

The building industry is increasingly recognizing that more energy efficient buildings provide an opportunity to improve net operating income (NOI), attract and retain tenants, raise property value, and minimize the effects of future energy price increases. Many tools have been developed in the government and private sectors to assist with building energy management, evaluation, and benchmarking. These include

- the commercial building energy asset scoring tool, which is currently being developed by the U.S. Department of Energy (DOE)

- ENERGY STAR Portfolio Manager (ESPM), a peer benchmarking tool developed by the U.S. Environmental Protection Agency (EPA)

- other tools available in the commercial building market.

These tools focus on different aspects of building energy efficiency; and while many tools are available, there is currently no standard, integrated toolkit that enables commercial building owners, operators, and financiers to measure, track, and evaluate energy performance of a building over its lifespan. Without such a platform, building owners and investors cannot recognize the long-term benefits of some energy efficiency technologies and strategies. Building owners and operators may misinterpret the result of energy efficiency measures (EEMs) without understanding the cause-and-effect relationship between energy use and their operating regimes or practices. Appraisers and lenders may not accurately value a high-performance building unless its energy-efficient features are consistently accounted for and tracked.

The energy asset scoring tool being developed by DOE is intended to give building stakeholders insight into building energy systems. However, this tool alone cannot meet the market needs described above. DOE's long-term goal is to have a linked set of tools that enables building owners and other market stakeholders to evaluate and identify improvements in commercial buildings. DOE's goal is to provide this linked toolkit to the market to promote standardized metrics and evaluation criteria for building energy performance in each segment of a building's life cycle: design/construction; acquisitions/leasing; operations/maintenance/facility management; renovation/retrofits/retrocommissioning; and valuation for finance, sale, and refinance.

The proposed toolkit would increase focus on the life-cycle benefits of the energy efficiency technologies and strategies and assist with the financial evaluation of the various attributes beyond the effects of initial capital cost and energy cost. A persistent system that oversees building energy performance over time would also help building stakeholders realize demonstrated benefits in energy performance and develop integrated solutions that achieve high performance.

\subsection{Scoping Study Purpose and Scope}

This scoping study analyzes the market needs for performance evaluation tools in the building lifecycle segments described above. The purpose is to identify gaps in the current tools and provide 
information for the DOE to use in developing the toolkit for evaluating and identifying energy efficiency improvements in commercial buildings.

While energy benchmarking has resulted in building energy management actions and energy efficiency improvements in buildings, the existing benchmarking tools (e.g., ESPM) have limited use for making decisions on energy efficiency because they do not identify areas for improvement (NMR Group 2012). More granular information about building energy use and predictions for savings could help building owners meet goals of continual improvement in energy performance. For example, the statewide benchmarking evaluation study in California suggests that there is a need for a tool that identifies energy efficiency opportunities within a building (NMR Group 2012).

A number of metrics have been used to evaluate building energy performance when a building is being designed, constructed, or renovated, or during operation. The meanings and measurements of these metrics may change over a building's lifetime. For example, energy use intensity (EUI, measured in thousand British thermal units per square foot $\left.\left(\mathrm{kBtu} / \mathrm{ft}^{2}\right)\right)^{1}$ for new construction is usually predicted from an energy model. The modeled energy use is compared to a baseline building, which is usually code compliant. After 12 months of occupancy, EUI is calculated using utility bills or metered data. ESPM provides a means to compare the measured EUI of a building to its peers using a statistical regression model. The original energy model created during the design phase is often considered inapplicable or inaccurate because design assumptions were used to create the model. Sometimes a second energy model is created during building energy audits or retrofits. This model is calibrated using utility bills.

These prevailing practices lack consistency. They treat a building as a static system throughout each of its life-cycle segments and do not consider that building energy performance is affected by the constant interaction of an engineered system with the behavior of people who operate it and occupy it. Without a consistent, standard, and dynamic evaluating methodology, energy management appears to be unpredictable, time-consuming, or expensive.

This scoping study considers the need for a linked set of tools and metrics to describe and evaluate a building's assets and operations over its life cycle. This study also discusses the challenges of linking tools based on physical models of building energy performance with tools based on measured performance. This study identifies the purpose and role of existing energy metrics and tools-accounting for planned expansions and updates of these tools — and the remaining gaps. Based on this gap analysis, this study suggests a possible approach for DOE to pursue to develop standard metrics and tools in this space.

In summary, the objectives of this study are to

- identify the benefits and market value of a toolkit to industry stakeholders

- illustrate the effect of the toolkit on the decision criteria of building stakeholders and identify the value proposition derived from the toolkit

- identify gaps in the existing tools

- propose a consistent set of metrics and a tool structure for the future development of the toolkit.

\footnotetext{
${ }^{1}$ In this study, building square foot values refer to gross floor unless otherwise noted.
} 


\subsection{Market Needs and Value Propositions of a Linked Toolkit}

Literature research and interviews with the building stakeholders (conducted during the market research for the energy asset scoring tool development) revealed that different building owners and managers, such as large-portfolio owners, mid-size building owners, and small-property owners, have needs in different areas. The value propositions of the proposed toolkit for building owners and managers would differ by building size and placement in real estate markets. On the other hand, all building owners and managers have common interest in a tool that tracks ongoing performance and provides a feedback loop. Moreover, a useful toolkit would need to incorporate the existing tools to the maximum extent possible. This would reduce both the cost of tool development and market confusion, and would encourage wide adoption. The following sections describe the attributes of the proposed toolkit to meet market needs and provide value to users.

\subsection{Meet Needs of Different Building Owners and Managers}

There are various categories of commercial real estate owners. Different types of owners have different interests and needs, depending on building occupancy, size, and location. To realize the expected value of the toolkit, the development effort needs to consider how the toolkit can provide the most valuable information to the appropriate audience with minimal effort on the part of the user.

For any given real estate owner, the decision to invest in energy efficiency is predicated on their individual risk/return perspective, worldview, and their own long-term objectives and corporate values, as reflected in Figure 2.1. The linked toolkit would be usable by all types of building owners and managers, and each type of stakeholder would be able to use it to make decisions relevant to their unique situation.

\section{Investor Type}

\begin{tabular}{|l|} 
Investor/Landlord \\
- $3-7$ year hold \\
period \\
- Core investor \\
- Institutional \\
- Private \\
\hline
\end{tabular}
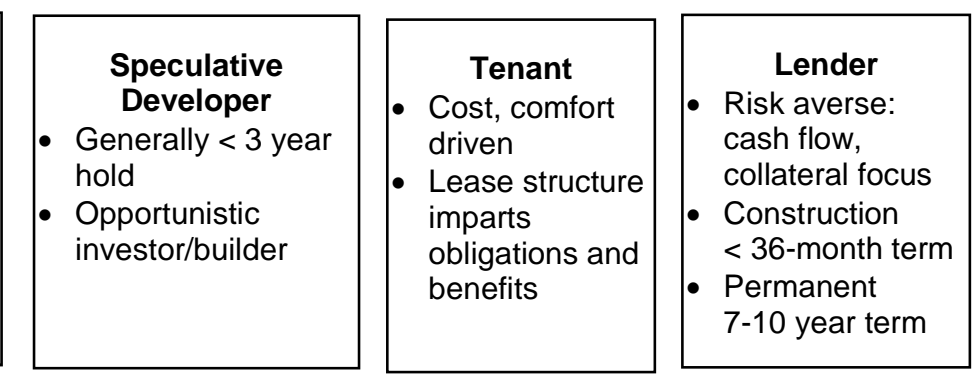

Figure 2.1. Basic investor context.

\section{Owner/Users}

Property owners who can be characterized as owner/users include both large-scale users-essentially the corporate market and MUSH market (municipal, state, and federal government entities, universities, or hospitals) with holdings of more than $50,000 \mathrm{ft}^{2}$ —and small businesses, which represent the majority of the market in terms of numbers of buildings. These owners generally are long-term holders of property 
where real estate ownership is not their primary business. They control real estate as a means to conducting business or governing. They manage the movement of their own occupants/workers in and out of space. They are interested in occupant comfort and health because this meets their corporate values and they believe it translates into enhanced worker satisfaction, retention, and recruitment, and possibly productivity. Although the large property owners might get their buildings ENERGY STAR- or Leadership in Energy and Environmental Design (LEED)-rated, they do it more because it correlates with their fundamental values or for public relations purposes rather than with any residual value driver. In the current economic environment, these entities may be capital constrained and want to retain cash for operational purposes. However, they are interested in ways of increasing cash flow, which allows them to invest more in their core business.

Owner/users evaluate the investment in the context of competing needs for capital along with a desire to meet certain corporate objectives (e.g., expense reduction, corporate social responsibility ${ }^{1}$ goals, corporate values, and public image). This segment of the commercial owner market is more likely to engage immediately in an efficiency project due to their long-term hold horizon, the direct benefits derived by their workers, and the corresponding impact on cash flow. A linked toolkit could help them identify and prioritize these capital improvements to both drive efficiency and improve cash flow.

\section{Investor/Owners}

Private-sector investors have, in the past, looked to a short-term increase in NOI that they can parlay into a higher sale value in the near term. In comparison, energy efficiency measures are generally seen as investments with longer-term returns. Most private sector investors look to hold properties for 3 to 5 years; 7 years is rare and would be considered a long-term hold. Consequently, efficiency improvements have not garnered much interest. However, as the markets have become more challenging, many investors, particularly in the institutional sector, now consider efficiency improvements and opportunities for energy-efficient capital improvements in their due diligence analysis. Capital improvements are made to increase efficiency, reduce operating expense, protect against future rises in energy costs, and create a differentiating factor when trying to attract tenants or buyers. A linked toolkit could facilitate this initial analysis and support capital allocation.

To meaningfully accrue value to the building upon sale, efficiency improvements must translate into both ongoing cash flow and residual value. To do this, the improvements must be clearly identified and performance indicators benchmarked. All things being equal, if one compares two similar buildings, the one retrofitted with efficiency improvements will more valuable than the one without, simply based on the improvements. Although it may not be a dollar-for-dollar value increase as compared to the cost of the improvements, the commercial building without efficient equipment should sell at a discount compared to the one with the efficient equipment. The ability to verify that the improvements translate into persistent savings supports the value enhancement.

Typically, high-performance and energy efficiency improvements are done in conjunction with a major retrofit - driven largely by the age of the property and its improvements but driven also by a desire to avoid competitive obsolescence as more efficient buildings come on line. Capital projects are budgeted in advance and prioritized based on necessity, enhanced lease desirability, and anticipated returns.

\footnotetext{
${ }^{1}$ Corporate social responsibility goals also may be referred to as environmental, social, and governance.
} 
In smaller-size properties, the energy cost savings are generally not significant enough to offset the transaction costs inherent in implementing a full-scale energy audit. However, a linked toolkit would be useful in identifying the energy profile of a building and providing the property owner with simple and easy-to-follow recommendations.

Research reflects a split between large portfolio owners, even those with a similar amount of square footage under ownership or management. Some owners have only Class A office space in strong urban markets (e.g., New York City and Washington, D.C.). Others may hold a similar amount of square footage and/or number of buildings but in varying property types (office, industrial, multi-family, Class A, Class B) and in Tier 2 or even Tier 3 markets. Those in the first category typically see the value of sustainability and anticipate regulatory changes, and their buildings are considered among the most desirable in their marketplace. For these property owners in these markets, rents are consistently high and vacancy is typically low.

Those in the second category may or may not appreciate the value of energy improvements, do not have the rents to support a lot of capital investment, and often do not have the internal capacity or expertise to do extensive auditing or retrocommissioning, much less continuous commissioning. These property owners are significantly affected by market dynamics, particularly in those markets where vacancy is high and rents are low. Their focus is just to keep the building leased. These owners will likely benefit the most from the energy efficiency diagnostic.

In summary, owner-occupied buildings are used primarily to house the building owner's employees and to meet the owner's business needs. Building owners may be corporate, institutional, or government entities. Owners in this group are more interested in infrastructure upgrades and building management and pay less attention to building valuation because their buildings are not for lease or sale. However, peer comparison can be important to these owners when energy efficiency or sustainability is included in their performance goals or helps their public image. The perceived influence of the built environment on employee productivity can also motivate these owners to upgrade their buildings. Tenant-occupied buildings may yield conflicting interests in the energy efficiency investments due to incentive conflict between landlords and tenants, depending on the lease type (single-, double-, or triple-net lease ${ }^{2}$ ). In most commercial buildings, the tenant pays for operating expenses, in one form or another. For example, the tenant pays directly for the actual use, such as electricity bills, through submetering; a flat-rate monthly utility charge may be applied when a central system is used. In triple-net leases, the landlord pays all building operating expenses and is reimbursed by the tenant. Even in leases where the landlord pays the base operating expenses, the lease usually requires that increases or decreases in operating expenses after the first year be passed on to the tenant. Thus, incentives are misaligned: the landlord pays the capital costs to make the building more energy efficient and the tenant benefits from the savings. For this group of building owners, the influence of energy efficiency on their property value is important because higher energy efficiency is likely to increase their building's leasing or selling price. A tool that can separate the energy costs and savings related to building infrastructure from those affected by tenant activities would help building owners and tenants better define their responsibilities.

\footnotetext{
${ }^{2}$ In addition to normal fees under agreement (rent, premises utilities, etc.), in a single net lease, the lessee is responsible for paying property taxes; in a double net lease, the lessee is responsible for paying property tax and building insurance; in a triple net lease, the lessee is responsible for property tax, building insurance, and maintenance on the property.
} 
The size of the commercial buildings should also be fully considered in the toolkit development. Of the total number of commercial buildings, $5 \%$ are larger than 50,000 $\mathrm{ft}^{2}$ and account for $50 \%$ of the total commercial floor area. The other half of the commercial floor area consists of buildings equal to or less than 50,000 $\mathrm{ft}^{2}$ (EIA 2006). Currently there is no standard way to categorize buildings into small, medium, or large. DOE reference buildings set up a prototype of approximately 5,000 $\mathrm{ft}^{2}$ for small office buildings, approximately 50,000 $\mathrm{ft}^{2}$ for medium office buildings, and approximately 500,000 $\mathrm{ft}^{2}$ for large office buildings (DOE 2011). The Advanced Energy Design Guide for Small to Medium Office Buildings (ASHRAE 2011) uses $100,000 \mathrm{ft}^{2}$ as a cutoff point for small and medium office buildings. From a heating, ventilation, and air conditioning (HVAC) design perspective, ANSI/ASHRAE/IESNA ${ }^{3}$ Standard 90.1 provides a simplified option for determining code compliance for buildings of less than 25,000 $\mathrm{ft}^{2}$. The vast majority of these buildings use simple HVAC systems, and they account for $90 \%$ of commercial buildings and 37\% of commercial floor area. Due to the simplicity of their structure and HVAC systems, most of these commercial buildings do not have designated staff to maintain or improve building performance. From a policy standpoint, some local jurisdictions (such as New York City, Seattle, and Philadelphia) apply the benchmark law to commercial buildings larger than 50,000 $\mathrm{ft}^{2}$. This report defines the large, medium, and small buildings as described in Table 2.1.

Table 2.1. Definitions of large, medium, and small buildings.

\begin{tabular}{|c|c|c|c|c|c|c|}
\hline & Floor Area & $\begin{array}{c}\text { Percentage of Total } \\
\text { No. of Commercial } \\
\text { Buildings }\end{array}$ & $\begin{array}{c}\text { Percentage of } \\
\text { Total Commercial } \\
\text { Floor Area }\end{array}$ & $\begin{array}{c}\text { Percentage of } \\
\text { Total Primary } \\
\text { Energy Use }\end{array}$ & $\begin{array}{l}\text { HVAC } \\
\text { System }\end{array}$ & $\begin{array}{c}\text { Designated } \\
\text { Facility } \\
\text { Operator }\end{array}$ \\
\hline Large Building & $>50,000 \mathrm{ft}^{2}$ & $5 \%$ & $50 \%$ & $56 \%$ & Complex & Most likely \\
\hline $\begin{array}{l}\text { Medium } \\
\text { Building }\end{array}$ & $\begin{array}{c}25,000 \mathrm{ft}^{2}- \\
50,000 \mathrm{ft}^{2}\end{array}$ & $5 \%$ & $13 \%$ & $11 \%$ & Complex & Unlikely \\
\hline Small Building & $<25,000 \mathrm{ft}^{2}$ & $90 \%$ & $37 \%$ & $33 \%$ & Simple & Unlikely \\
\hline
\end{tabular}

There are significant differences in the capacity and business focus between large building owners in top markets and the owners of mid- and small-size buildings. Many larger building owners and managers are actively benchmarking their portfolios in ESPM and making capital decisions accordingly. According to the Global Real Estate Sustainability Benchmark survey, more institutional real estate investors are tracking their energy use (GRESB Foundation 2010). These companies represent the 5\% of large buildings (greater than 50,000 $\mathrm{ft}^{2}$ ). For this user group, the standard information on peer comparison and building valuation is more important than building diagnosis because many of these buildings have a designated energy manager or facility operator. A study of firms with revenues of at least $\$ 250$ million shows that $85 \%$ of their energy efficiency projects were funded through capital budgets and company profits (McGraw-Hill 2011).

The owners of mid- and small-size buildings often lack the capital or expertise to consider efficiency measures. The building diagnosis and improvement provided by a low-cost tool could positively influence the mid-size building owners and managers with Class $\mathrm{B}^{4}$ buildings. There is a significant

\footnotetext{
${ }^{3}$ ANSI is the American National Standards Institute; ASHRAE is the American Society of Heating, Refrigerating and Air-Conditioning Engineers; IESNA is the Illuminating Engineering Society of North America.

${ }^{4}$ Class A buildings refer to the most prestigious buildings competing for premier office users with rents above average for the area. Class A buildings have high-quality standard finishes, state-of-the-art systems, exceptional accessibility, and a definite market presence. Class B buildings refer to buildings competing for a wide range of users with rents in the average range for the area. Class B building finishes are fair to good for the area and systems
} 
difference between building owners who hold assets in high-rent markets and those who hold the same square footage in lower-rent markets. Building owners who have lower rental income have less capital, lower margins, and probably fewer internal resources for energy auditing and retrocommissioning. These owners may find low-cost energy-saving strategies (such as those focused on building operation and occupant behavior) more attractive. Information about building performance must be understandable to building owners, who usually do not have a background in energy efficiency. Reaching out to these building owners is the important first step. Free training materials, first-hand information about their buildings, and actionable strategies that can be implemented by building owners with less professional assistance will motivate these building owners.

In summary, implementation of EEMs in the broader market continues to be held back by a lack of information and awareness, conflicting incentives, and comparatively small profits. Many building owners have insufficient knowledge of the factors that significantly affect building energy use, and have even less knowledge of how to increase efficiency. Stakeholder interviews (among property owners, institutional and private equity investors, financiers, appraisers, property and asset managers, and senior managers from nonprofit organizations and state and federal government agencies) conducted by Pacific Northwest National Laboratory in 2011 show that building stakeholders want to know the potential efficiency for a building, given its structural makeup and the cost to achieve it (McCabe and Wang 2012). The energy asset scoring tool is developing a baseline from which improvements can be made. However, a single tool will not address all questions. There are significant contractual complexities such as distinguishing among future savings that are due to greater efficiency, savings that may occur because of occupancy changes, and savings due to unusual weather. Such complexities make it hard to convince building owners to purchase an efficient-building energy package, according to some of the building managers interviewed. Building an integrated toolkit requires an understanding of what questions will be answered at which stage of the building life cycle and what information is needed to provide consistent answers (Table 2.2).

are adequate, but the building does not compete with Class A at the same price. Class C buildings refer to buildings competing for tenants requiring functional space at rents below the average for the area (BOMA 2011). 
Table 2.2. Key questions for each stage of a building's lifespan.

\begin{tabular}{|c|c|c|c|c|}
\hline Stage & Key Questions & $\begin{array}{l}\text { Tool Function } \\
\text { Components }\end{array}$ & $\begin{array}{c}\text { Data } \\
\text { Resources }\end{array}$ & Tool User Activities \\
\hline \multirow[t]{2}{*}{ Design } & \multirow[b]{2}{*}{$\begin{array}{l}\text { How does the building compare to the } \\
\text { current code? Is the designed building } \\
\text { considered efficient? What are the } \\
\text { expected energy and maintenance } \\
\text { bills? Is it net zero capable? Does it } \\
\text { capture all cost-effective energy } \\
\text { efficiency? }\end{array}$} & \multirow[t]{2}{*}{ Asset } & Architect & Enter building characteristics \\
\hline & & & Engineer & $\begin{array}{l}\text { Enter miscellaneous loads and } \\
\text { anticipated operating schedule }\end{array}$ \\
\hline \multirow[t]{2}{*}{ Construction } & \multirow{2}{*}{$\begin{array}{l}\text { Do changes during the construction } \\
\text { phase affect the building energy } \\
\text { efficiency? }\end{array}$} & \multirow[t]{2}{*}{ Asset } & Architect & \multirow{2}{*}{$\begin{array}{l}\text { Update building characteristics } \\
\text { based on construction } \\
\text { Update the miscellaneous loads } \\
\text { based on the actual inventory }\end{array}$} \\
\hline & & & Engineer & \\
\hline \multirow[t]{6}{*}{ In Operation } & \multirow{2}{*}{$\begin{array}{l}\text { Is the building operated efficiently? } \\
\text { What improvements can building } \\
\text { operators make? How does occupant } \\
\text { behavior affect building energy use? }\end{array}$} & \multirow[t]{2}{*}{ Operation } & Building & Update operating schedule \\
\hline & & & $\begin{array}{l}\text { Operator, } \\
\text { Facility } \\
\text { Manager }\end{array}$ & $\begin{array}{l}\text { Input information on } \\
\text { miscellaneous electric loads }\end{array}$ \\
\hline & $\begin{array}{l}\text { How are the building's maintenance } \\
\text { costs and energy costs compared to } \\
\text { other buildings? Is there a way to save } \\
\text { more while keeping tenants? }\end{array}$ & $\begin{array}{l}\text { Cost } \\
\text { (operations } \\
\text { and } \\
\text { maintenance } \\
(\mathrm{O \& M}) \text { ) }\end{array}$ & $\begin{array}{l}\text { Building } \\
\text { Owner, } \\
\text { Facility } \\
\text { Manager }\end{array}$ & $\begin{array}{l}\text { Track maintenance and energy } \\
\text { costs }\end{array}$ \\
\hline & \multirow{2}{*}{$\begin{array}{l}\text { How is the building's energy use } \\
\text { compared to similar buildings? }\end{array}$} & Portfolio & Facility & \multirow[t]{2}{*}{ Track utility consumption data } \\
\hline & & Manager & Manager & \\
\hline & $\begin{array}{l}\text { Are the installed building systems } \\
\text { efficient? How could the building } \\
\text { infrastructure be improved? }\end{array}$ & Asset & $\begin{array}{l}\text { Building } \\
\text { Owner, } \\
\text { Facility } \\
\text { Manager }\end{array}$ & $\begin{array}{l}\text { Enter building characteristics if } \\
\text { the building does not have } \\
\text { energy asset score information } \\
\text { from the design stage }\end{array}$ \\
\hline \multirow[t]{2}{*}{$\begin{array}{l}\text { Retro- } \\
\text { commissioning }\end{array}$} & $\begin{array}{l}\text { How much can I save through retro- } \\
\text { commissioning? }\end{array}$ & Operation & $\begin{array}{l}\text { Engineer/ } \\
\text { Contractor }\end{array}$ & $\begin{array}{l}\text { Update operating/control } \\
\text { schedules based on retuning }\end{array}$ \\
\hline & $\begin{array}{l}\text { Does retrocommissioning improve the } \\
\text { asset value of the building? }\end{array}$ & Asset & $\begin{array}{l}\text { Engineer/ } \\
\text { Contractor }\end{array}$ & $\begin{array}{l}\text { Update HVAC efficiencies } \\
\text { based on the test results }\end{array}$ \\
\hline Renovation & $\begin{array}{l}\text { Does the renovation improve the asset } \\
\text { value of the building? How much can I } \\
\text { save in energy and maintenance } \\
\text { expenses? }\end{array}$ & Asset & $\begin{array}{l}\text { Architect/ } \\
\text { Engineer }\end{array}$ & $\begin{array}{l}\text { Update building characteristics } \\
\text { based on building renovation }\end{array}$ \\
\hline \multirow[t]{3}{*}{ Lease or Sale } & $\begin{array}{l}\text { How do I translate a building's } \\
\text { efficiency level into its asset value? } \\
\text { What is the potential of this building? }\end{array}$ & Asset & $\begin{array}{l}\text { Appraiser, } \\
\text { Potential }\end{array}$ & Query building information \\
\hline & $\begin{array}{l}\text { How do I separate building } \\
\text { infrastructure from its O\&M? }\end{array}$ & Operation & $\begin{array}{l}\text { Buyer or } \\
\text { Tenant }\end{array}$ & \\
\hline & $\begin{array}{l}\text { What is the long-term cost of } \\
\text { operating this building? What is the } \\
\text { maintenance cost? }\end{array}$ & Cost (O\&M) & $\begin{array}{l}\text { Buyer or } \\
\text { Tenant }\end{array}$ & \\
\hline
\end{tabular}




\subsection{Support Ongoing Measurement and Provide Feedback Loop}

ENERGY STAR Portfolio Manager provides decision makers with an understanding of how much energy the whole building consumes and how it compares to similar buildings. Decision makers with this information are more likely to pursue energy efficiency opportunities. To this end, ESPM provides a portal to help users pursue energy efficiency by establishing an energy performance goal. A path toward the goal is also important. Decision makers need to understand how an action can affect the outcome. A survey conducted by CBRE, Inc. of its portfolio of managed properties shows that $98 \%$ of respondents tracked whole-building energy metrics (Pogue and Laquidara-Carr 2011). The replies from 54 energy managers indicate that tracking facility energy performance data on an increasingly granular level is a growing priority.

The energy asset scoring tool being developed by DOE provides more granular building information and identifies a way to improve building energy efficiency. However, this tool addresses only one aspect of the market needs by examining the building infrastructure. The other aspect that needs to be addressed is building operation. Providing a way to gauge operational success would deliver the means to track and ensure the persistence of energy savings, increasing the certainty of returns and reducing risk of investment in energy efficiency. Combining the energy asset score with an operational rating would establish a feedback loop that provides accountability and increases confidence over the long term.

Further, the ability to compare the as-designed/as-built building structure to actual building performance would increase learning and ultimately innovation in the design and construction sector. It would also give the appraisal community a way to concretely value the efficiency improvements and confidently incorporate the energy savings into the building analysis. Financing mechanisms and government incentives could also be structured based on the combination of efficient infrastructure and system operation.

\subsection{Incorporate the Existing Tools}

According to building stakeholders interviewed during market research for the energy asset scoring tool, the building community and policy makers should focus on accepting a single method or program to reduce confusion, contradictions, and complications. Many stakeholders pointed to ESPM because most large real estate owners have incorporated ESPM into their business models, and many regularly benchmark their assets. In addition, most investors use ESPM as a baseline for evaluating the energy efficiency of their buildings. The program provides a year-over-year comparison in terms of cost per square foot; the cost data in ESPM are extracted from monthly utility bills and for self-tracking (instead of benchmarking) over time.

This market feedback suggests that the proposed toolkit should be developed as an add-on to the existing tools and complement existing benchmarking efforts. For example, ESPM has no function for calculating cost savings of a specific retrofit measure; however, the energy asset scoring tool provides such capability. Users should benefit from this new function without having to re-enter their building information through a different portal.

Stakeholder interviews revealed a strong desire in the market to link the energy asset score to building operation data. As discussed in the previous section, this linkage could provide an effective feedback 
loop. One real estate investor commented, “An asset score system would evaluate the existing building's potential performance. If that were available alongside an actual performance data point, the industry would have a very powerful tool to accelerate capital investment for financial and environmental returns." An energy engineer expressed an opinion typical of those interviewed, stating, "An asset score is a reflection of modeled energy efficiency-how efficient, in this case, is a commercial property, on paper. The actual in-use performance of the building is strongly dependent on O\&M as well as plug loads and occupant behavior. Ideally, an asset score is accompanied by some kind of in-use rating, like ENERGY STAR.”

From both a financial and a technical perspective, a comprehensive examination of building infrastructure and operation and its performance outcome is essential to ensure information reliability and build investor confidence in short- and long-term returns, and thus stimulate capital investment in energy efficiency.

Currently, the energy asset score and ESPM (the in-use rating) are not directly comparable because the energy asset scoring tool calculates energy use from an uncalibrated energy model while ESPM extracts energy use from utility bills. A study of 121 newly constructed buildings designed to meet LEED specifications (Turner and Frankel 2008) shows that measured EUIs for more than half of the buildings deviate by more than 25\% from design projections, with 30\% significantly better and $25 \%$ significantly worse (Figure 2.2). The discrepancy between the modeled energy use and measured energy use is attributed to two categories of parameters: those related to the building infrastructure and those related to the building occupants. It is assumed that the quality of the models is equal, although modeler interpretations of the building data and the chosen modeling tools unavoidably add uncertainty to the model results.
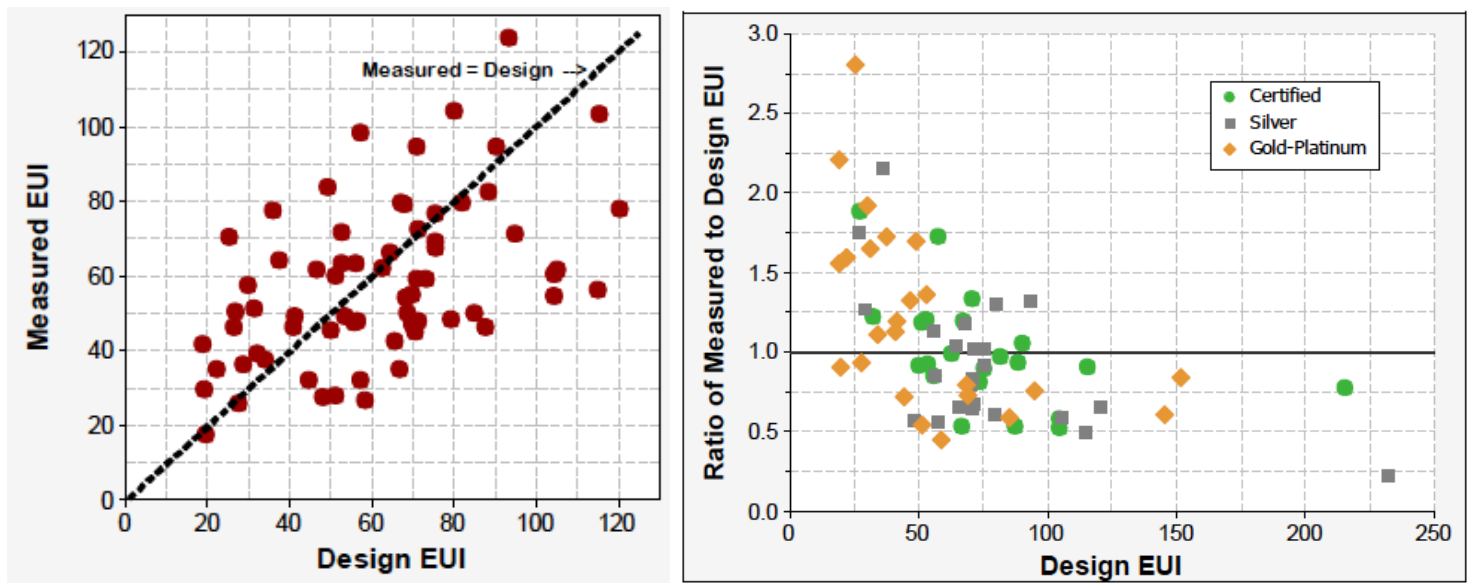

Figure 2.2. Measured versus design EUIs $\left(\mathrm{kBtu} / \mathrm{ft}^{2}\right)$ of LEED new construction buildings (Source: Turner and Frankel 2008).

The infrastructure-related parameters include building insulation, air exchange rate, and HVAC efficiencies. Accurate measurement of these parameters is costly and unpractical. The energy asset score is focused on a building's as-built efficiency and its upgrade potentials. The same model assumptions are made for the similar infrastructure parameters (with same type and vintage). Therefore, the relative results between building models are more accurate, although the absolute results are less accurate when compared to actual energy consumption. In other words, a more efficient building will be rated higher than a less efficient building. Therefore, an uncalibrated model is adequate for energy asset rating. 
Uncalibrated models have been used largely to estimate the energy savings from proposed EEMs, although this practice may lead to large differences (7-98\%) when compared with measured energy use of whole building or by system (Monfet et al. 2009). There are multiple causes for this discrepancy (faulty assumptions by modelers, difficulty determining how the existing equipment is controlled, etc.). Nevertheless, a calibrated model improves the accuracy of prediction for EEM savings (Monfet et al. 2009), although some researchers have concluded that a finely calibrated model does not ensure an accurate estimation of energy savings due to the building retrofit (Corson 1990; Kaplan et al. 1990). For example, infiltration can be one of the most significant energy drivers in a building, but the modeler is likely to have the poorest information about the infiltration rate. Infiltration assumption can overshadow most other inputs for buildings that are subject to a significant heating load and significantly affect EEM saving estimates (Kaplan and Caner 1992).

The energy asset scoring tool provides a certain level of quality assurance by controlling the assumptions made by tool users. The tool's centralized modeling engine also eliminates the discrepancy caused by using different modeling software. Calibration of the energy asset rating model is unnecessary as the tool is not intended to replace engineering evaluations but to provide a preliminary analysis of building asset.

Occupant-related parameters include building operating schedules, plug loads, and lighting and temperature settings controlled by occupants. A study by Norford et al. (1994) found that the building energy model underestimated building energy use by $150 \%, 64 \%$ of which could be caused by unanticipated occupant energy use due to extended hours of occupation and higher plug loads. Additional causes of the underestimated energy use were HVAC operation and actual (rather than rated) performance. In the case of the energy asset score, occupant-related parameters are controlled variables. Standard assumptions of building plug loads and schedules are made to enable "apples-to-apples" comparisons between the as-built efficiencies of the same types of buildings.

To address the market's requirement for a direct comparison between the energy asset score and ESPM results, an additional indicator is needed to examine whether a building is operating optimally. This indicator should be based on modeling of the as-built building using the actual weather and operating conditions. In this case, the standard assumptions used for energy asset rating no longer apply. This building model with building characteristics can be derived from the energy asset scoring tool, but the model needs to be calibrated to the actual utility consumption, possibly exported from ESPM. In addition, the actual operational details that are not collected by ESPM (plug loads, temperature setting, control schedule, etc.) need to be collected and reflected in the new building model. This needs to be considered in the proposed toolkit development.

\subsection{Reduce Implementation Cost}

Implementation cost and label fatigue present barriers to new energy efficiency systems and tools in the broader market. With a seemingly endless number of new rating systems and tools being developed, users often lack the time and interest to learn a new system or tool. Although most new systems or tools are intended to fill market gaps and provide new functionalities, the new functions may not seem significant enough for building owners or other stakeholders to abandon familiar systems or tools. Adopting a new system or tool can also mean additional staff costs. 
With energy costs in U.S. commercial buildings averaging \$1.43/ft ${ }^{2}$ (EIA 2006), a 10-30\% improvement in efficiency could yield savings of $\$ 0.14-\$ 0.42 / \mathrm{ft}^{2}$. A comprehensive energy audit and modeling analysis can cost up to $\$ 0.50 / \mathrm{ft}^{2}$ (CEC 2000). The cost of an audit depends on a facility's location, level of detail, size, and complexity. For example, one consulting firm charges base fees of $\$ 200$ plus $\$ 0.25 / \mathrm{ft}^{2}$ for an ASHRAE Level 1 audit (walkthrough analysis) and $\$ 200$ plus $\$ 0.35 / \mathrm{ft}^{2}$ for an ASHRAE Level 2 audit (energy survey and analysis). The cost of an audit service (\$0.25-0.50/ $\left.\mathrm{ft}^{2}\right)$, which may exceed 1 year of potential energy savings $\left(\$ 0.14-\$ 0.42 / \mathrm{ft}^{2}\right)$, has made it less cost effective for building owners to invest in energy efficiency. Often, detailed audits and modeling can be costprohibitive for all but the largest building owners.

Low implementation cost is one reason for ESPM's wide adoption. The energy asset scoring tool has been developed to minimize the additional cost burden. The proposed toolkit should fill the data gap with little additional data required from the tool user. ESPM users are the most likely users of the energy asset scoring tool and the proposed toolkit. Therefore, data transfer between ESPM and the new tools should be as seamless as possible to ease use and avoid redundant effort.

The key program challenge is to balance the validity of results (via rigor of data collection and modeling) with the implementation cost. Data input requirements need to be simplified and limited. More simplified data acquisition reduces the expertise, time, and effort required of tool users, reducing the assessment cost. Tool design should involve multidisciplinary stakeholders to ensure the correct balance between default values and data acquisition. 


\subsection{Energy Metrics in Building Performance Evaluation}

This section identifies the key metrics that have been or could be used to measure energy efficiency. It also discusses how they are calculated and related to building performance at every stage of a building's life cycle. The benefits and limitations of using each metric are also discussed. Some of these key metrics are used in the existing tools, while others are not. Understanding how these key metrics have been used and should be used will help identify the gaps in the existing tools.

\subsection{Building Energy Use Intensity}

Building EUI is the most commonly used metric to evaluate energy performance and to establish performance goals for buildings during the design stage and in operation. EUI is measured in thousand British thermal units per square foot $\left(\mathrm{kBtu} / \mathrm{ft}^{2}\right)$ and can be calculated in terms of either site EUI or source EUI. Site EUI is usually used either by design teams to establish performance goals or by building operators to track energy use history. Source EUI is adopted by EPA and DOE for benchmarking in ESPM and the energy asset scoring tool.

Source energy incorporates all transmission, delivery, and production losses and thereby enables a complete assessment of building energy efficiency. Source energy provides a fair comparison by bringing the primary energy (such as natural gas directly burned onsite) and secondary energy (such as electricity generated offsite) into equivalent units. It is also a proxy to energy price. Gross floor area is usually used to calculate the site and source EUIs, although the definition (e.g., whether to include the enclosed parking garage) varies in different applications. Conditioned floor area and rentable floor area are also used in some cases. The means by which EUI is calculated can significantly influence its accuracy and effectiveness for comparison.

EUI can be calculated using unadjusted historical energy use data, normalized historical energy use data, and simulation (Mathew et al. 2011).

\subsubsection{Unadjusted Site EUI Based on Utility Bills}

Unadjusted site EUI is the easiest and most straightforward way to track building energy use over time when there are no significant changes in weather, operational practices, and vacancy level. It is more useful for owner-occupied buildings because building occupancy and operation regime are stable over a long period. Building operators can establish their own baseline energy use based on the historical average. In this case, electricity and gas consumption are separately recorded monthly in the units of kilowatt-hours and therm (or other units from the utility bills) without being converted to thousand British thermal units (kBtu).

Given that weather constantly changes throughout the year, cooling degree days and heating degree days can be used to understand the relationship between building energy use and weather (Figure 3.1). However, most building operators do not have the knowledge, time, or means to extract cooling degree days and heating degree days from the National Oceanic and Atmospheric Administration (NOAA) weather database. 
A major limitation of unadjusted EUI is that the effect of operational changes cannot be easily understood, especially given the potential for variance over multiple variables (i.e., weather, occupancy, and building system operations). Because building systems and interactions between a building and its occupants are complex, unadjusted energy use data may deliver misleading information on changes and their corresponding results. A major change to a building may require building operators to disregard historical data and reestablish their baseline, which often requires a minimum observation time of 1 year.

However, the advantages of this method cannot be ignored: it is fast and convenient, requires little training, and offers tangible results (the savings are directly linked to the monthly bills). In developing the toolkit, DOE should consider providing features that help building operators effectively record their utility data in a standard format and correctly interpret the results by tracking the changes in weather and O\&M activities. Moreover, energy use data directly from utility bills are used to calculate the greenhouse gas emissions of a building and estimate its environmental impact. This application should also be considered in the toolkit development.
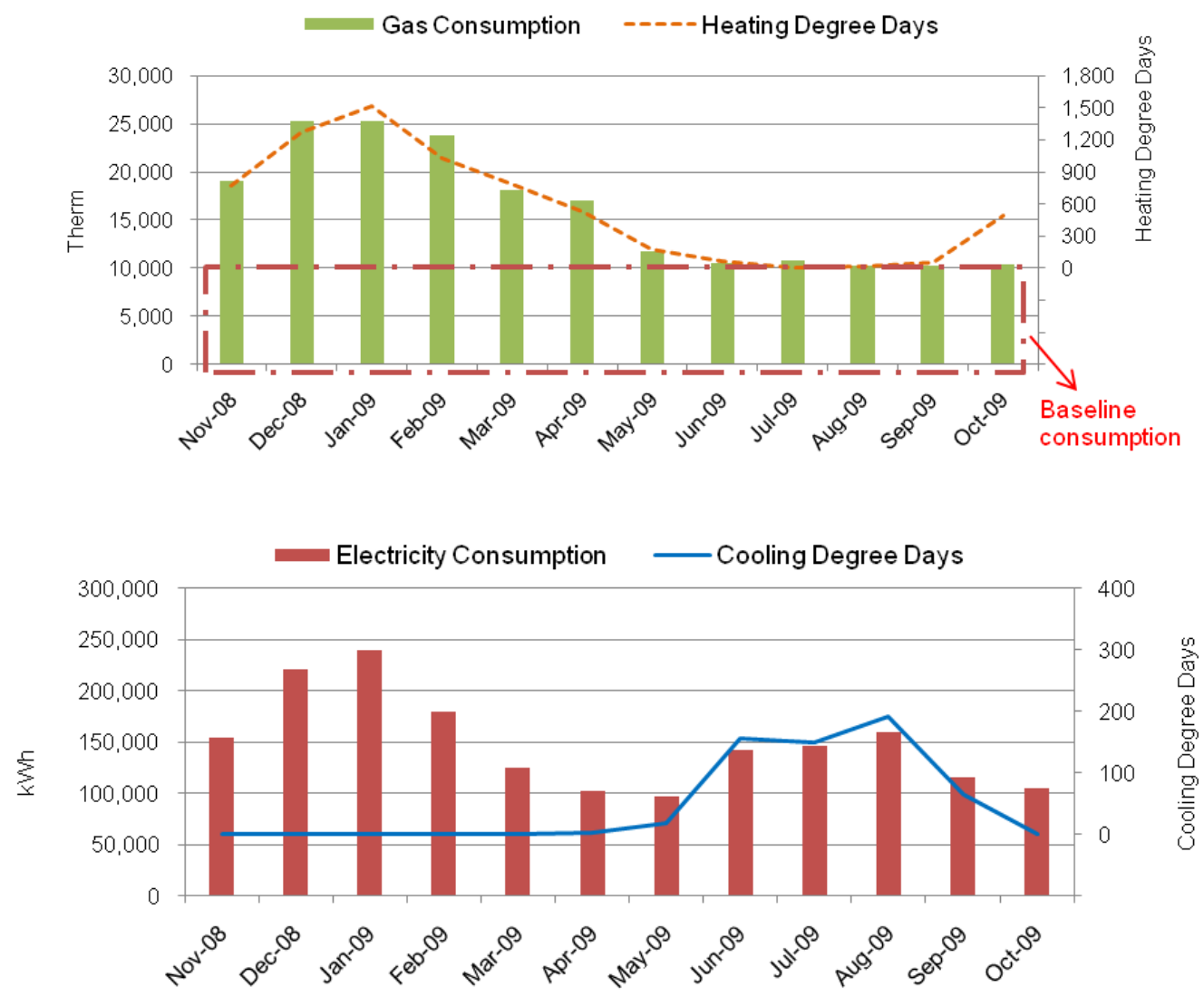

Figure 3.1. Using cooling degree days and heating degree days to understand energy consumption with respect to weather changes.

\subsubsection{Normalized EUI Based on Utility Bills}

Normalized EUI accounts for variations in weather, vacancy levels, and operational practices. A regression model is used to adjust some of these variations. For example, ESPM considers seven variables when normalizing energy use of office buildings: (1) gross floor area, (2) weekly operating 
hours, (3) number of workers on main shift, (4) number of personal computers, (5) percentage of floor area air conditioned ( $\geq 50 \%,<50 \%$, or none), (6) percentage of floor area heated $(\geq 50 \%,<50 \%$, or none), and (7) and weather (cooling degree days and heating degree days). The excluded variables, such as temperature setpoints, maintenance/commissioning, and other plug loads, can significantly influence energy use but are difficult to normalize using regression models.

ASTM recently developed Standard E2797-11 for buildings involved in a real estate transaction to provide a consistent methodology for collecting and analyzing building energy use and cost data. It standardizes a number of variables associated with data collection and normalization, considering timeframe, calculation of gross floor area, heating and cooling degree days, vacancy rate, building operating hours, and other relevant factors.

\subsubsection{Calculated EUI through Energy Simulation}

Energy simulation is a valuable analytical tool that allows valuation of EEMs by adjusting the characteristics of systems, operation, and occupancy. Energy simulation is usually used during the design stage or during energy audits. During the design stage, building energy use is modeled under a set of standard consumptions, for example, as specified in ANSI/ASHRAE/IESNA Standard 90.1-2004, Appendix G. During an in-depth energy audit, actual operating conditions are used, and the model inputs are adjusted to match the utility bills. In addition to calculating the EUI, energy simulation can provide a rich amount of information at a very granular level (e.g., daily energy use by system). This information cannot be obtained from utility data, and submetering to measure the building energy use in a specific area is usually expensive.

Concerns with energy simulation include limitations of simulation tools; buildings not being constructed, operated, or occupied as designed; and accuracy and accountability in the models. Improper use of models by inexperienced users can produce invalid results. Even experienced modelers may generate different results for the same building due to their interpretations of building data and their understanding of the modeling software, and determining which modeler's results were more "correct" would not be trivial.

A centralized simulation tool with controlled user inputs could help alleviate some of the drawbacks inherent in simulations. First, with controlled user inputs, users would only need to provide a limited number of building data inputs. This could reduce unnecessary data collection and enable users with less modeling expertise to generate more robust, consistent results. Second, a centralized simulation tool built on a highly detailed, dynamic modeling engine could still model complex building energy components and systems, especially those of today's high-performance buildings.

A simplified user interface does not equate to a simplified or static energy calculation, which uses a number of approximations and simplifications. The challenge of developing a centralized modeling tool is to filter the most important variables for the user inputs and make appropriate assumptions for the controlled variables that are not entered by users. The energy asset scoring tool, for example, uses an inference engine to map one-to-many relationships between the different building characteristics. These relationships are derived from survey data, equipment efficiency standards, building energy codes, ASHRAE handbooks, energy model internal system sizing algorithms, and empirical data from previous research. Sensitivity analyses are needed to test the accuracy of the combined user inputs and inferred values. 
As discussed in Section 2.3, energy simulation is mainly used to estimate current energy use (if measured data are incomplete or missing) and potential savings from EEMs. A calibrated energy model with detailed building information provides more reliable predictions. However, considering the expense, a low-cost aid is needed for making preliminary decisions on whether retrofitting a building is worthwhile, where the opportunities are, and how to prioritize these activities. The energy asset scoring tool is not intended to replace engineering evaluation or a detailed energy modeling service by a professional. Rather, the tool is meant to encourage building owners to take action by diagnosing their building systems and showing them how to improve building energy efficiency.

\subsection{Other Energy Use per Unit of Value}

Although EUI is widely used to benchmark energy performance across building types, it is not always a proxy for value to all business owners. When the profitability standard is not based on sales or net income per square foot, other energy use per unit of value needs to be considered, with different relevant units of value for different types of businesses. For example, hotel management looks at revenue per available room, and therefore energy use for hotels is usually measured by available room. EPA reports that hotels spend \$2,196 per available room each year (EPA 2007a). From a consistency standpoint, ESPM still benchmarks hotels using EUI; however, an additional metric, like energy use per available room, provides more meaningful information to hotel managers.

Even for building types that can be meaningfully measured by EUI, other units of value can give more comprehensive insight into a building's energy use. A good example is energy use per person or occupant. The number of occupants is usually counted using full-time equivalent employees; however, sometimes the number of customers, students, or patients is used for non-office building types. Unlike water use per person, energy use per person has not become a standard metric for measuring building energy efficiency. However, energy use per person could be an effective metric to link energy use to tenant activities. For example, the measured EUI of the LPA Inc. office in Irvine, California, was $115 \mathrm{kBtu} / \mathrm{ft}^{2}$, which yields an ENERGY STAR score of around 40. However, the company reported the average energy use per person to be 19.1 million British thermal units (MBtu), 23\% lower than that of the average Commercial Buildings Energy Consumption Survey (CBECS) office space (Ring 2009). The validity of such comparison needs further investigation; however, this case raises the question of whether EUI is sufficient to evaluate building energy performance.

Using energy use (or cost) per person can also take into account building vacancy rate. Assuming the EUI of a $10,000 \mathrm{ft}^{2}$ building is $100 \mathrm{kBtu} / \mathrm{ft}^{2}$ at $50 \%$ vacancy and $150 \mathrm{kBtu} / \mathrm{ft}^{2}$ when it is fully occupied by a total of 100 occupants, the EUI change would not offer a direct link to the vacancy rate. If the metric of energy use per person is introduced-20 MBtu per person at 50\% vacancy and 15 MBtu per person at $0 \%$ vacancy_building owners can more easily understand how their building performance is related to the occupants.

Energy use per student is a useful performance indicator for schools. ENERGY STAR information on energy cost per student indicates that schools spent nearly \$75 per student on gas bills and \$130 per student for electricity in 2005 (EPA 2006), although this was not used by ESPM as an energy benchmark. EPA used this metric to demonstrate the success of Davenport Community School District in Iowa, which was able to reduce costs per student to $\$ 88.46$ per school year, compared to the national average of \$181.53 (EPA 2007b). 
Another popular non-EUI metric is power usage effectiveness (PUE) for data centers. PUE, the ratio of total energy use and information technology (IT) energy use, has been recommended by industry leaders and federal agencies to measure energy efficiency of data center (EPA 2011). To calculate PUE, IT energy consumption should be metered at the output to the uninterruptable power supply.

To develop useful non-EUI energy metrics, it is important to understand what profitability indicators have been used for different types of business and what additional data are required from users.

\subsection{Energy Cost, Time Value, and Peak Demand}

The real estate industry has looked to building ratings and certifications as indicators quality. Buildings rated by ESPM reflect lower energy consumption and higher rental and value premiums (Goldman et al. 2005; Mills 2009). Research (Fuerst and McAllister 2011) on the price differential between LEED/ENERGY STAR certified buildings and non-certified commercial buildings in the United States shows that certified buildings (197 LEED and 834 ENERGY STAR) have an average rental premium of $4-5 \%$. Furthermore, a sample of sale prices for 559 ENERGY STAR and 127 LEED certified buildings shows price premiums of $26 \%$ and $25 \%$, respectively, with higher levels of certification achieving higher premiums. Literature suggests that, compared to non-certified buildings, certified buildings may offer benefits related to lower operating costs, improved employee productivity, tax credits, and image (Fuerst and McAllister 2011).

Net operating income is a major component of building value. In the income capitalization approach described by the Institute for Market Transformation and the Appraisal Institute, appraisers divide the NOI by a capitalization rate (determined by the appraiser) to translate the NOI to value (IMT and AI 2012). Maintenance and energy account for $73 \%$ of building operating costs (IFMA 2009) and play an important role in the valuation.

The increasing market recognition of energy efficiency is reflected in increased rents and sales prices of a high-performance building (Gripne et al. 2012). This may further increase the value of a highperformance building. Although energy costs are not used as a main performance metric, due to their high variability and complexity, building energy efficiency boils down to costs or net present value for building owners, investors, and valuators.

Energy costs for commercial buildings vary considerably in different areas of the country and change over time, including over the course of the day. Without much more specific information about a building's operations and its time-dependent per-unit energy prices, energy cost does not provide a durable, comparable metric upon which to base a rating. However, cost information is still a useful metric for building owners and investors because it is directly related to NOI and asset value. Its importance and an appropriate means to present this information should be considered in the toolkit development.

Another challenge of using energy cost is that the cost includes a peak demand component, which relates to the utility infrastructure and varies significantly by region. To address the time value (peak demand) of energy use and cost, the State of California developed time-dependent valuation (TDV) and adopted it in the cost-effectiveness calculation for the Title 24 energy standards beginning in 2005. The recent update is the 2013 standard published in 2011 (Price et al. 2011). Compared to energy cost savings 
based on annual average price of electricity or natural gas, TDV accounts for variations in cost related to time of day, seasons, geography, and fuel type by summing the hourly savings over the analysis year.

The TDV method encourages more efficient building energy performance during periods of high energy cost. This method requires developing an hourly TDV factor for each location (16 sets of TDV factors for 16 climate zones in California). The net present value of TDV ( $\$ / \mathrm{kWh}$ of each hour's energy cost over analysis periods of 15 and 30 years) is predicted and then converted to an energy unit, presented in British thermal units per kilowatt-hour (Btu/kWh), or Btu/therm for natural gas.

In the Title 24 energy standards, TDV energy is used to compare proposed designs to their energy budget when the performance compliance approach is used. TDV energy is calculated by multiplying site energy use for each energy type by the applicable TDV multiplier. TDV is used as a substitute for source energy. It uses energy unit (Btu/kWh) instead of cost unit $(\$ / \mathrm{kWh})$ to reduce the likelihood that building owners will mistakenly interpret it as an estimate of dollar savings.

Under a similar concept, the Commercial Energy Services Network (COMNET) also developed timeof-use (TOU) rate schedules for electricity, gas, steam, and chiller water. Energy costs are derived from COMNET default TOU prices. COMNET TOU prices estimate the present value of energy costs at different time periods (on-peak, mid-peak, off-peak, weekdays, weekends) in 15 climate zones by calculating the marginal electricity cost based on the sum of energy value components (including generation energy, losses, ancillary series, system capacity, transmission and distribution capacity, and environment). This method is intended to provide more accurate estimates of long-term energy cost savings.

\subsection{Maintenance Cost}

According to the International Facility Management Association (IFMA), the cost of building operations consists of utility cost (38\%), janitorial cost (27\%), and maintenance cost (35\%). IFMA divides maintenance cost into five categories: external building maintenance, interior system maintenance, roads and grounds, utility system maintenance, and process treatment/environmental system maintenance (IFMA 2009). The last two categories are likely incurred by manufacturing facilities and large campuses with central utility plants. All five categories have energy-related components, although some categories, such as roads and grounds, are less obvious than others. Each category has mixed items (Table 3.1), which makes it difficult to track maintenance costs and savings related to building energy efficiency. 
Table 3.1. Maintenance cost categories.

\begin{tabular}{|c|c|c|c|c|c|}
\hline & $\begin{array}{l}\text { External } \\
\text { Building }\end{array}$ & Interior Systems & Roads and Grounds & $\begin{array}{l}\text { Utility / } \\
\text { Central } \\
\text { System }\end{array}$ & $\begin{array}{l}\text { Process Treatment and } \\
\text { Environmental Systems }\end{array}$ \\
\hline $\begin{array}{l}\text { Energy- } \\
\text { related }\end{array}$ & $\begin{array}{l}\text { Roof, skin, } \\
\text { exterior } \\
\text { signage } \\
\text { (exterior } \\
\text { lighting) }\end{array}$ & $\begin{array}{l}\text { Electrical systems, } \\
\text { mechanical } \\
\text { systems, interior } \\
\text { signage (electric } \\
\text { or lit signage) }\end{array}$ & $\begin{array}{l}\text { Parking lots (lighting), } \\
\text { landscaping (if } \\
\text { landscaping equipment is } \\
\text { electric), underground } \\
\text { fire systems and hydrants } \\
\text { (pump energy use) }\end{array}$ & $\begin{array}{l}\text { Electrical, } \\
\text { mechanical }\end{array}$ & $\begin{array}{l}\text { Process cooling water } \\
\text { systems, process gas } \\
\text { systems, water } \\
\text { treatment plants, } \\
\text { incinerator operation }\end{array}$ \\
\hline $\begin{array}{l}\text { Not } \\
\text { energy- } \\
\text { related }\end{array}$ & & $\begin{array}{l}\text { Building and } \\
\text { general } \\
\text { maintenance, } \\
\text { administrative } \\
\text { support services- } \\
\text { trouble desks }\end{array}$ & $\begin{array}{l}\text { Roadways, sidewalks, } \\
\text { parking structures, storm } \\
\text { sewers }\end{array}$ & & $\begin{array}{l}\text { Air discharge } \\
\text { scrubbers, waste water } \\
\text { systems, solid waste } \\
\text { management system }\end{array}$ \\
\hline
\end{tabular}

According to IFMA (2009), the average annual maintenance cost is $\$ 2.22$ per rentable square foot (RSF), including repair, preventive, materials, direct labor, and contract costs (Figure 3.2), with a range from $\$ 0.27 /$ RSF (1 percentile) to $\$ 9.80 /$ RSF (99 percentile). Interior systems ( $\$ 0.06$ - \$6.59/RSF) contribute to this wide variation. Unfortunately, there is no breakout data for the energy-related maintenance cost.

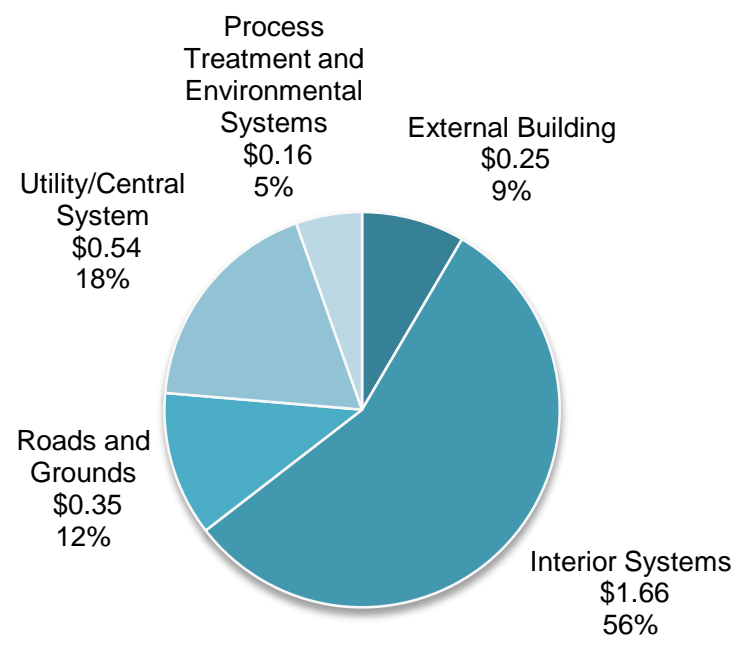

Figure 3.2. Average maintenance cost, dollars per rentable square foot (Source: IFMA 2009).

Most existing O\&M guides are prescriptive and their outcomes have never been systematically assessed and included in the building performance measurement. This is partially because more than half of the commercial buildings use a reactive maintenance approach-equipment maintenance is performed as outlined in service manuals and failed equipment is repaired or replaced as needed (Chimack et al. 2005). This practice can cause equipment failure and increase maintenance and energy costs.

Unlike reactive maintenance, scheduled maintenance or preventive maintenance detects equipment degradation, maintains equipment efficiency, and extends equipment service life. An effective scheduled 
maintenance program can reduce energy bills by an estimated 5-20\% in commercial buildings (Chimack et al. 2005). Scheduled service and maintenance also extends equipment life and therefore reduces capital (replacement) cost.

The disconnect between building maintenance cost and building energy use measurement makes scheduled maintenance appear labor-intensive and unnecessary. If maintenance costs are not considered, building owners and operators may not fully recognize the life-cycle cost of an energy efficiency technology. The key questions are how to associate EEMs with the resulting changes in maintenance cost and how to track the portion of maintenance cost that is associated with energy. This information can help building operators understand the cause and effect of their O\&M practices and improve accordingly. The answers to these questions are complicated by the fact that building equipment is often interrelated and should be operated and maintained as a system of components. The proposed toolkit could use energy simulation to help building owners and operators gain insight into the interaction between building systems and the positive influence of good O\&M. In addition, the toolkit should provide a standard method to document and track energy-related maintenance cost. 


\subsection{Existing Tools and Programs to Determine Building Energy Performance}

This section examines 14 existing tools, standards, and rating systems that assist building energy efficiency design, benchmark, tracking, and/or diagnosis. The purpose of this review is to identify the existing components that can be directly used in the proposed toolkit and suggest components that should be developed for the proposed toolkit. Table 4.1 shows a summary of 14 programs being reviewed. The user groups, market adoption, and limitations of these programs are discussed in the following sections.

Table 4.1. Summary of programs being reviewed.

\begin{tabular}{|c|c|c|c|c|c|}
\hline Program Name & Focus Area & Tool & Tool Inputs & Main Functions & Developed By \\
\hline $\begin{array}{l}\text { Energy Asset } \\
\text { Score }\end{array}$ & $\begin{array}{l}\text { Building } \\
\text { infrastructure } \\
\text { (as-built) }\end{array}$ & $\begin{array}{l}\text { A web-based } \\
\text { tool running } \\
\text { whole building } \\
\text { simulation }\end{array}$ & $\begin{array}{l}\text { Building envelope } \\
\text { and system } \\
\text { characteristics }\end{array}$ & $\begin{array}{l}\text { Evaluate building as- } \\
\text { built efficiency (overall, } \\
\text { envelope, and systems) } \\
\text { and upgrade potentials } \\
\text { Identify building } \\
\text { upgrade opportunities } \\
\text { based on life-cycle cost } \\
\text { analysis }\end{array}$ & DOE \\
\hline $\begin{array}{l}\text { ENERGY STAR } \\
\text { Portfolio } \\
\text { Manager }\end{array}$ & $\begin{array}{l}\text { Total energy } \\
\text { use and } \\
\text { emissions }\end{array}$ & $\begin{array}{l}\text { A web-based } \\
\text { tool using } \\
\text { regression } \\
\text { analysis }\end{array}$ & $\begin{array}{l}\text { Building utility } \\
\text { data, limited } \\
\text { operating } \\
\text { conditions }\end{array}$ & $\begin{array}{l}\text { Compare building } \\
\text { energy use to peers } \\
\text { Evaluate water use and } \\
\text { greenhouse gas } \\
\text { emissions }\end{array}$ & EPA/DOE \\
\hline COMcheck & $\begin{array}{l}\text { Building } \\
\text { infrastructure } \\
\text { (as-designed) }\end{array}$ & $\begin{array}{l}\text { A desktop or } \\
\text { web-based tool } \\
\text { performing code } \\
\text { compliance } \\
\text { calculations }\end{array}$ & $\begin{array}{l}\text { Building envelope } \\
\text { and system } \\
\text { characteristics }\end{array}$ & $\begin{array}{l}\text { Calculate percentage of } \\
\text { code compliance }\end{array}$ & DOE \\
\hline EnergyIQ & $\begin{array}{l}\text { Building } \\
\text { infrastructure } \\
\text { and energy use }\end{array}$ & $\begin{array}{l}\text { A web-based } \\
\text { tool using } \\
\text { regression } \\
\text { analysis and } \\
\text { performance } \\
\text { mapping (pre- } \\
\text { simulated } \\
\text { database) }\end{array}$ & $\begin{array}{l}\text { Building system } \\
\text { envelope and types }\end{array}$ & $\begin{array}{l}\text { Compare building } \\
\text { energy use to peers (in } \\
\text { California) } \\
\text { Provide upgrade analysis } \\
\text { (under development) }\end{array}$ & $\begin{array}{l}\text { California Energy } \\
\text { Commission }\end{array}$ \\
\hline $\begin{array}{l}\text { B3 } \\
\text { Benchmarking }\end{array}$ & $\begin{array}{l}\text { Building } \\
\text { infrastructure } \\
\text { and energy use }\end{array}$ & $\begin{array}{l}\text { A web-based } \\
\text { tool running } \\
\text { whole building } \\
\text { simulation }\end{array}$ & $\begin{array}{l}\text { Building envelope } \\
\text { and system } \\
\text { characteristics, } \\
\text { operating } \\
\text { conditions, utility } \\
\text { data }\end{array}$ & $\begin{array}{l}\text { Compare building } \\
\text { energy use to peers } \\
\text { (nationwide and in } \\
\text { Minnesota), expected } \\
\text { energy use, and } \\
\text { historical data }\end{array}$ & $\begin{array}{l}\text { Minnesota Department of } \\
\text { Administration }\end{array}$ \\
\hline EnCompass & $\begin{array}{l}\text { Building } \\
\text { infrastructure }\end{array}$ & $\begin{array}{l}\text { A web-based } \\
\text { tool using } \\
\text { performance } \\
\text { mapping (pre- } \\
\text { simulated } \\
\text { database) }\end{array}$ & $\begin{array}{l}\text { Building envelope } \\
\text { and system } \\
\text { characteristics, } \\
\text { operating } \\
\text { conditions }\end{array}$ & 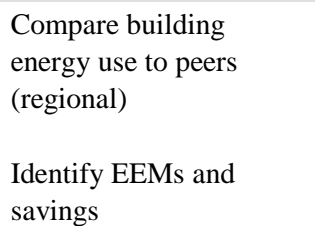 & Energy Impact Illinois ${ }^{\mathrm{a}}$ \\
\hline
\end{tabular}




\begin{tabular}{|c|c|c|c|c|c|}
\hline Program Name & Focus Area & Tool & Tool Inputs & Main Functions & Developed By \\
\hline $\begin{array}{l}\text { Energy } \\
\text { Performance } \\
\text { Standard } \\
\text { Calculation } \\
\text { Toolkit }\end{array}$ & $\begin{array}{l}\text { Building } \\
\text { infrastructure }\end{array}$ & $\begin{array}{l}\text { A web-based } \\
\text { tool running } \\
\text { whole building } \\
\text { simulation }\end{array}$ & $\begin{array}{l}\text { Building envelope } \\
\text { and system } \\
\text { characteristics }\end{array}$ & $\begin{array}{l}\text { Calculate building } \\
\text { energy use and } \\
\text { greenhouse gas } \\
\text { emissions }\end{array}$ & $\begin{array}{l}\text { Georgia Institute of } \\
\text { Technology }\end{array}$ \\
\hline FirstFuel & $\begin{array}{l}\text { Lighting and } \\
\text { mechanical } \\
\text { systems and } \\
\text { building } \\
\text { energy use }\end{array}$ & $\begin{array}{l}\text { A paid online } \\
\text { tool analyzing } \\
\text { meter data }\end{array}$ & $\begin{array}{l}\text { Hourly meter data } \\
\text { and weather data }\end{array}$ & $\begin{array}{l}\begin{array}{l}\text { Benchmark building } \\
\text { end-use energy } \\
\text { performance }\end{array} \\
\text { Provide operational and } \\
\text { retrofit recommendations } \\
\text { Monitor and verify } \\
\text { savings from actions } \\
\text { over time }\end{array}$ & FirstFuel Software, Inc. \\
\hline FirstView & $\begin{array}{l}\text { Building } \\
\text { overall } \\
\text { performance }\end{array}$ & $\begin{array}{l}\text { An automated } \\
\text { protocol } \\
\text { generating } \\
\text { building energy- } \\
\text { use patterns }\end{array}$ & $\begin{array}{l}\text { Monthly utility } \\
\text { data }\end{array}$ & $\begin{array}{l}\text { Interpret energy-use } \\
\text { patterns }\end{array}$ & New Buildings Institute \\
\hline ASTM E2792-11 & Data collection & N/A & N/A & $\begin{array}{l}\text { Develop a methodology } \\
\text { for collection and } \\
\text { analysis of energy audit } \\
\text { data }\end{array}$ & ASTM \\
\hline $\begin{array}{l}\text { International } \\
\text { Organization for } \\
\text { Standardization } \\
\text { (ISO) } \\
\text { 50001:2011 }\end{array}$ & $\begin{array}{l}\text { Energy } \\
\text { management }\end{array}$ & $\begin{array}{l}\text { An eGuide was } \\
\text { developed by } \\
\text { DOE }\end{array}$ & N/A & $\begin{array}{l}\text { Provide a framework } \\
\text { within which to plan, } \\
\text { manage, measure, and } \\
\text { continually improve } \\
\text { energy performance }\end{array}$ & ISO \\
\hline $\begin{array}{l}\text { COMNET } \\
\text { Commercial } \\
\text { Buildings } \\
\text { Energy } \\
\text { Modeling } \\
\text { Guidelines and } \\
\text { Procedures }\end{array}$ & $\begin{array}{l}\text { Energy } \\
\text { modeling }\end{array}$ & N/A & N/A & $\begin{array}{l}\text { Provide a standard } \\
\text { modeling approach for } \\
\text { building energy } \\
\text { modeling professionals }\end{array}$ & COMNET \\
\hline LEED & $\begin{array}{l}\text { Whole } \\
\text { building } \\
\text { sustainability }\end{array}$ & $\begin{array}{l}\text { COMNET Portal } \\
\text { performing } \\
\text { quality assurance } \\
\text { checks and } \\
\text { submitting the } \\
\text { energy model } \\
\text { results to LEED } \\
\text { Online }\end{array}$ & N/A & $\begin{array}{l}\text { Evaluate building } \\
\text { sustainability in five } \\
\text { areas (energy is one of } \\
\text { them) }\end{array}$ & $\begin{array}{l}\text { U.S. Green Building } \\
\text { Council }\end{array}$ \\
\hline $\begin{array}{l}\text { Building Energy } \\
\text { Quotient }\end{array}$ & $\begin{array}{l}\text { Building } \\
\text { infrastructure } \\
\text { and operation }\end{array}$ & N/A & N/A & $\begin{array}{l}\text { Evaluate building as- } \\
\text { built efficiency } \\
\text { Evaluate building in- } \\
\text { operation efficiency }\end{array}$ & ASHRAE \\
\hline
\end{tabular}




\subsection{National Public Tools}

\subsubsection{Energy Asset Score}

The DOE Building Technologies Program is developing a commercial building energy asset score system to enable building owners, managers, and operators to more accurately assess building energy performance. ${ }^{1}$ The energy asset score system will provide a standard way to evaluate the physical characteristics and as-built energy efficiency of buildings. As part of this system, the energy asset scoring tool will be offered as free online tool that provides

- a rating of the building's current energy efficiency (on a scale of 1 to 100 points) based on building envelope, mechanical and electrical systems, and other major energy-using equipment

- an evaluation of building systems that identifies areas for improvement

- a set of recommended, cost-effective improvements

- an "after upgrades" rating that demonstrates the potential energy impact of the recommended improvements.

The energy asset scoring tool is built on EnergyPlus simulation software. It requires minimum data from "simple-level" users to generate a preliminary report. A simple-level user can be anyone who has basic knowledge of the subject building and has access to the required building information. A complete and verified data set is required from qualified assessors to generate a verified energy asset score report about a building’s overall energy efficiency, infrastructure evaluations, and upgrade potentials.

An energy asset score model is generated based on standard assumptions of operating conditions by building use type, including plug loads, schedules, occupancy density, and temperature setpoints. Users can enter the actual operating conditions when calculating the upgrade potential. This functionality can be expanded to develop an operational rating system, which is focused on building in-operation.

\subsubsection{Market Adoption}

The energy asset scoring tool is being deployed in three phases based on building type. The tool is currently is in the pilot stage of Phase I, which includes office, retail, education, and non-refrigerated warehouse buildings.

\subsubsection{Tool Inputs and Outputs}

The energy asset scoring tool requires building information in five categories:

- general information and geometry (use type, number of floors, floor height, orientation, footprint dimension)

- building envelope (roof type, wall type, floor type, insulation thickness or R-values, window framing and glass types, window layout, window-to-wall ratio, shading dimension)

\footnotetext{
${ }^{1}$ Commercial Building Energy Asset Rating Program. http://www1.eere.energy.gov/buildings/commercial_ initiative/assetrating.html.
} 
- lighting systems (mounting type, lighting type, number of fixtures, lighting controls)

- mechanical systems (thermal zone layout and depth; cooling and heating equipment types, year of manufacture, capacity, and efficiency; fan efficiency and fan motor efficiency)

- hot water system (fuel type, distribution type, efficiency, tank insulation).

The energy asset scoring tool generates a report that includes building overall energy use (site and source) before and after upgrades, energy use by systems and system evaluation, and opportunities for EEMs. The energy model can also produce more detailed information, such as hourly energy use.

\subsubsection{Limitations and Future Development}

The current pilot project for the energy asset scoring tool will provide user feedback on the data collection, model accuracy, and relevance of recommendations. The results from the pilot will direct further tool testing and improvement. The tool testing in FY13 will be focused on key variables that cannot be accurately collected by the users (e.g., infiltration, plug and process loads, fan efficiency, insulation R-value) and establish quality control parameters. The key sources of uncertainty in results and their contribution to overall uncertainly will be identified.

Although the energy asset scoring tool is not intended to match measured energy usage data perfectly, the tool testing will compare the modeled results with the utility information to identify key sources of difference. Not only will this help calibrate the energy asset score model and thus improve tool reliability, but it is also is an essential step to building an operational rating tool.

The energy asset scoring tool has a powerful modeling backend that is linked to a simplified frontend. The toolkit can leverage this capability.

\subsubsection{ENERGY STAR Portfolio Manager}

ENERGY STAR Portfolio Manager ${ }^{2}$ is an online tool that allows property owners to enter building data and receive a rating based on EPA's national energy performance rating system for commercial buildings. EPA established the performance rating system "to provide an easy, cost-effective method to compare the efficiency of a building relative to the national building stock, provide a simple 1-100 metric to help communicate that relative performance, and establish a national performance target for excellence” (Von Neida and Hicks 2010, p. 2).

ESPM is a measured energy rating tool that allows building owners to compare actual energy use of their buildings to similar buildings in the same climate zone. The program produces a comparative rating relative to the mean score of similar buildings based on the most recent CBECS data. ESPM scores present the building in a historical context based on the CBECS data for the specific building type or other survey data where CBECS lacks sufficient data.

ESPM-certified buildings represent the top 25\% of buildings as compared to the relevant CBECS data pool (or other data pool used by ESPM) and reach a minimum score of 75 on a relative scale of 0 to 100 , where 100 is the best. CBECS, a survey of approximately 5,000 buildings nationally (about $0.1 \%$ of the

\footnotetext{
${ }^{2}$ Portfolio Manager Overview. www.energystar.gov/index.cfm?c=evaluate_performance.bus_portfoliomanager.
} 
number of total buildings), is typically done once every 4 years. The most recent data available are based on the survey conducted in 2003 (EIA 2006).

\subsubsection{Market Adoption}

ESPM has been widely adopted nationally, especially by owners of large buildings and portfolios. As of June 2011, ESPM had been used to assess the energy use of more than 230,000 buildings representing 24 billion $\mathrm{ft}^{2}$ of floor space. Of those, 14,520 buildings representing more than 2 billion $\mathrm{ft}^{2}$ were qualified for the ENERGY STAR certification, which equates to about $6 \%$ of the total number of buildings evaluated using ESPM and 12\% of total square footage (EPA 2011).

These numbers demonstrate that the majority of ESPM-certified buildings would be considered large properties $\left(>50,000 \mathrm{ft}^{2}\right)$. This is borne out by the institutional market's acceptance of ESPM and its widespread use of the rating system as a benchmarking tool. Many of these firms have incorporated ESPM into their business models and look to the rating as an indicator of value.

Increasingly, both government and corporate occupants are favoring (and in some cases requiring) ESPM-certified properties when they lease or acquire property (McCabe and Wang 2012). Further, ESPM is the basis for a number of state and municipal rating and disclosure programs as well as the energy efficiency points of the U.S. Green Building Council (USGBC) LEED certification system (for existing buildings). In addition to the mandated programs in place across the United States, more than 20 national voluntary incentive programs and competitions leverage ESPM tools. These programs generally use some comparison of the ESPM efficiency scores to rate and reward the "greenest" properties (EPA 2010).

\subsubsection{Tool Inputs and Outputs}

ESPM requires a fairly simple set of data based on a minimum of 50\% occupancy, 12 consecutive months of metered utility bills, and basic building and space use characteristics (e.g., building size and location, operating hours, and number of occupants) to compute performance metrics. ESPM normalizes for factors including climate, vacancy, and space use.

The ESPM tool generates a score for the candidate building and associated energy use (normalized site and source) and greenhouse gas emission. If the building achieves a score of 75 or better, the user can obtain a Statement of Energy Performance, which requires a licensed professional (a professional engineer and registered architect with a license in a discipline related to commercial building systems) to sign and stamp.

\subsubsection{Limitations and Future Development}

Although ESPM is the predominant rating system in the United States, stakeholders interviewed during the development of the energy asset scoring tool identified components of ESPM that limit usability, some of which are as follows:

- ESPM benchmarking rules require that all buildings, including those with mixed uses, benchmark as a single structure. Users can enter different space types; however, "more than $50 \%$ of the building's 
gross floor area (excluding parking lots and garages) must be defined by one space type eligible to receive an energy performance rating, such as Office or Hotel” (EPA (undated)).

- Ratings are on a relative scale (currently based on 2003 CBECS data), giving a building rating in comparison to only those buildings within the dataset. Due to the lack of homogeneity and sample size in the CBECS database, some property types_-for example, mixed-use buildings, restaurants, college campuses, libraries, museums, and laboratories — cannot use ESPM to generate a rating. State-level benchmarks (or anything geographically smaller) are also not available. (Other localized data sources, such as the California Commercial End-Use Survey (CEUS), are beginning to address this need.)

- Although all properties can use ESPM to track energy use, not all can achieve a rating. Ratings are based on 12 months of continuing operations and minimum occupancy, which precludes new buildings and those with low lease-up from participating. Whole-building utility data are not always readily or legally available for multitenant buildings.

- The rating scale at the top end is not granular enough to differentiate substantive efficiency improvements.

- Although owners can make reasoned guesses about the drivers of energy use, the tool does not provide a way to isolate the components of building form, systems, O\&M, and occupant behavior.

- There is no feedback loop between the energy design and construction function and "in-operation" performance of the building.

- ESPM does provide the means to prospectively analyze a building via a tool called ENERGY STAR Target Finder. Target Finder estimates the ESPM rating that a building might obtain upon completion and 12 months of operation, if the building manages to achieve the estimated EUI. However, stakeholders indicated that the tool was not robust enough, requiring additional work in Target Finder to make it useful from an energy asset analysis perspective.

The data collected by ESPM and the energy asset scoring tool are mutually exclusive, except for the basic information about building location and use. ESPM requires some operation characteristics, such as number of occupants and hours of operation. This information normalizes the measured energy use in a linear regression model, but is inadequate to develop a complete operational rating. For example, ESPM does not gather control information, such as temperature set points; it only considers limited plug loads like number of computers. On the other hand, from the user's perspective, maintaining building data in one central place and reducing possible data duplication is important.

Therefore, the proposed toolkit should first extract all information from ESPM to ensure seamless data exchange, then gather information that is missing in ESPM to develop a more complete operational rating system. The utility information collected by ESPM can calibrate the energy model used by both energy asset score and operational rating systems. The greenhouse gas emissions and utility costs information from ESPM should also be included in a comprehensive building evaluation report, which could be one of the outputs of the proposed toolkit. 


\subsubsection{COMcheck ${ }^{\mathrm{TM}}$}

COMcheck $^{3}$ was developed to facilitate the implementation of commercial building energy requirements. It is intended to simplify energy code compliance by offering an alternative to manual calculation. COMcheck applies to commercial and high-rise residential buildings (except single-family and multifamily under four stories in height). Target users include architects, designers and builders, engineers, manufacturers, distributors, building owners and lenders, code adopters, and code enforcement officials (Bartlett et al. 2012, p. 1.8).

COMcheck provides both desktop software and an online tool. The online tool offers a streamlined process for demonstrating compliance with code requirements for building envelope, lighting, and mechanical systems. Support codes include the International Energy Conservation Code (IECC) (2003, 2004, 2006, 2009, and 2012), ANSI/ASHRAE/IESNA Standard 90.1 (2001, 2004, 2007, and 2010), and various state-developed energy codes.

\subsubsection{Market Adoption}

Building designers in most states (except Washington, California, Minnesota, Florida, and Alaska) can use COMcheck to demonstrate code compliance. States that have not adopted COMcheck use forms or other computer programs to show code compliance. For example, many jurisdictions in Washington state require a set of forms created by the Northwest Energy Efficiency Council. ${ }^{4}$ California uses a list of approved computer programs for Title $24 .^{5}$ COMcheck is not available for the 2009 Minnesota energy code, but commercial building envelope and interior lighting compliance can be determined by COMcheck. ${ }^{6}$ Some states allow COMcheck use only by county or jurisdiction rather than statewide (Figure 4.1).

\footnotetext{
${ }^{3}$ COMcheck-Web. https://energycode.pnl.gov/COMcheckWeb/.

${ }^{4}$ Nonresidential Energy Code Compliance Forms. https://fortress.wa.gov/ga/apps/sbcc/Page.aspx?nid=57.

${ }^{5}$ List of 2008 Approved Computer Compliance Programs. http://www.energy.ca.gov/title24/2008standards/ 2008 computer_prog_list.html.

${ }^{6}$ Minnesota Energy Code Resource. http://mn.gov/commerce/energy/topics/efficiency/Energy-Code.jsp.
} 


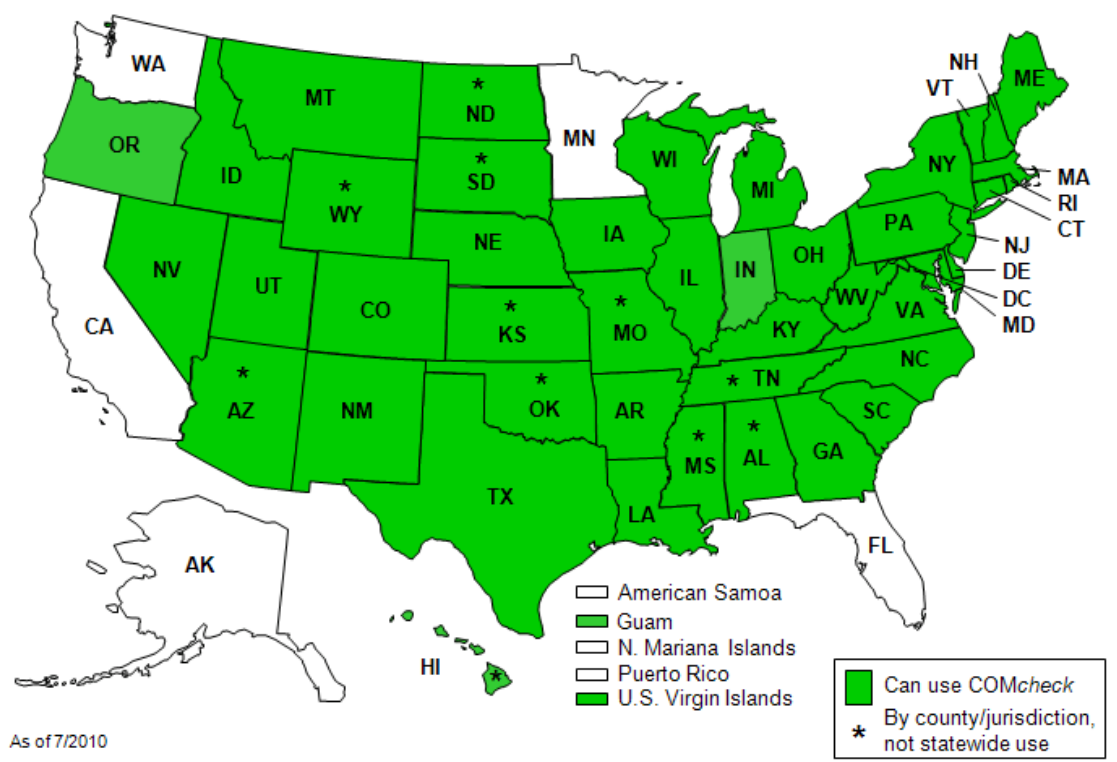

Figure 4.1. States that can use COMcheck to show compliance (Source: DOE 2012).

\subsubsection{Tool Inputs and Outputs}

COMcheck users must first define the project by selecting the local code, building location, and building use types (Figure 4.2). Then users can enter data for specific building systems-envelope (roof, skylight, exterior wall, window, door, basement, and floor), interior and exterior lighting, and mechanical (HVAC, heat pump, plan, and water heating).

The COMcheck tool shows applicable prescriptive requirements as users enter building specifications. The tool can also display the compliance results indicating pass, fail, and the percentage of compliance. After entering the complete building information, users can download a report that includes individual certificates of compliance for the envelope, interior lighting, exterior lighting, and mechanical systems, plus a description of mechanical system requirements. The report explains applicable requirements and contains checklists for building departments to use in plan review and field inspection. Users can fill in the required information and include the compliance certificates with their permit application. 


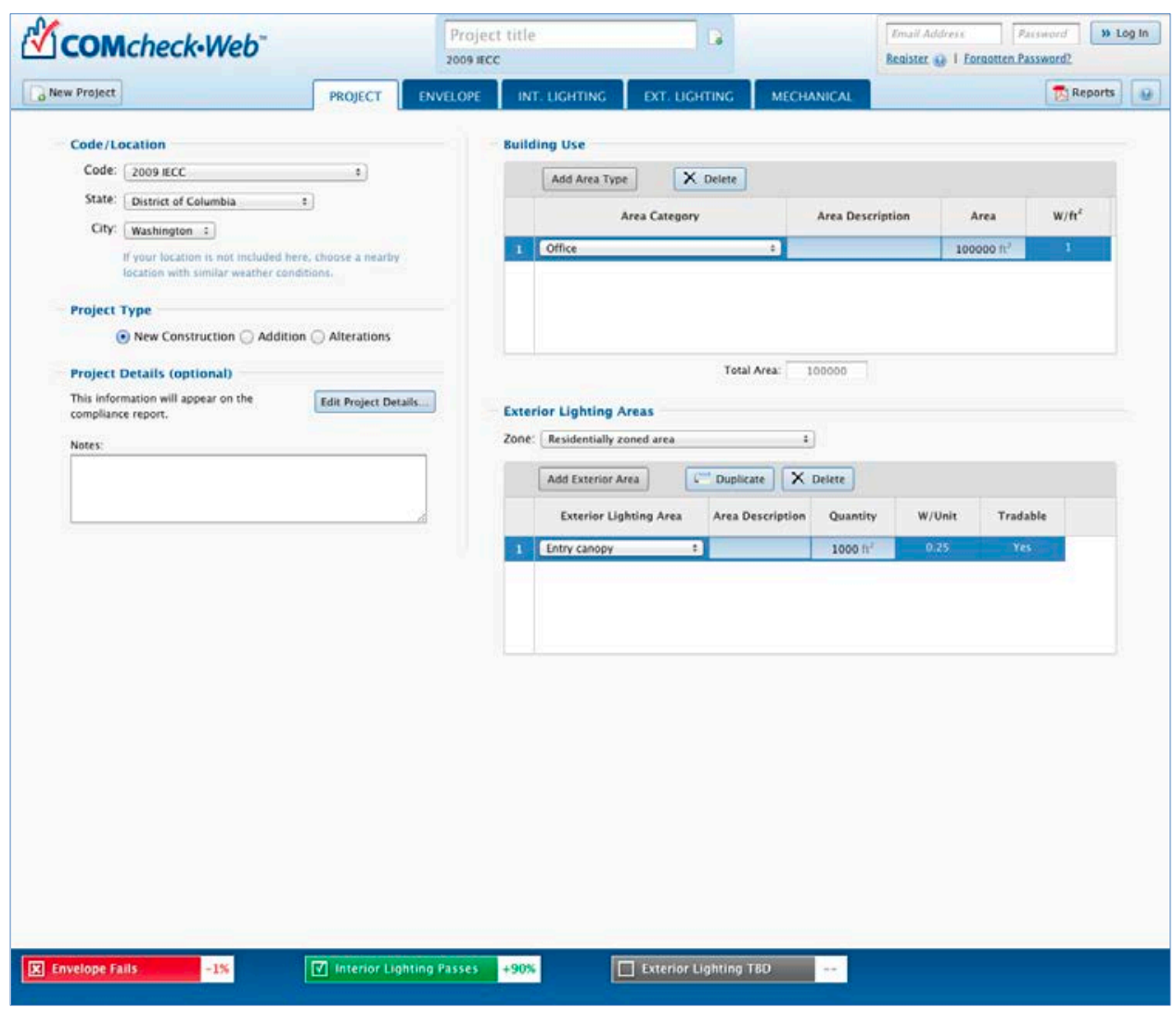

Figure 4.2. COMcheck-Web tool screenshot.

\subsubsection{Limitations and Future Development}

COMcheck is designed only for new construction, additions, and alterations. It is not applicable to existing buildings. COMcheck requires no specialized technical knowledge of commercial codes. However, users must provide very specific design information (e.g., cavity insulation R-value, continuous insulation R-value) to check code compliance. Although the tool can be used by a broad audience, the primary users are very likely to be designers who have access to the complete building drawings and specifications.

The current COMcheck tool is primarily based on prescriptive packages and allows envelope tradeoffs and limited mechanical systems tradeoffs (e.g., a trade-off of economizer requirements for more efficient equipment). The other paths to demonstrate code compliance (energy cost budget method in ANSI/ASHRAE/IESNA Standard 90.1 and total building performance in IECC) require energy simulation and are not included in COMcheck. Whole building simulation is being considered for future versions of COMcheck. This opens up an opportunity to use the energy model after the building is in operation.

Currently, building data entered into COMcheck are seldom used once building construction is complete. These building data, however, contain most of the information needed for an energy asset score. Extracting data from COMcheck to the energy asset scoring tool will potentially save building owners a significant amount of time that would otherwise be spent recollecting and reentering building data. With minimum update from the design stage to the construction stage, data transfer from 
COMcheck to the proposed toolkit would help provide a smooth transition from building design to building operation.

One technical challenge of linking COMcheck with the energy asset scoring tool is the use of COMcheck inputs, which contain detailed space-by-space information, to build an energy asset score model, which is designed to simplify building spaces to minimize the data collection requirements for existing buildings. If a COMcheck model with more building information is directly used for the energy asset score, the additional information for one building may lead to unfair comparison with a building with limited information. If a COMcheck model is simplified into an energy asset score model, the discrepancy between the two simulation results is unavoidable. Both need further investigation.

\subsection{State-Level Tools}

In the United States, two states (California and Washington) and six major cities (New York, San Francisco, Austin, Seattle, Philadelphia, and Washington, D.C.) have passed legislation to require privately owned commercial buildings to benchmark and disclose their energy use. Another 10 states and the city of Portland, Oregon, are considering commercial building ratings along with some form of disclosure legislation.

All of these local programs have accepted the ENERGY STAR rating system as a benchmark tool. However, implementation is complicated by privacy and capacity issues. For example, since 2009, utility companies in California have been obligated to maintain energy consumption records in a way that is compatible with ESPM. The larger utility companies have been working with the California Energy Commission to ensure they can upload utility data into ESPM. Concerns remain over privacy issues related to occupant (as opposed to owner) energy use information. Building owners have been tasked with obtaining written permission from separately metered occupants. Many smaller utilities across the state do not have the capacity to upload energy consumption data. California will rely on the private market to provide quality assurance for data inputs at the point of disclosure (McCabe and Wang 2012).

Some states and utilities have developed their own tools to help buildings achieve performance goals, although the disclosure requirements are focused more on transparency and do not set performance targets. Some tools can run comprehensive energy evaluations for individual buildings. Examples include EnergyIQ in California, B3 Benchmarking in Minnesota, and EnCompass in Illinois. Other tools focus on providing guidance on best practice. For example, FLEX, developed by Colorado Governor's Energy Office, is made up of an energy handbook ${ }^{7}$ and an eWorkbook ${ }^{8}$ (an electronic worksheet to share among the design team members). The Massachusetts Department of Energy and Resources published a white paper on the development of a commercial building energy asset rating and labeling program. ${ }^{9} \mathrm{~A}$ pilot project is underway to further investigate the program design and tool development options.

Three comprehensive state-level tools are discussed in the following sections.

\footnotetext{
${ }^{7}$ Flex Energy for Buildings. Change is coming to our energy infrastructure. Will your building be ready? http://www.danbihn.com/downloads/products/flex-docs/FlexEnergyIntroduction-Logo.pdf.

${ }^{8}$ Flex Energy for Buildings. Flex Energy Workbook. http://www.danbihn.com/downloads/products/flexdocs/FlexEnergy-FORM-Logo.pdf.

${ }^{9}$ Energy Labeling for Commercial Buildings. http://www.mass.gov/eea/energy-utilities-clean-tech/energyefficiency/ee-for-business-institutions/energy-labeling-for-commercial-buildings.html.
} 


\subsubsection{EnergylQ}

Built on the Cal-Arch online commercial building energy benchmarking tool, ${ }^{10}$ EnergyIQ ${ }^{11}$ is an action-oriented benchmarking tool for nonresidential buildings. The tool has three major functions: benchmarking, tracking, and upgrade analysis (Figure 4.3). The tool is intended to provide more specific benchmarking functions than a general peer comparison by allowing users to specify the characteristics of the benchmark group. It is also intended to provide standardized opportunity assessments. EnergyIQ users can import building data directly from ESPM.

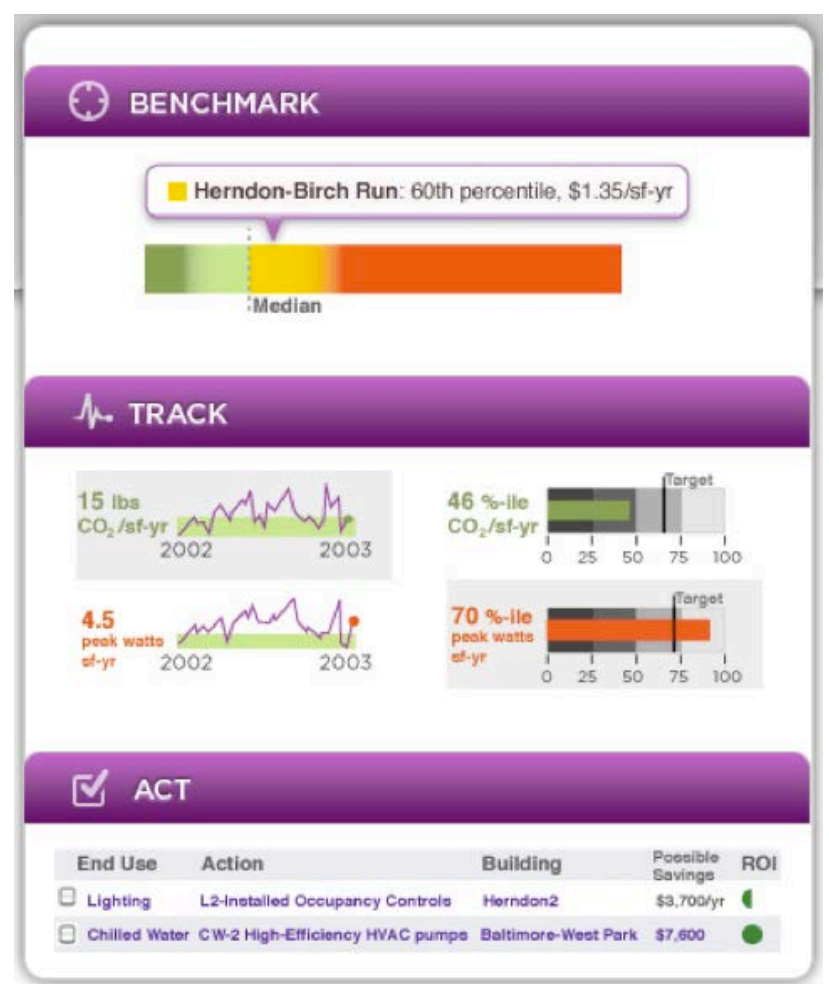

Figure 4.3. EnergyIQ’s three functions (Source: energyiq.lbl.gov/).

The EnergyIQ tool is based on the California CEUS, which provides details on energy use and characteristics for about 2,800 buildings and 62 building types, and the CBECS, which provides national data allowing benchmarking across the country. Users can benchmark in either of these two databases.

Compared to ESPM's whole-building benchmark based on source energy use, EnergyIQ provides a wide array of metrics, such as electricity use, peak demand, and system-specific end use (Figure 4.4). Users can also compare a specific building feature against a selected peer group. CBECS has 14 features available, and CEUS has 92 features available. When the building features are benchmarked, the more specifically a peer group is defined (by age, size, location, and use type), the smaller the available sample is. The result becomes less robust, and sometimes no result can be generated due to lack of similar buildings in the database. This limitation is common to the survey-based benchmarking tools.

\footnotetext{
${ }^{10}$ Cal-Arch: California Building Energy Reference Tool. http://poet.lbl.gov/cal-arch/index.html.

${ }^{11}$ EnergyIQ: Action Oriented Energy Benchmarking. http://energyiq.lbl.gov/.
} 


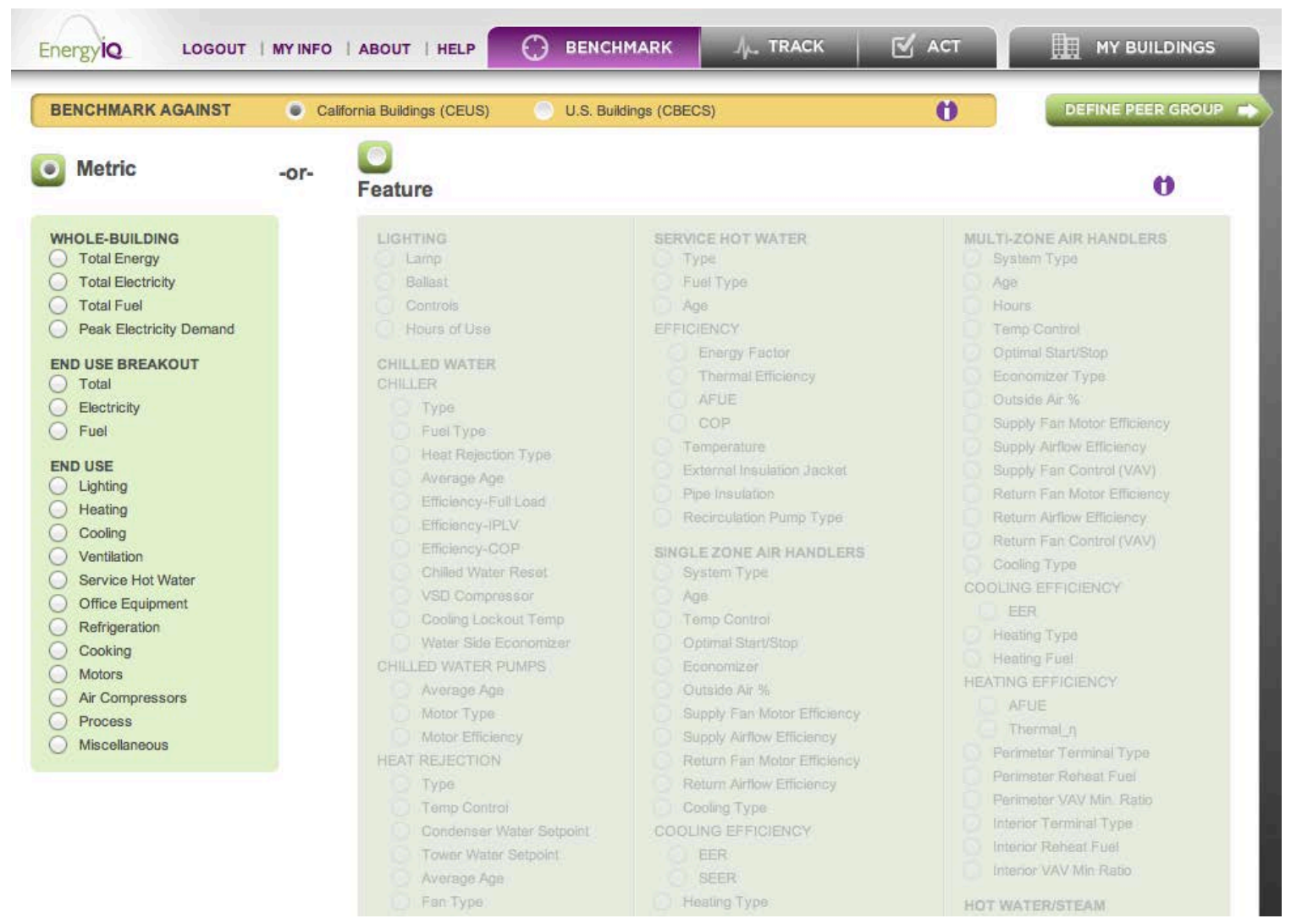

Figure 4.4. EnergyIQ benchmark metrics (Source: energyiq.lbl.gov/).

The EnergyIQ tool features upgrade analysis, which is still under development. Based on user inputs, the EnergyIQ tool will examine the impact of implementing a select group of 50 distinct EEMs and generate a list of opportunities and recommended actions. The recommendations and associated savings will be based on pre-simulated data. More than 65,000 measure-building combinations will be presimulated using eQuest. The EnergyIQ tool will use the subset of CEUS buildings that matches the user's peer group and present the savings for those peer buildings. Pre-simulation can provide fast results; however, the robustness of the results is limited by the building characteristics of the sample buildings in the database. Due to the complexity of commercial buildings, limited combinations cannot represent all building scenarios. Expanding or updating the database may introduce tremendous numbers of simulation runs or geometrically increase the size of the database. It is even more difficult to take this approach to develop a similar tool at the national level because of the numerous weather locations across the country.

\subsubsection{B3 Benchmarking}

In Minnesota, the Buildings, Benchmarks and Beyond (B3) Project incorporated sustainable building guidelines for the state. The B3 Benchmarking program started in 2004 as a coordinated effort to achieve advanced energy performance in Minnesota public buildings and to guide the allocation of energy conservation investments in existing buildings. 
The B3 Benchmarking tool ${ }^{12}$ is a building energy management system for public buildings in Minnesota, including state, local government, and public school buildings. The Benchmarking tool uses monthly utility billing information and some basic facility data (size, space types, occupancy, and climate) to provide comparisons in four areas (Figure 4.5):

- benchmark - consuming more or less energy than expected

- peer rating - consuming more or less energy than similar buildings in the B3 system

- ENERGY STAR rating - consuming more or less energy than similar buildings nationwide

- baseline - consuming more or less energy than in a previous 12-month period.

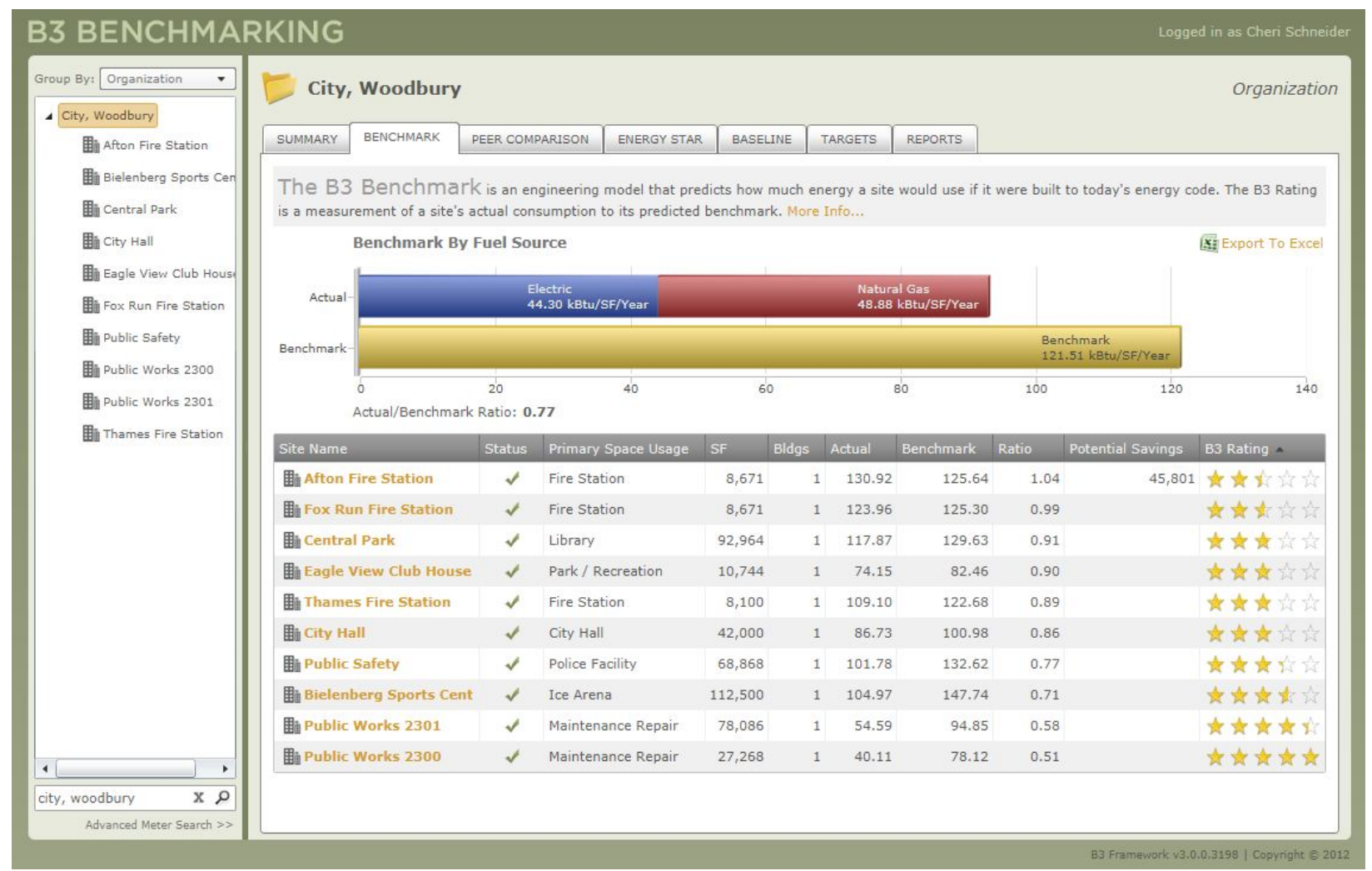

Figure 4.5. B3 Benchmarking program screenshot (Source: Admin Minnesota 2012a).

The benchmarking compares the actual consumption of each candidate building to the consumption predicted by an energy model. It uses a real-time energy simulation (DOE-2) to calculate the energy consumption of the candidate building as if it were built to the current energy code. The benchmark ratio is the actual metered consumption divided by the predicted consumption from the model. A higher ratio indicates higher return on investment of funds spent on energy performance improvements. The benchmarked results are used to rank a building portfolio and identify the buildings that have the greatest opportunity for improvement.

The Benchmarking tool also allows building owners (public sector only) to gauge their ENERGY STAR rating if the building type meets ENERGY STAR parameters to receive a rating. As of July 9,

\footnotetext{
12 State of Minnesota B3 Benchmarking Tool. https://mn.b3benchmarking.com/Overview.aspx?r=1.
} 
2012, 6,486 public buildings totaling more than 284 million $\mathrm{ft}^{2}$ have been benchmarked using the B3 Benchmarking tool (Admin Minnesota 2012b).

\subsubsection{EnCompass}

The EnCompass tool ${ }^{13}$ is designed to help owners and managers of commercial office buildings in the Chicago area evaluate their buildings' potential for energy efficiency. Application is limited to large office buildings, including high-rise buildings greater than $800,000 \mathrm{ft}^{2}$ in the downtown area and suburban office park buildings greater than $165,000 \mathrm{ft}^{2}$. The tool is intended to streamline the energy efficiency process by providing benchmark comparison and connecting building owners and managers with the next steps (assistance from financial and technical experts) to acting on the opportunities identified.

EnCompass does not require information on metered energy consumption from utility bills. It relies on energy models (EnergyPlus) to calculate the office building energy use in Chicago. The database stores results from more than 275,000 energy models. After users enter the building information, the tool selects a best-fit baseline energy model from the database and presents the pre-simulated results (total EUI with breakdown by fuel types). The pre-simulated building models are modified DOE reference buildings (medium and large offices). Building characteristics were defined using multiple resources, including CBECS 2003, ANSI/ASHRAE/IESNA Standard 90.1, and the Building Owners and Managers Association (BOMA) Experience Exchange Report (Energy Impact Illinois 2012).

The selected baseline energy model, which represents the candidate building, is compared against the industry average EUI in the Midwest region defined by CBECS 2003 and the data from ENERGY STAR Target Finder. The users receive their benchmark results and a set of recommended EEMs with associated energy and cost savings (Figure 4.6). To encourage users to take the next step in improving their building efficiency, the tool also provides information on local and federal incentives, utility programs, and service providers who can fund or implement the selected EEMs. Users can send their building information directly to the incentive programs and to a list of approved energy auditors.

EnCompass demonstrates a simple, low-cost approach to streamlining the building retrofit process by providing the most needed information to building owners and managers. However, its application is limited to large office buildings. Market research (McCabe and Wang 2012) reveals that the owners of medium-size or small buildings are the user groups who lack the information and resources to improve their building energy efficiencies. In addition, as discussed in the previous sections, a pre-simulation method based on survey data may limit the expansion and update of the tool in the future.

${ }^{13}$ EnCompass. http://encompass.energyimpactillinois.org/. 

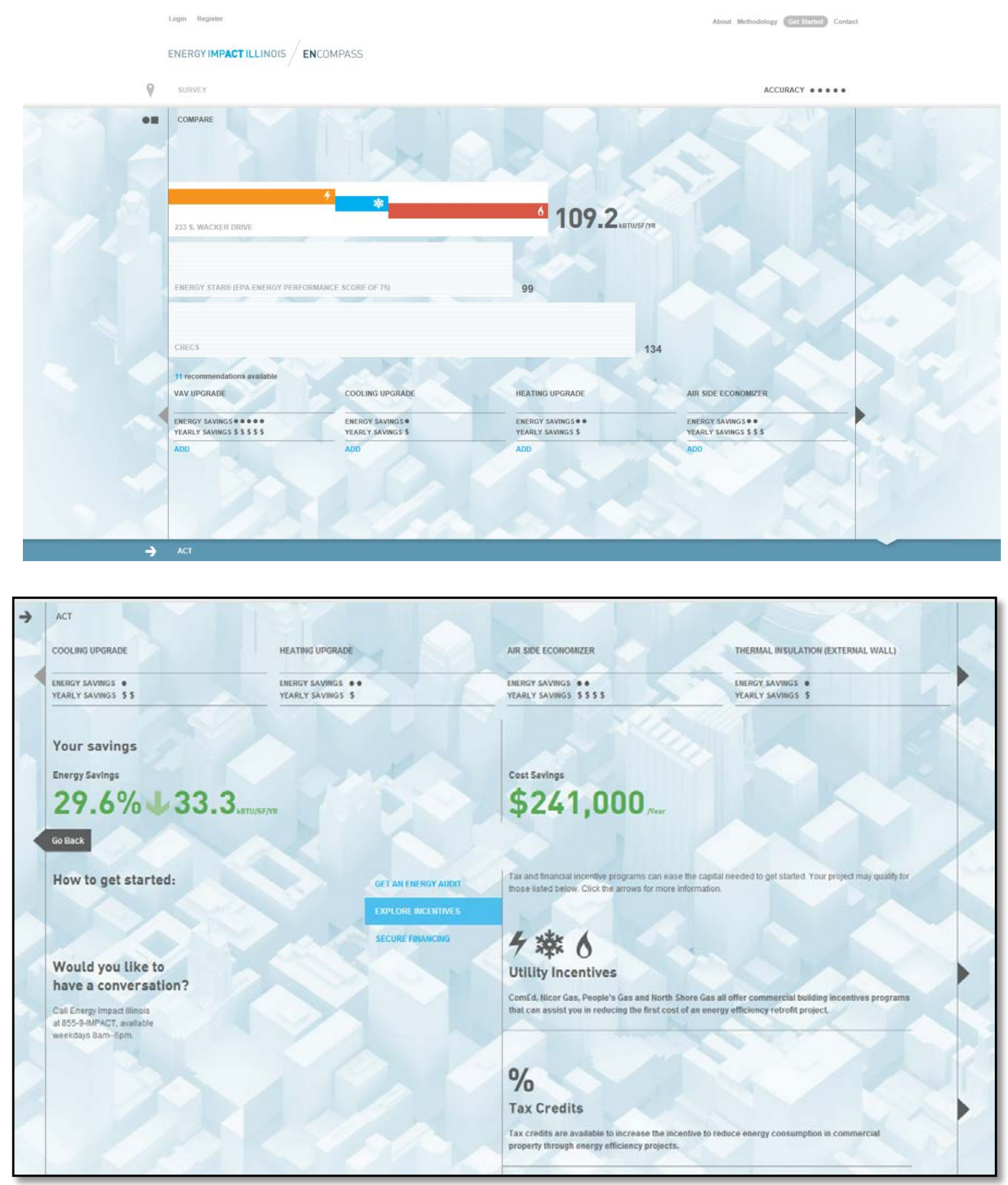

Figure 4.6. EnCompass output example.

\subsection{Other Tools}

A number of analysis tools have been developed by universities, building research institutes, and energy consulting firms. Compared to the government-sector tools, the private sector effort is focused more on analysis and diagnosis rather than on benchmarking. Examples of efforts in the private sector 
include FirstView, ${ }^{14}$ developed by the New Buildings Institute; EPSCT (the Energy Performance Standard Calculation Toolkit), ${ }^{15}$ developed at Georgia Institute of Technology; FirstFuel ${ }^{16}$ from FirstFuel Software, Inc.; and Building Energy Intelligence ${ }^{\mathrm{TM}},{ }^{17}$ developed by Retroficiency.

These tools provide users with deep analytics using more granular building energy use information obtained from energy model and submetered data. There is neither consistency nor standardization among these the modeling methods. For example, EPSCT uses a normative method standardized by ISO 13790:2008. FirstView relies on a regression solution stemmed from analysis of a set of 185 natural gasheated commercial office buildings selected from the ESPM database and other available measured building data, and Building Energy Intelligence uses dynamic energy simulation.

Many tools that are less technical in the private sector are not free for use. The free tools such as EPSCT are designed primarily for research purposes. Further, building owners still need assistance from a professional to collect and enter data into these tools or receive an analytical report from the tool development company, which may provide energy audit services at the same time.

The following sections provide more information on private sector tools. Because it is impossible to discuss all of the tools developed in the private sector in this report, EPSCT, FirstFuel, and FirstView were chosen to represent different approaches taken in developing the industry tools.

\subsubsection{EPSCT}

EPSCT is a real-time simulation tool that uses the normative method to assess building energy performance (Figure 4.7). It has been used to study the buildings on the campus of the Georgia Institute of Technology.

The normative method is widely applied in Europe to calculate building energy performance and defines the calculation recipe according to a set of normative statements about building function category, assumed usage scenario, system efficiency, and so on. The fully prescribed monthly quasi-steady-state method was adopted by the United Kingdom (UK) Department of Communities and Local Government and developed into a simplified asset-based calculation procedure, the Simplified Building Energy Model (SBEM). The SBEM is also used by Ireland to calculate energy use of simple, nonresidential buildings for the energy performance certificate (energy asset rating).

The monthly calculation method gives more accurate results on an annual basis, but large relative errors occur in the shoulder months - the months close to the beginning and the end of the heating and cooling season (ISO 13790:2008, Section 5.3). Supporters of the normative method have argued that the accuracy of the calculated energy use becomes less relevant for energy asset rating because a standardized expression of performance to generate an energy asset rating does not need to predict the actual energy consumption (Lee et al. 2011). In the case of the European energy asset rating system, energy asset rating is defined as the energy performance coefficient of the rated building and the comparator building. The normative method is adequate to guarantee the results of the ratings, but may not properly consider

\footnotetext{
${ }^{14}$ FirstView. http://firstviewtool.com/.

${ }^{15}$ EPSCT. http://epsct.org/?id=402.

${ }^{16}$ FirstFuel. http://www.firstfuel.com/.

${ }^{17}$ Building EfficiencyIntelligence. http://www.retroficiency.com/products/.
} 
special energy-saving technologies because normative calculations ignore the dynamics between the steady states. Therefore, some countries, such as Ireland, allow the use of approved dynamic simulation software. This dual approach complicates the rating system and decreases the standardization.

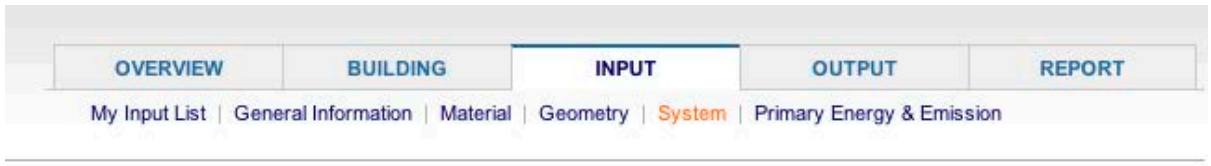

\section{(1) System}

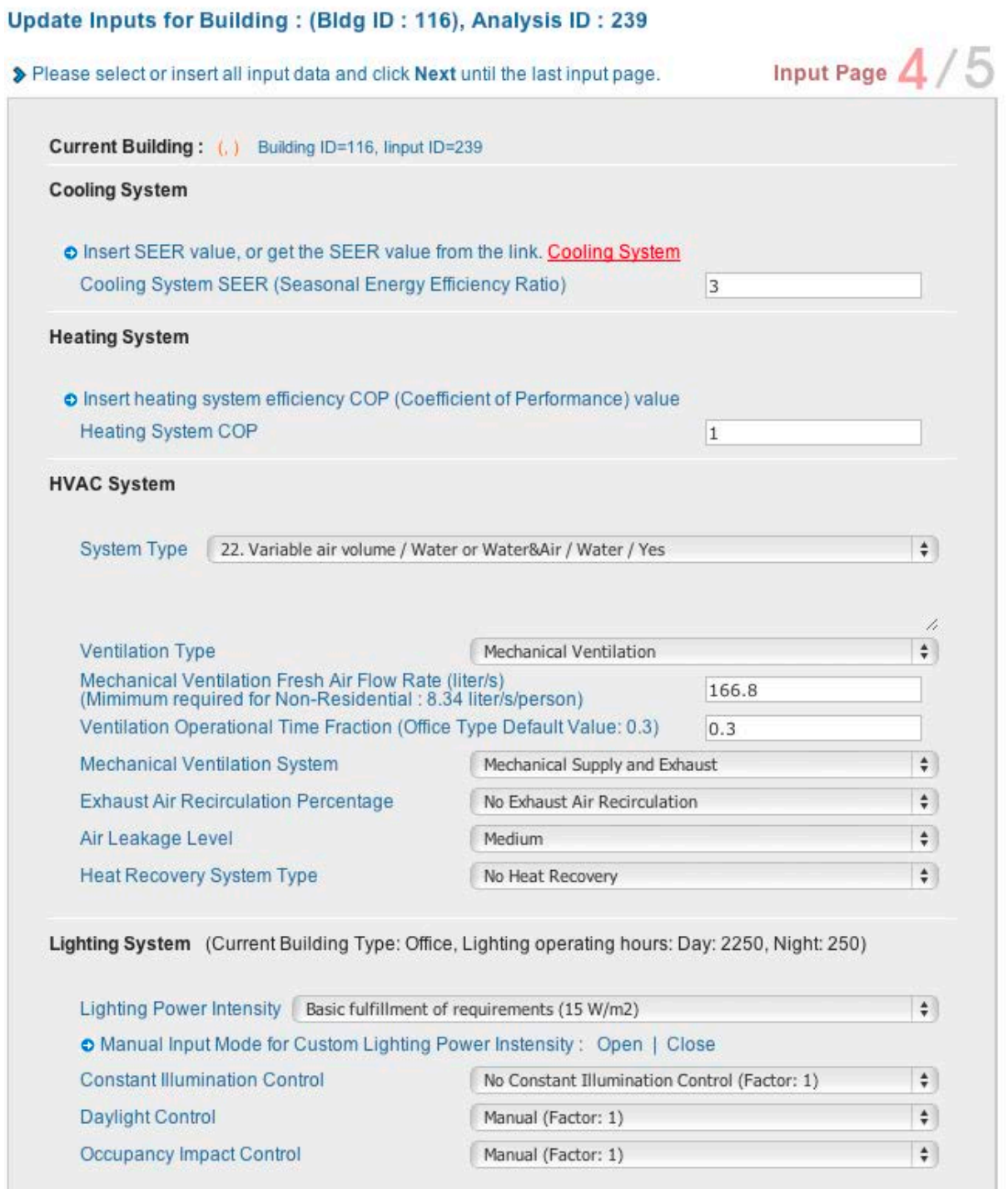

Figure 4.7. EPSCT screenshot (Source: http://www.epsct.org/). 


\subsubsection{FirstFuel}

Another method used by the private-sector tools is time series data analysis, which predicts a building's energy use pattern or structure by examining an ordered sequence of metered data. FirstFuel is an example (Figure 4.8).

FirstFuel combines 1 year of hourly electricity consumption data from the utility with hourly local weather data and geographic information system building data. The tool delivers a remote building assessment, which benchmarks building end-use energy performance, customizes operational and retrofit recommendations, and monitors and verifies savings from actions over time.

FirstFuel is an effective tracking and monitoring tool for building operation. However, building operators are generally not trained to analyze a large amount of building data. Expert assistance from the software company or the building professionals is often needed.

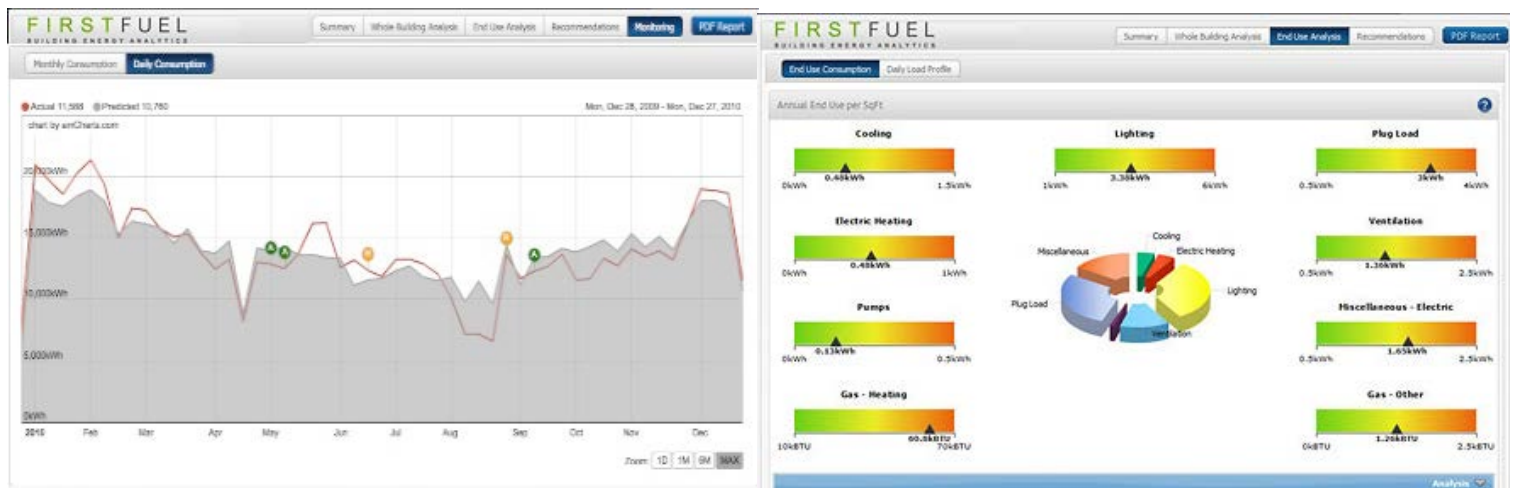

Figure 4.8. FirstFuel screenshot (Source: FirstFuel 2012).

\subsubsection{FirstView}

FirstView is an automated protocol for generating energy-use patterns and basic interpretive messages about building performance using monthly energy bill and location information. The regression solution stemmed from analysis of a set of 185 natural gas-heated commercial buildings selected from the ESPM database.

As its name indicates, FirstFuel is intended to provide a general description of current building performance and identify operational patterns that suggest areas of possible savings. The initial prototype development includes numerical and graphic summary outputs, which are useful for building professionals and researchers (Figure 4.9). A later development stage will consider adapting this technical information to an understandable and useful format for building operators and other analysts. 


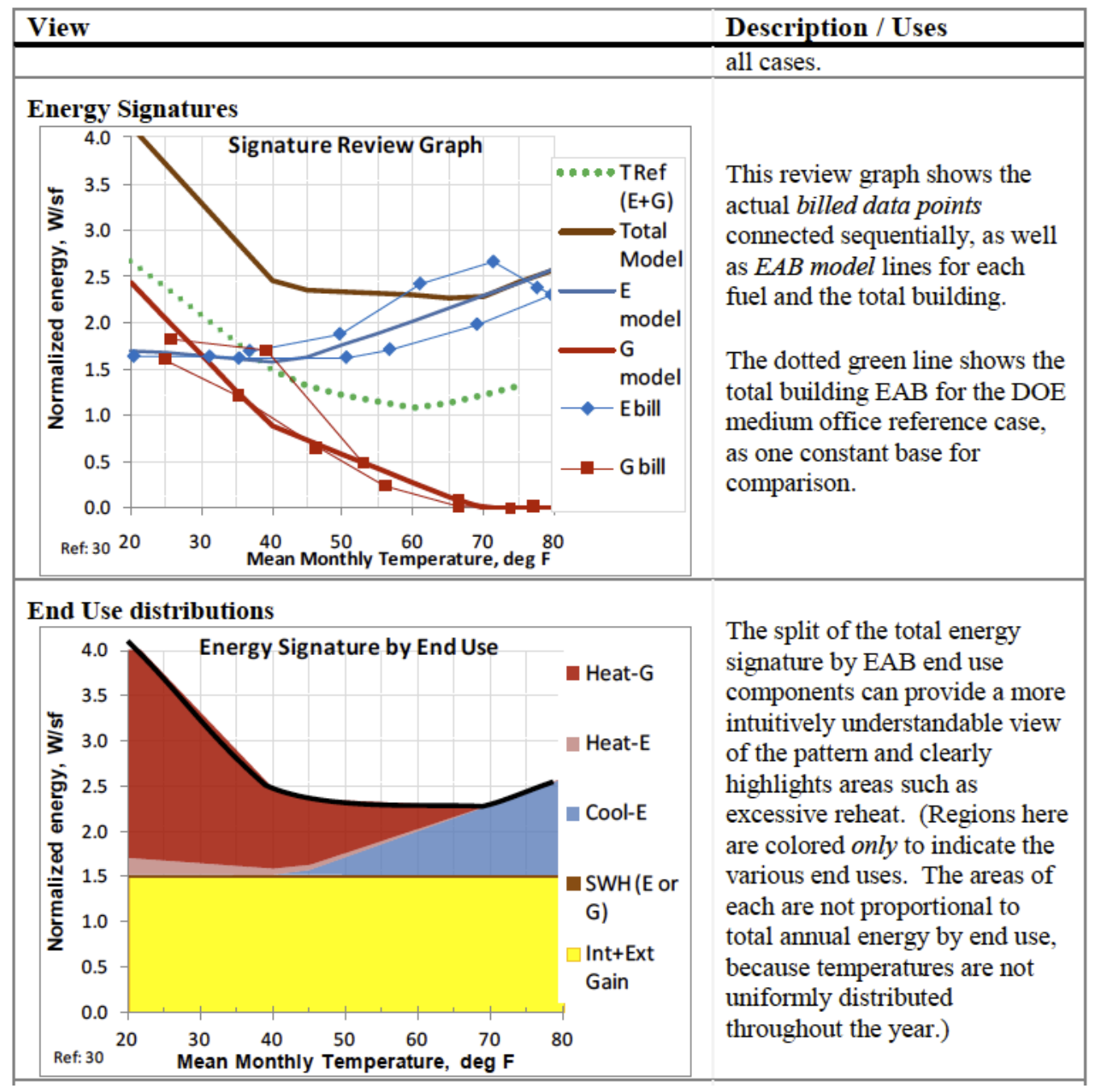

Figure 4.9. Sample site analysis (Source: Reichmuth and Turner 2011).

\subsection{Standards and Guidelines}

\subsubsection{Data Collection and Energy Management Standards}

Several industry standards have been developed for building energy audit and management. ASHRAE energy audit guidelines define three levels, and multiple components of energy audits and have been used by many private or public organizations to guide onsite data collection. ASTM E2797-11, published in February 2011, further developed a methodology for collection and analysis of energy audit data. The ASTM building energy performance assessment standardizes a number of major variables such as the time period over which building energy use data are to be collected, how to normalize partialmonth data, and how to analyze weather conditions, building operating hours, and building vacancy.

ISO 50001:2011 provides a framework within which to plan, manage, measure, and continually improve energy performance. It specifies requirements for establishing, implementing, maintaining, and improving energy management systems, including measurement, documentation, and reporting energy 
use consumption, design, and procurement practices for equipment, systems, processes, and personnel. DOE supports ISO 50001:2011 as a proven approach and has designed an eGuide to help organizations implement an energy management system. ${ }^{18}$ Through a step-by-step approach, this toolkit includes forms, checklists, templates, and examples.

\subsubsection{Energy Modeling Guidelines}

In the United States, existing guidance for certifying energy and power cost savings in energyefficient commercial buildings (Deru 2007) specifies that the energy modeling must be completed in accordance with the performance rating method in ANSI/ASHRAE/IESNA Standard 90.1-2004, Appendix G. The COMNET Commercial Buildings Energy Modeling Guidelines and Procedures also provide a standard modeling approach for building energy modeling professionals (COMNET 2010). The ASHRAE Building Energy Quotient (bEQ) program is developing a modeling specification similar to Standard 90.1-2004, Appendix G, to guide individual professionals to create energy models for bEQ asset rating. All of these modeling guidelines aim to provide references for individual modelers developing consistent energy models.

The DOE energy asset scoring tool uses the standard operating inputs (schedules, occupancy density, and plug loads) defined in COMNET. The schedule and occupancy data are derived from the COMNET Commercial Buildings Energy Modeling Guidelines and Procedures, Appendix B, Modeling Data, and Appendix C, Schedules (COMNET 2010). These modeling data are consistent with the Performance Rating Method in Appendix G of ANSI/ASHRAE/IESNA Standard 90.1-2007. COMNET also establishes baselines for receptacle (plug loads) power density and commercial refrigeration power density, which do not exist in Standard 90.1. The HVAC setpoints, which are not specified in COMNET or the ANSI/ASHRAE/IESNA standard, follow the inputs specified in the DOE commercial reference buildings models (NREL 2011).

No research has tested whether the standard assumptions truly reflect the average building operating conditions. The complexity and variety of commercial building operations make it difficult to obtain submetered energy use data of unregulated loads. An ongoing research project at the Center for the Built Environment (CBE) — Simulated and Actual Energy Use: The Role of Plug Loads—aims to identify the range of assumptions made by energy modelers and explore the accuracy of simulated plug load end-use components (CBE 2011). Such a project can fill the gap between simulated and actual energy use in buildings. To build a link between energy asset score and operational rating, a standard protocol to provide guidance on calculating unregulated loads is essential.

COMNET also developed TOU prices to predict energy cost savings more accurately. COMNET TOU prices estimate the present value of energy costs at different time periods (on-peak, mid-peak, offpeak, weekdays, weekends) in 15 climate zones by calculating the marginal electricity cost based on the sum of energy value components (including generation energy, losses, ancillary series, system capacity, transmission and distribution capacity, and environment). Considering there is no complete database of the local utility costs and that the cost structures vary significantly among service providers and change over time, COMNET TOU prices provide more accurate estimates of long-term energy cost savings than does the use of a national or state average. The TOU method is used in the energy asset scoring tool. OpenEI provides an open source utility database using crowdsourcing. It could become a good resource

\footnotetext{
${ }^{18}$ DOE Guide for ISO 50001. https://save-energy-now.org/EM/SPM/Pages/Home.aspx.
} 
of utility tariffs. However, the current database does not contain complete dataset (Figure 4.10) and the user-uploaded data needs an additional quality check.

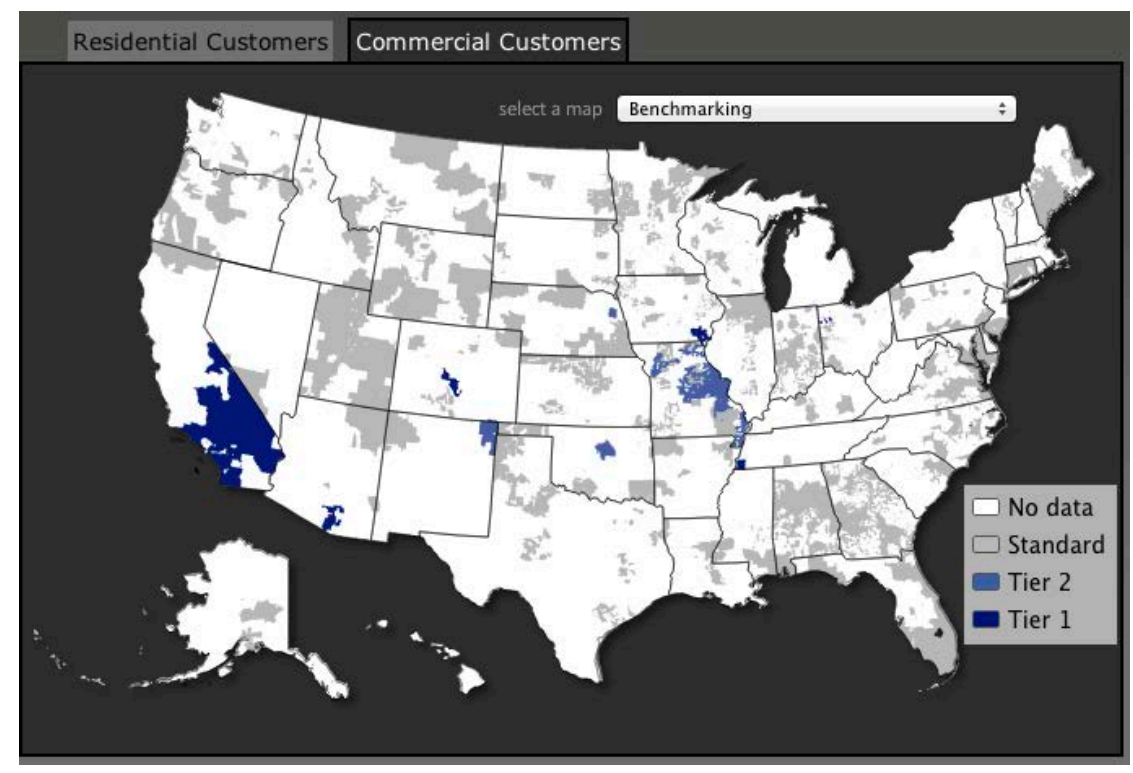

Figure 4.10. OpenEI utility data access map (Source: OpenEI 2012).

\subsection{Private-Sector Rating Systems}

\subsubsection{Leadership in Energy and Environmental Design}

Verification of new buildings under the USGBC LEED program is becoming increasingly common in the commercial building sector. LEED is a well-known green building certification system in the United States, particularly for Class A office space. Under the voluntary program, building design is rated on a points scale, evaluating various metrics such as energy usage, water efficiency, indoor air quality, and stewardship of resources.

The LEED rating is based on seven categories; the largest point allocation in the current version is accorded to energy. Under LEED 2009, 35 of the total 100 base points in the rating system relate directly to building energy efficiency. LEED Online ${ }^{19}$ is the primary resource for a project team to manage and submit their LEED documents. COMNET Portal ${ }^{20}$ was recently developed to collect energy modeling simulation results, perform quality checks, and submit the results to LEED Online.

Under the LEED rating system, a building must achieve minimum energy performance as determined by an approved energy modeling program (for new constructions or major renovations) or by meeting a minimum ESPM score of 69 (for existing buildings). LEED NC is used as an independent system from LEED EBOM. $^{21}$ There is no direct comparison between these two energy performance requirements.

\footnotetext{
${ }^{19}$ LEED Online. http://www.gbci.org/main-nav/building-certification/leed-online/about-leed-online.aspx.

${ }^{20}$ COMNET Energy Modeling Portal. http://www.comnet.org/mgp/portal/?purpose=0.

${ }^{21} \mathrm{NC}=$ New Construction; EBOM = Existing Buildings: Operations \& Maintenance.
} 
The former is based on modeled energy use compared to ANSI/ASHRAE/IESNA Standard 90.1-2007; the latter is based on measured energy use.

There have been concerns about the actual performance of LEED buildings. A LEED rating is not necessarily representative of the relative energy performance of a building. Studies have shown that buildings with the same LEED rating having widely varying projected energy use compared to actual energy use. These conclusions were supported in a report issued by the New Buildings Institute for the USGBC (Turner and Frankel 2008). USGBC has received criticisms such as "LEED certification has never depended on actual energy use, and it's not going to. You can use as much energy as you want and report it and keep your plaque” (Cater 2010).

LEED 2009 requires that “[a]ll certified projects must commit to sharing with USGBC and/or GBCI all available actual whole-project energy and water usage data for a period of at least 5 years” (USGBC 2011, p. 5). This measure brings the energy use measurement and verification to the agenda and takes a first step to link the as-designed performance with the in-operation results.

However, a tool to actually fulfill this task is still missing. The energy asset scoring tool could provide an acceptable alternative to the existing approved modeling method to achieve LEED NC energy goals. The proposed toolkit built on the energy asset scoring tool would help fill the gap between the NC and EBOM energy requirements for certification.

\subsubsection{Building Energy Quotient}

The ASHRAE $\mathrm{bEQ}^{22}$ is a building energy labeling program slated to include both an operational label and an asset label. The current rollout of the bEQ only includes the in-operation rating (Figure 4.11).

${ }^{22}$ Building Energy Quotient. http://buildingenergyquotient.org/. 

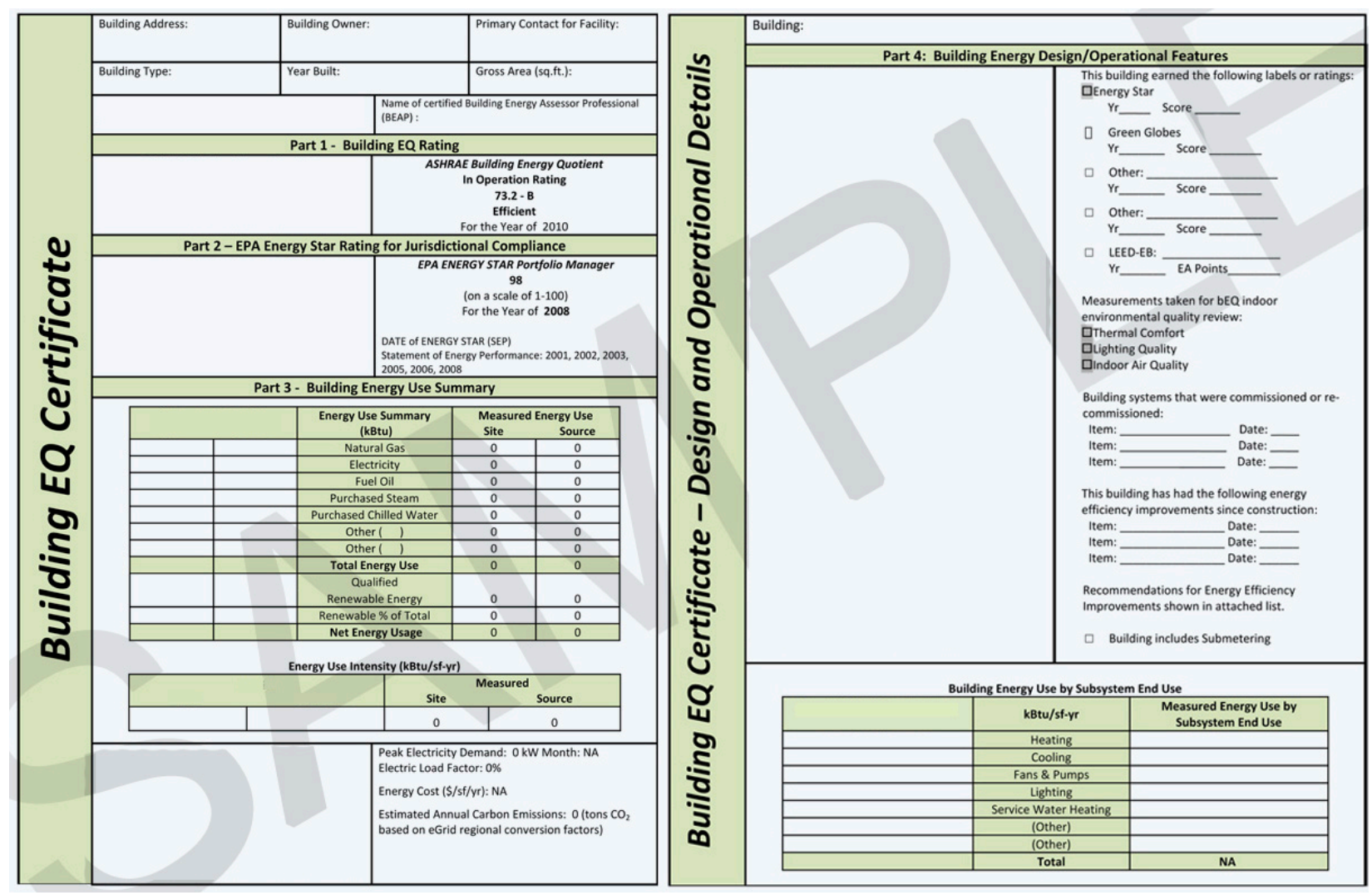

Figure 4.11. Building EQ Certificate (Source: http://buildingenergyquotient.org/images/sample-beqcertificate.jpg).

The in-operation rating provides information on measured energy use based on building type and operations. It compares measured data to a median (obtained from ESPM or the 2003 CBECS). Building owners receive rating materials through certified assessors. Assessors conduct an ASHRAE Level 1 energy audit onsite, complete the bEQ in Operation Workbook, and submit to ASHRAE for development of the label materials (Building EQ 2012a). The registration fee for bEQ is \$500, which does not include the cost of assessment. The assessment cost is determined by the selected ASHRAE-certified Building Energy Assessment Professional (Building EQ 2012b).

The energy asset (or as-designed) label (currently being piloted), will provide a modeled assessment of the building, taking into account design components such as mechanical systems, envelope, orientation, and daylighting. The rating will be based on the results of an energy model comparing the building to a baseline building compliant with a chosen energy code. The energy asset label is designed to provide granular information and is expected to be particularly useful for buildings at the top end of the energy efficiency spectrum-high-performance buildings striving toward net zero performance. Modeling results from a qualified energy modeler are required to obtain a bEQ asset rating. The challenge will be regulating energy modelers, who may interpret building data and simulation tool results differently, to generate consistent results, not mentioning the various capabilities of different modeling tools.

The bEQ is intended to link a building's energy asset rating with its operational rating. However, the current rating schemes have not provided an effective linkage yet because the baselines to generate the in- 
operation rating and energy asset rating are different. The former is the ratio of the measured energy use and the median energy use from the survey database; the latter is the ratio of the modeled energy use and a chosen code-compliant reference building. 


\subsection{Missing Components in the Existing Tools and Thoughts on Toolkit Development}

This section identifies the major gaps in the existing tools in four areas:

- missing linkage between calculated (modeled) and measured building energy use

- disconnect between energy metrics and cost information

- inconsistent use of input values

- lack of actionable strategies to help building owners take the next step after benchmarking.

This section also suggests a possible approach for developing a toolkit to fill in the identified gaps, based on the market and technical analyses discussed in the previous sections. The toolkit should be designed with simplicity in mind. The goal is to improve the maximum number of buildings by minimizing the amount of personnel time required to compile, submit, and track the necessary information.

Important features to be considered for the proposed toolkit include the following:

- provide a method to calibrate energy model data and link it to the DOE energy asset score and ESPM

- develop a standard metric to incorporate energy and maintenance cost information

- develop an effective feedback loop to assist long-term performance tracking from building design to building operation

- utilize and link to key existing tools.

\subsection{Missing Components}

\subsubsection{Link Between Modeled and Measured Energy Use}

Energy modeling is used primarily during the design stage or sometimes during a building retrofit to estimate savings. The modeled energy use is compared to a modeled baseline (defined by a chosen energy code for new construction and the existing building before retrofit) to predict energy or cost savings. It is commonly believed that energy modeling used for the design is less useful once the building is in operation.

Measured energy use has been widely used to benchmark and track building energy performance for existing buildings. Building energy use is compared to the national or local average, its peers, or itself to inform building owners of their building's rank. However, metered data alone has not yet been proven effective to diagnose problems and identify improvement opportunities because the measured energy use is affected by many infrastructural, operational, and behavioral factors. Building owners must seek professional help to gain insight into their building infrastructure and energy use at a more granular level.

The different methods used to evaluate new buildings and existing buildings fail to connect designed building performance to in-operation performance. This is a major problem faced by the many building 
rating systems, such as LEED and ASHRAE bEQ. Although it is challenging to link modeled and measured energy use data, these two sets of data should not be treated as apples and oranges. Both modeled and measured energy uses are extracted from and used for the same building; they should be integrated instead of separated. Both should also be maintained and updated with the changes in building performance over its life cycle. To generate meaningful results through linked modeled and measured data, it is essential to calibrate, maintain, and thoughtfully use the energy model. Autotune (currently under development) is intended to develop a methodology to automatically calibrate building energy models to reproduce measured data. ${ }^{1}$

\subsubsection{Standard Measurement of O\&M Costs in Energy Benchmarking}

Existing tools lack a standard way to estimate energy cost and maintenance cost. Complicated utility tariff structures make it difficult to predict energy cost. Existing tools use different reference values (e.g., local average, historical average, TDV) based on which total energy costs can be estimated. Building owners have been methodical about reducing costs and raising net income. Appraisers, however, need a reliable and consistent source that provides a building's energy cost information and a method to incorporate it into valuation.

Maintenance cost is part of life-cycle analysis; however, there has not been a standard way to estimate maintenance cost savings related to EEMs. The BOMA Experience Exchange Report and the IFMA O\&M benchmark report (BOMA 2009; IFMA 2009) are the main resources where building owners can find O\&M cost information, but this information has never been separately sorted and analyzed from an energy efficiency perspective. Various maintenance activities and costs are combined in a very general category. For example, interior maintenance includes electrical systems, mechanical systems, building and general maintenance, interior signage, and administrative support service. Among these, items like lighting systems, HVAC, chiller, and boiler are related to building energy systems, while interior walls, pest control, backflow prevention, extinguishing systems, and the like are less relevant to building energy efficiency. A mixed record of these cost data makes it difficult to present the entire benefits of energy efficiency to building owners. Without seeing the whole picture of building energy use and O\&M practice, building owners tend to neglect the influence of O\&M on energy efficiency and vice versa.

\subsubsection{Standard Definitions of Various Metrics for Different Applications}

The means by which energy use is calculated can significantly affect its accuracy and effectiveness for comparison. Energy use intensity is used throughout the building industry; however, its definition varies in different applications. In some cases, EUI could affect decisions in different ways. For example, should an enclosed parking garage area be included in the gross floor area? For two identical buildings in the same city, "if the EUI area definition includes parking garages, the building that promotes the use of automobiles over public transportation will show a lower EUI due to additional low energy building area in the parking garage” (Peterson and Crowther 2010, p. 42).

Although this may seem beyond the building energy domain, using practical and easy-to-understand metrics is essential to stimulating the market to improve building energy efficiency. Most standards and programs (including ANSI/ASHRAE/IESNA standards 105 and 90.1, ESPM, CBECS, and Section 433 of

\footnotetext{
${ }^{1}$ Autotune. http://autotune.roofcalc.com/main/?q=content/autotune.
} 
the Energy Independence and Security Act of 2007) use gross floor area as the denominator to calculate EUI. According to ASHRAE's definition, parking garages are excluded. In reality, not all buildings have submeters to separate energy use (lighting and ventilation) in the parking area from their main bills. Consequently, the reported energy use per gross floor area will be higher than the actual use intensity when the garage energy use is included in the building energy use but the garage area is excluded.

Other measurements include conditioned floor area and rentable floor area. Conditioned floor area is specified in the California Energy Code, Title 24, and ANSI/ASHRAE/IESNA Standard 100-2006. Rentable floor area is a popular way to measure building income and expense by BOMA and IFMA. For example, IFMA's benchmark report (IFMA 2009) measures cost of operations in dollars per rentable square foot, and BOMA's Experience Exchange Report (BOMA 2009) lists all rental incomes in dollars per rentable square foot. Energy cost accounts for a major portion of operational cost. It creates confusion when building owners benchmark their operations in dollars per rentable square foot but receive energy information in dollars per gross square footage.

Although EUI is used as the main metric to evaluate building energy performance, the existing tools have not paid enough attention to other metrics, such as energy use per student for school, energy use per guest room for a hotel, and so on. These metrics may not be as meaningful as EUI across all building types, but they can be better incorporated with management activities among a certain groups of owners or managers. This link can help raise decision makers' attention on building energy use.

In summary, consistent inputs and outputs are necessary. The consistency allows seamless data exchange between tools. Consistent definitions of inputs, outputs, and terminology across tools will increase market acceptance and usage. As an example, Energy Ireland paid specific attention to balancing issues, which include clarity and consistency, in their energy asset rating program (BPIE 2010). This has resulted in relatively high public acceptance and awareness.

\subsubsection{Actionable Strategies}

Existing tools provide sufficient benchmark information on building energy performance at a national or local level. The tools are built either directly on the national or local survey data or indirectly through ESPM. These tools can detect some problems in a building by comparing its energy use to a baseline building. However, the robustness of this level of diagnosis is limited by the sample size in the database. A deeper-level analysis and actionable strategies are necessary to help building owners take the next step to invest in energy audits or building upgrades.

Some local-level tools have started linking benchmark and action by offering opportunity assessment. Such tools include EnergyIQ in California and EnCompass in Illinois. One limitation is that these tools are designed only for their local building market. Both tools are built on a pre-simulated database using the existing survey data. This method limits their expansion to the wider national market, as well as their updates with building technology changes.

\subsection{Ideas for Toolkit Development}

This section suggests a possible approach to developing the operational rating system. As already discussed in this report, the linkage between building asset and operation is important. To bridge these 
two components, the energy model developed for the energy asset score system could be used. Although this proposed approach might not be the only way to create such a linkage, it fully leverages existing work, considers the tool consistency, and avoids redundancy from the user perspective. A tool architecture to implement the suggested approach is also discussed in this section.

\subsubsection{Linkage Between Building Asset and Operation}

The commercial building market widely accepts that considering both capital assets and operational effectiveness eventually will provide more useful information than considering just one or the other. A good energy asset score demonstrates an efficient building technology, but good technology does not ensure low energy use. A high ENERGY STAR score proves a building uses less energy than its peers, but offers no customized guidance as to the infrastructure and operation improvement potential of the individual buildings. To unleash the power of a combined rating system, a link between calculated and measured building energy use should first be established. Such a link could be developed through an operational metric based on an energy model using the actual operating conditions of a building.

A similar concept, the Calibrated O\&M Index, has been proposed by Goldstein and Eley (2011) to address the need to understand physical efficiency of buildings and the operational effectiveness. The Calibrated O\&M Index is the ratio of actual metered energy performance of the rated building to the modeled performance of the rated building using the operating conditions of the building as it is operated for the period for which the energy bills are collected. This approach would require a modeler to calibrate the model assumptions so that the calibrated model can be compared directly to the measured data. The ratio is likely to indicate how well the building is operated. This proposed rating index is aligned with the ratio scales that have been adopted by the ASHRAE bEQ. The three energy indices are summarized as follows:

$$
\begin{gathered}
\text { Asset Rating }=\frac{\text { Candidate Building's Modeled Energy Use under Standard Conditions }}{\text { Reference Building's Modeled Energy Use under Standard Conditions }} \\
\text { Calibrated O\&M Index }=\frac{\text { Candidate Building's Measured Energy Use under Actual Conditions }}{\text { Candidate Building's Modeled Energy Use under Actual Conditions }} \\
\text { Operational Rating }=\frac{\text { Candidate Building's Measured Energy Use }}{\text { Median Building's Energy from CBECS }}
\end{gathered}
$$

The Calibrated O\&M Index is intended to link energy asset score with operational rating. However, the different numerators and denominators used in the three equations do not communicate the meanings of the three indices to the users. Introducing the reference building and CBECS median building to the equations introduces more variables and uncertainty that complicate the relationships of the energy indices.

The DOE energy asset score does not require comparison with a baseline building; rather, a building is directly scored based on its modeled building energy use. A similar approach should be used to develop the operational metric. An operational score can be calculated using the following equation:

$$
\text { Operational Score }=\frac{\text { Modeled Energy Use under Standard Conditions }}{\text { Modeled Energy Use under Actual Conditions }} \times \text { Measured Energy Use }
$$


The ratio of modeled energy use under standard conditions and modeled energy use under actual conditions is used to normalize the measure energy use. The ratio also reduces the model uncertainty because both models are generated using the same simulation software and same model settings except for operating conditions. Table 5.1 shows an example of four buildings that have the same energy asset score but different operating conditions. Figure 5.1 illustrates how the proposed operational rating could be integrated with the energy asset score. The comparison of the two score systems could help building owners gain insight into their building systems and operation and focus on the areas that need improvement the most.

\section{Scores}
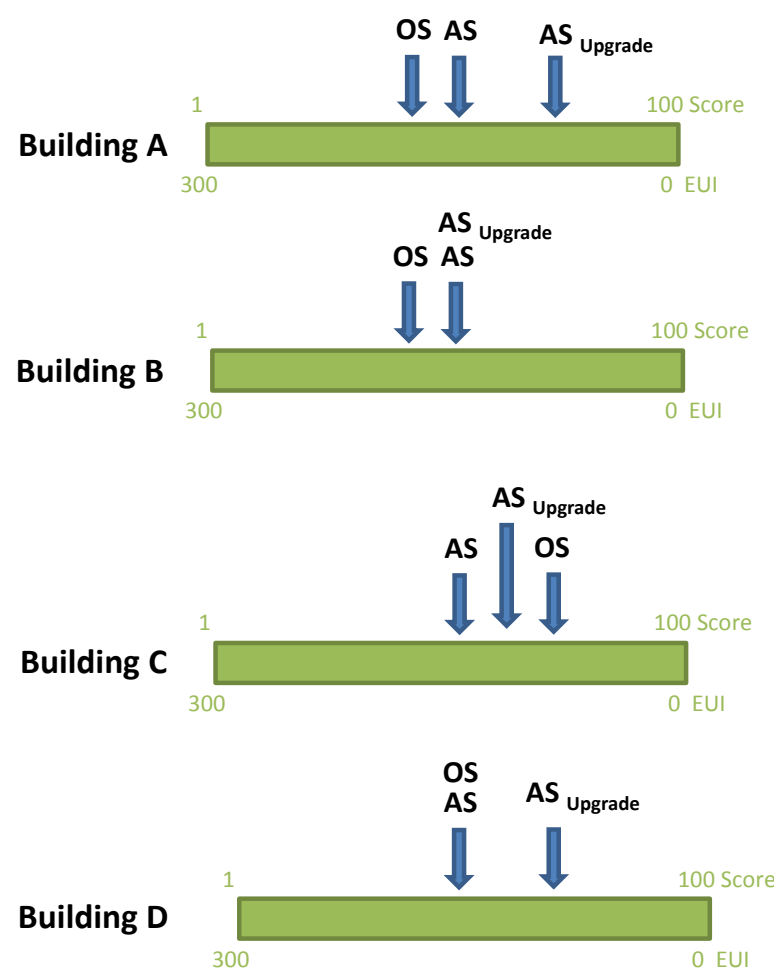

\section{Actions}

AS Upgrade $>$ AS : improve building efficiency AS > OS : improve O\&M

$\mathrm{AS}_{\text {Upgrade }}=\mathrm{AS}:$ best in class AS > OS : improve O\&M

(Building A has more Asset potential than Building B.)

$\mathrm{AS}_{\text {Upgrade }}>\mathrm{AS}$ : improve building efficiency AS < OS : Building C is operated very well (e.g. lights are turned off during the office hours) or some systems are not in use.

AS Upgrade $>$ AS : improve building efficiency AS = OS : Building D is operated well.

Figure 5.1. Integration of asset score and operational score. 
Table 5.1. Example of four buildings with the same asset score.

\begin{tabular}{|c|c|c|c|c|}
\hline & Building A & Building B & Building C & Building D \\
\hline EUI Actual & 120 & 98 & 80 & 120 \\
\hline $\mathrm{EUI}_{\mathrm{AS}}$ & 100 & 100 & 100 & 100 \\
\hline EUI Upgrade & 80 & 100 & 90 & 80 \\
\hline EUI Model & 110 & 90 & 100 & 120 \\
\hline EUI os & 109 & 109 & 80 & 100 \\
\hline $\begin{array}{l}\text { Building } \\
\text { Scenarios }\end{array}$ & $\begin{array}{l}\left(\mathrm{EUI}_{\mathrm{AS}}<\mathrm{EUI}_{\text {Model }}\right) \\
\text { High density or } \\
\text { longer period of use }\end{array}$ & $\begin{array}{l}\left(\mathrm{EUI}_{\mathrm{AS}}>\mathrm{EUI}_{\text {Model }}\right) \\
\text { Low density or } \\
\text { shorter period of use }\end{array}$ & $\begin{array}{l}\left(\mathrm{EUI}_{\mathrm{AS}}=\mathrm{EUI}_{\text {Model }}\right) \\
\text { Normal density and } \\
\text { use }\end{array}$ & $\begin{array}{l}\left(\mathrm{EUI}_{\mathrm{AS}}<\mathrm{EUI}_{\text {Model }}\right) \\
\text { High density or } \\
\text { longer period of use }\end{array}$ \\
\hline \multicolumn{5}{|c|}{$\begin{array}{l}\text { - } \quad \text { EUI Actual = energy use intensity obtained from utility bills. } \\
\text { - } \quad \text { UI As = energy use intensity obtained from a simulation model for a given building under standard } \\
\text { weather, occupancy, and operation schedule. } \\
\text { - EUI Model = energy use intensity obtained from a simulation model for a given building using the } \\
\text { actual weather, occupancy, and operation schedule. } \\
\text { - EUI os = energy use intensity calculated using the proposed equation above. }\end{array}$} \\
\hline
\end{tabular}

$\mathrm{EUI}_{\text {Actual }}$ should not be directly compared to $\mathrm{EUI}_{\mathrm{AS}}$ before any calibration process because (1) $\mathrm{EUI}_{\text {Actual }}$ is measured data and EUI $\mathrm{ES}_{\mathrm{AS}}$ is modeled data, and (2) EUI $\mathrm{Ectual}_{\text {is }}$ under actual conditions and $\mathrm{EUI}_{\mathrm{AS}}$ is under standard conditions. $\mathrm{EUI}_{\mathrm{AS}}$ can be compared to $\mathrm{EUI}_{\text {Model }}$ because both are modeled data. The difference reflects the actual occupancy, schedule, and plug load. The ratio of EUI $\mathrm{OR}_{\text {to }} \mathrm{EUI}_{\text {Model }}$ is used to normalize $\mathrm{EUI}_{\mathrm{Actual}}$ and calculate $\mathrm{EUI}_{\mathrm{OS}}$. The difference between $\mathrm{EUI}_{\mathrm{As}}$ and $\mathrm{EUI}_{\mathrm{OS}}$ reflects O\&M effectiveness.

\subsubsection{Three Components of the Toolkit}

To establish a comprehensive score system that can provide a deeper evaluation and analysis, the proposed toolkit should include three components: asset score, operational score, and O\&M costs. Such a toolkit could be built on the energy asset scoring tool and ensure its consistency, simplicity, and integration. The proposed tool architecture is presented in Figure 5.2.

- The energy asset scoring tool already has real-time simulation capability and has collected the basic information to build the energy model. A second model for the operational rating could be developed by modifying the operational conditions of the energy asset score model. The operational conditions include plug loads, HVAC schedules, number of occupants, temperature setpoints, and lighting controls. These are the additional inputs that could be entered by users of the proposed toolkit. Users could also enter their utility prices to enable the tool to better estimate the potential cost savings.

- To enhance the resulting accuracy, measured energy use obtained from ESPM can be used by the proposed toolkit to calibrate energy models. To obtain an ENERGY STAR score, building owners upload their monthly utility data to ESPM. These data could be extracted from ESPM to the proposed toolkit via web service. An automated model calibration method should be developed. As discussed in Section 5.1, Oak Ridge National Laboratory is developing Autotune-an automated building energy model tuning methodology. 
- O\&M costs related to energy systems should also be collected from the users. Large buildings with onsite facility managers usually have maintenance records. BOMA and IFMA also collect and publish O\&M data in the benchmark and experience exchange reports. These existing efforts should be streamlined through the proposed toolkit. This would require developing a standard method to document energy-related maintenance data.

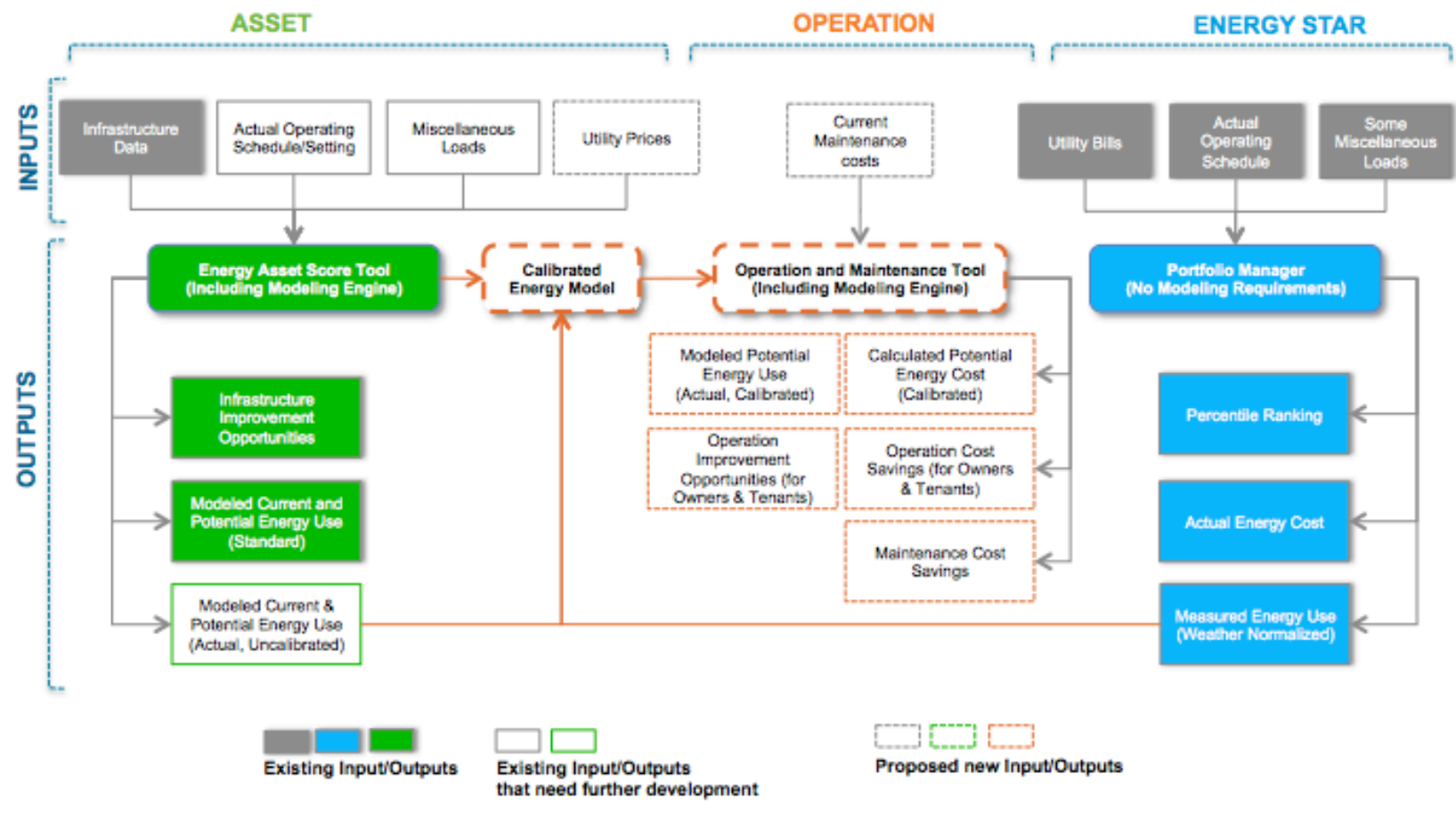

Figure 5.2. Proposed tool architecture.

Continuous monitoring of building energy data is essential to keeping building owners and maintenance personnel informed about the operating efficiencies of their facilities. The information stored in the toolkit should be maintained and updated over the life cycle of a building. The energy asset score would remain unchanged unless an upgrade is implemented. The operational rating and the cost information would be expected to change from year to year as the building operation and occupancy change. The tool should provide clear instructions and easy access for multiple users to update building information and monitor building performance over time.

The toolkit should be linked to other federal- and private-sector tools through an application programming interface (API). The API should allow seamless data exchange between different databases. Linkage with other tools would facilitate innovation in the private sector, which could develop other tools or programs using the existing functionality and data from the proposed toolkit. For example, LEED new construction could use the energy asset score to evaluate new buildings and operational score to evaluate the same building once it is in operation. A contractor could update the building energy asset information if equipment were replaced. A building engineer or an energy auditor could update operational characteristics if building commissioning were performed. An effective connection between the toolkit and other tools would also fully leverage the existing efforts, increase market adoption, and open future opportunities. 


\subsection{References}

Admin Minnesota. 2012a. B3 Benchmarking Overview. Minnesota Department of Administration, Saint Paul, Minnesota. Available from https://mn.b3benchmarking.com/Overview.aspx (2012).

Admin Minnesota. 2012b. State of Minnesota B3 Benchmarking: Current Statistics. Minnesota Department of Administration, Saint Paul, Minnesota. Available from https://mn.b3benchmarking.com/ Statistics.aspx?r=1 (2012).

ASHRAE. 2011. Advanced Energy Design Guide for Small to Medium Office Buildings: Achieving 50\% Energy Savings Toward a Net Zero Energy Building. American Society of Heating, Refrigerating and Air-Conditioning Engineers, Inc., Atlanta, Georgia.

ANSI/ASHRAE/IESNA Standard 90.1-2001, Energy Standard for Buildings Except Low-Rise Residential Buildings. American Society of Heating, Refrigerating and Air-Conditioning Engineers, Inc., Atlanta, Georgia.

ANSI/ASHRAE/IESNA Standard 90.1-2004, Energy Standard for Buildings Except Low-Rise Residential Buildings. American Society of Heating, Refrigerating and Air-Conditioning Engineers, Inc., Atlanta, Georgia.

ANSI/ASHRAE/IESNA Standard 90.1-2007, Energy Standard for Buildings Except Low-Rise Residential Buildings. American Society of Heating, Refrigerating and Air-Conditioning Engineers, Inc., Atlanta, Georgia.

ANSI/ASHRAE/IESNA Standard 90.1-2010, Energy Standard for Buildings Except Low-Rise Residential Buildings. American Society of Heating, Refrigerating and Air-Conditioning Engineers, Inc., Atlanta, Georgia.

ANSI/ASHRAE/IESNA Standard 100-2006, Energy Conservation in Existing Buildings. American Society of Heating, Refrigerating and Air-Conditioning Engineers, Inc., Atlanta, Georgia.

ANSI/ASHRAE Standard 105-2007, Standard Methods of Measuring, Expressing and Comparing Building Energy Performance. American Society of Heating, Refrigerating and Air-Conditioning Engineers, Inc., Atlanta, Georgia.

ASTM E2797-11, Standard Practice for Building Energy Performance Assessment for a Building Involved in a Real Estate Transaction. ASTM International, Conshohocken, Pennsylvania.

Bartlett R, LM Connell, K Gowri, MA Halverson, RG Lucas, EE Richman, RW Schultz, and DW Winiarski. 2012. Technical Support Document for Version 3.9.0 of the COMcheck Software. PNNL-SA-20798, Pacific Northwest National Laboratory, Richland, Washington. Available from http://www.energycodes.gov/comcheck/documents/comcheck_tsd_390.pdf (July 2012).

BOMA. 2009. Experience Exchange Report. Building Owners and Managers Association International, Washington, D.C. Available from http://www.boma.org/resources/benchmarking/Pages/default.aspx (July 2012). 
BOMA. 2011. Building Class Definitions. Building Owners and Managers Association International, Washington, D.C. Available from http://www.boma.org/resources/classifications/Pages/default.aspx (July 2012).

BPIE. 2010. Energy Performance Certificates across Europe: From design to implementation. The Buildings Performance Institute Europe, Brussels, Belgium.

Building EQ. 2012a. Steps to Earn a Label. American Society of Heating, Refrigerating and AirConditioning Engineers, Inc., Atlanta, Georgia. Available from http://buildingenergyquotient.org/getstarted-with-beq-to.html (2012).

Building EQ. 2012b. Frequently Asked Questions. American Society of Heating, Refrigerating and AirConditioning Engineers, Inc., Atlanta, Georgia. Available from http://buildingenergyquotient.org/ frequently-asked-questions.html (March 2012).

California Code of Regulations, Title 24, Part 6. 2007 California Energy Code. California Building Standards Commission, Sacramento. Available from http://publicecodes.citation.com/st/ ca/st/b1900v07/st_ca_st_b1900v07_cover.htm (July 2012).

Cater F. 2010. Critics Say LEED Program Doesn't Fulfill Promises. NPR.org, Washington, D.C. Available from http://www.npr.org/templates/story/story.php?storyId=129727547 (September 2010).

CBE. 2011. Simulated and Actual Energy Use: The Role of Plug Loads. Center for the Built Environment, University of California, Berkeley. Available from http://www.cbe.berkeley.edu/research/ plug-loads.htm\#publications (July 2012).

CEC. 2000. How to Hire an Energy Auditor to Identify Energy Efficiency Projects. P400-00-001C, Efficiency Division, California Energy Commission, Sacramento.

Chimack M, C Walker, R Miller, J Aarsdma, and D Novosol. 2005. National Center for Energy Management and Building Technologies - Task 10: Energy Reduction Through Practical Scheduled Maintenance - Subtask 10.1: Literature Review. NCEMBT-051231-1, National Center for Energy Management and Building Technologies, Alexandria, Virginia. Available from http://www.ncembt.org/ downloads/NCEMBT-051231-1.pdf (July 2012).

COMNET. 2010. COMNET: Commercial Buildings Energy Modeling Guidelines and Procedures. Commercial Energy Services Network. RESNET, Oceanside, California. Available from http://www.comnet.org/sites/default/ files/images/COMNET-MGP-2.pdf (July 2012).

Corson GC. 1990. A Comparative Evaluation of Commercial Building Energy Simulation Software: Final Report. Prepared for the Bonneville Power Administration, Portland, Oregon, under Contract DEAC79-89BP96543. Gale C. Corson Engineering, Bend, Oregon.

Deru M. 2007. Energy Savings Modeling and Inspection Guidelines for Commercial Building Federal Tax Deductions - Second Edition. NREP/TP-550-40467, National Renewable Energy Laboratory, Golden, Colorado. Available from http://www.nrel.gov/docs/fy07osti/40467.pdf (July 2012). 
DOE. 2011. Commercial Building Initiative - Commercial Reference Buildings. Office of Energy Efficiency and Renewable Energy, U.S. Department of Energy, Washington, D.C. Available from http://www1.eere.energy.gov/buildings/commercial_initiative/reference_buildings.html (June 2011).

DOE. 2012. States That Can Use COMcheck to Show Compliance. Office of Energy Efficiency and Renewable Energy, U.S. Department of Energy, Washington, D.C. Available from http://www.energycodes.gov/comcheck/comcheck_states.stm\# (August 2012)

EIA. 2006. 2003 Commercial Buildings Energy Consumption Survey - Commercial Energy Uses and Costs. Energy Information Administration, U.S. Department of Energy, Washington, D.C. Available from http://www.eia.gov/consumption/commercial/index.cfm (January 2012).

EISA 433. Energy Independence and Security Act of 2007. Public Law 110-140 (H.R. 6), Section 433, Federal Building Energy Efficiency Performance Standards.

Energy Impact Illinois. 2011. Our Methodology. Positive Energy Practice, LLC, Chicago, Illinois. Available from http://encompass.energyimpactillinois.org/methodology/Default.aspx (2012).

EPA (undated). Guidance for Benchmarking Mixed-Use Properties in Portfolio Manager. U.S. Environmental Protection Agency, Washington, D.C. Available from http://www.energystar.gov/ index.cfm?c=eligibility.bus portfoliomanager eligibility mixed.

EPA. 2006. ENERGY STAR Building Manual. Chapter 10, Facility Type: K-12 Schools. U.S. Environmental Protection Agency, Washington, D.C. Available from http://www.energystar.gov/index.cfm?c=business.EPA BUM CH10 Schools (November 2006).

EPA. 2007a. Hotels: An Overview of Energy Use and Energy Efficiency Opportunities. U.S. Environmental Protection Agency, Washington, D.C. Available from http://www.energystar.gov/ia/business/challenge/learn_more/Hotel.pdf (August 2007).

EPA. 2007b. Schools: An Overview of Energy Use and Energy Efficiency Opportunities. U.S. Environmental Protection Agency, Washington, D.C. Available from http://www.energystar.gov/ia/business/challenge/learn_more/Schools.pdf (August 2007).

EPA. 2010. Federal, State, and Local Governments Leveraging ENERGY STAR (Updated May 23, 2012). U.S. Environmental Protection Agency, Washington, D.C. Available from http://www.energystar.gov/ia/business/government/State_Local_Govts_Leveraging_ES.pdf (July 2012).

EPA. 2011. Recommendations for Measuring and Reporting Overall Data Center Efficiency, Version 2 - Measuring PUE for Data Centers. U.S. Environmental Protection Agency, Washington, D.C. Available from http://www.energystar.gov/ia/partners/prod_development/downloads/ Data Center_Metrics Task Force Recommendations V2.pdf?294f-ff43 (May 2011).

FirstFuel. 2012. How It Works. FirstFuel Software, Inc., Lexington, Massachusetts. Available from http://www.firstfuel.com/home/how_it_works (2012) 
Fuerst F and P McAllister. 2011. Green Noise or Green Value? Measuring the Effects of Environmental Certification on Office Values. Real Estate Economics 39(1):45-69.

Goldman CA, NC Hopper, and JG Osborn. 2005. Review of US ESCO industry market trends: an empirical analysis of project data. Energy Policy 33(3):387-405.

Goldstein DB and C Eley. 2011. Three Types of Energy Indices for Buildings, and Why Fixed Energy Budgets Should Not Be One of Them. Unpublished white paper, November 9, 2011, Natural Resources Defense Council and Eley Consulting Group.

GRESB Foundation. 2011. The Global Real Estate Sustainability Benchmark Research Report 2011. The Global Real Estate Sustainability Foundation, Amsterdam. Available from http://gresb.com/content/GRESB-2011-Report-v2.pdf (July 2012).

Gripne S, JC Martel, and B Lewandowski. 2012. Colorado’s High Performance Commercial Buildings: An Index and Market Evaluation. Leeds School of Business, University of Colorado, Boulder, Colorado. Available from http://leeds.colorado.edu/asset/realestate/coloradohighperformancecommercial building.pdf (January 2012).

IECC, 2003 International Energy Conservation Code. International Code Council, Washington, D.C. IECC, 2004 International Energy Conservation Code. International Code Council, Washington, D.C. IECC, 2006 International Energy Conservation Code. International Code Council, Washington, D.C. IECC, 2009 International Energy Conservation Code. International Code Council, Washington, D.C. IECC, 2012 International Energy Conservation Code. International Code Council, Washington, D.C. IFMA. 2009. Operations and Maintenance Benchmarks. Research Report \#32, Internal Facility Management Association, Houston, Texas. Available from http://www.ifma.org/resources/ research/reports/pages/32.htm (July 2012).

IMT and AI. 2012. Recognition of Energy Costs and Energy Performance in Real Property Valuation Considerations and Resources for Appraisers. Institute for Market Transformation, Washington, D.C. Available from http://www.imt.org/files/Energy Reporting_in_Appraisal.pdf (July 2012).

ISO 13790:2008, Energy Performance of Buildings - Calculation of Energy Use for Space Heating and Cooling. International Organization for Standardization, Geneva.

ISO 50001:2011, Energy Management Systems - Requirements with Guidance for Use. International Organization for Standardization, Geneva.

Kaplan M and P Caner. 1992. Guidelines for Energy Simulations of Commercial Buildings. DOE/BP26683-2. Prepared for the Bonneville Power Administration, Portland, Oregon. Available from http://www.osti.gov/bridge/product.biblio.jsp?osti_id=5291948 (June 2009). 
Kaplan MB, J McFerran, J Jansen, and R Pratt. 1990. Reconciliation of a DOE 2.1C model with monitored end-use data for a small office building. ASHRAE Transactions 96(1)981-993.

Lee S, Z Fei, and G Augenbroe. 2011. The Use of Normative Energy Calculation Beyond Building Performance Rating Systems. In Proceedings of Building Simulation 2011, pp. 2753-2760. International Building Performance Simulation Association, Sydney, Australia.

McCabe MJ and N Wang. 2012. Commercial Building Energy Asset Rating Program - Market Research. PNNL-21310, Pacific Northwest National Laboratory, Richland, Washington.

Mathew P, X-F Pang, and L Wang. 2011. Incorporating Energy Efficiency into Commercial Mortgage Underwriting - Task 3: Determining Energy Use Volatility for Commercial Mortgage Valuation. Draft report, May 13, 2011, Building Technologies Department, Lawrence Berkeley National Laboratory, Berkeley, California.

McGraw-Hill. 2011. Business Case for Energy Efficient Building Retrofit and Renovation. McGrawHill Construction, Bedford, Massachusetts. Available from http://apps1.eere.energy.gov/buildings/ publications/pdfs/alliances/business_case_for_energy_efficiency_retrofit_renovation_smr_2011.pdf (July 2012).

Mills E. 2009. Building Commissioning - A Golden Opportunity for Reducing Energy Costs and Greenhouse Gas Emissions. Lawrence Berkeley National Laboratory, Berkeley, California. Available from http://cx.lbl.gov/documents/2009-assessment/LBNL-Cx-Cost-Benefit.pdf (July 2012).

NMR Group. 2012. Statewide Benchmarking Process Evaluation (Volume 1: Report). NMR Group, Inc., Somerville, Massachusetts. Available from http://www.calmac.org/publications/ Statewide_Benchmarking_Process_Evaluation_Report_CPU0055.pdf (April 2012).

Norford LK, RH Socolow, ES Hsieh, and GV Spadaro. 1994. Two-to-one discrepancy between measured and predicted performance of a "low-energy" office building: insights from a reconciliation based on the DOE-2 model. Energy and Buildings 21:121-131.

NREL. 2011. U.S. Department of Energy Commercial Reference Building Models of the National Building Stock. NREL/TP-5500-46861, National Renewable Energy Laboratory, Golden, Colorado. Available from http://www.nrel.gov/docs/fy11osti/46861.pdf (April 2012).

OpenEI. 2012. Utility Data Access Map. Open Energy Info. National Renewable Energy Laboratory, Golden, CO. Available from http://en.openei.org/wiki/OpenEI:Utility data access map (2012)

Peterson K and H Crowther. 2010. Building EUIs. High Performing Buildings Summer 2010:40-42, 44, 46-48.

Pogue DL and D Laquidara-Carr. 2011. Do Green Buildings Make Dollars \& Sense? CBRE, Inc., and McGraw-Hill Construction. BuildingRating.org, Washington, D.C. Available from http://www.buildingrating.org/sites/default/files/DoGreenBuildingsMakeDollarsAndSense-v3.pdf (July 2012). 
Price S, A Mahone, N Schlag, D Suyeyasu. 2011. Time Dependent Valuation of Energy for Developing Building Efficiency Standards: 2013 Time Dependent Valuation (TDV) Data Sources and Inputs. Prepared for the California Energy Commission. Energy and Environmental Economics, Inc., San Francisco, California. Available from http://www.energy.ca.gov/title24/2013standards/prerulemaking/ documents/general_cec_documents/Title24_2013_TDV_Methodology_Report_23Feb2011.pdf (February 2011).

Reichmuth H and Turner CA. 2011. A Tool for First Views of Building Energy Performance. Unpublished report. New Buildings Institute, Vancouver, Washington.

Ring E. 2009. Challenges of Building Energy Metrics. LPA Blog: Integrated Sustainable Design. LPA Inc., Irvine, California. Available from http://blog.lpainc.com/lpa-blog/bid/24046/Challenges-ofBuilding-Energy-Metrics (July 2009).

Turner C and M Frankel. 2008. Energy Performance of LEED ${ }^{\circledR}$ for New Construction Buildings. New Buildings Institute, Vancouver, Washington. Available from http://www.usgbc.org/ ShowFile.aspx?DocumentID=3930 (July 2012).

USGBC. 2011. LEED 2009 Minimum Program Requirements. U.S. Green Building Council, Washington, D.C. Available from http://www.usgbc.org/ShowFile.aspx?DocumentID=6715 (July 2012).

Von Neida B and T Hicks. 2010. Building Performance Defined: the ENERGY STAR ${ }^{\mathrm{TM}}$ National Energy Performance Rating System. U.S. Environmental Protection Agency, Washington, D.C. Available from http://www.energystar.gov/ia/business/tools resources/aesp.pdf (July 2012). 


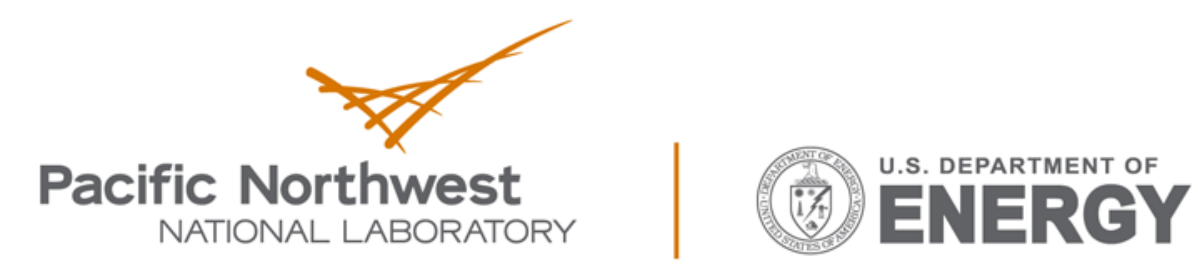

Proudly Operated by Battelle Since 1965

902 Battelle Boulevard

P.O. Box 999

Richland, WA 99352

1-888-375-PNNL (7665)

www.pnnl.gov 